Universidad de Lima

Facultad de Comunicación

Carrera de Comunicación

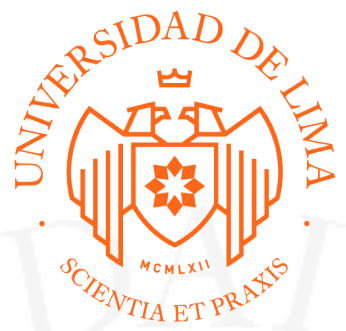

\title{
"PROYECTO FOTOGRÁFICO "BEKANWE" - PLANTEAMIENTO DE UNA EXPOSICIÓN FOTOGRÁFICA"
}

Trabajo de suficiencia profesional para optar el Título Profesional de Licenciado en Comunicación

\section{Pedro Enrique Horna Horna}

Código 20130627

\section{Asesor}

Franz Krajnik Baquerizo

$$
\text { Lima - Perú }
$$

26 de febrero de 2020 


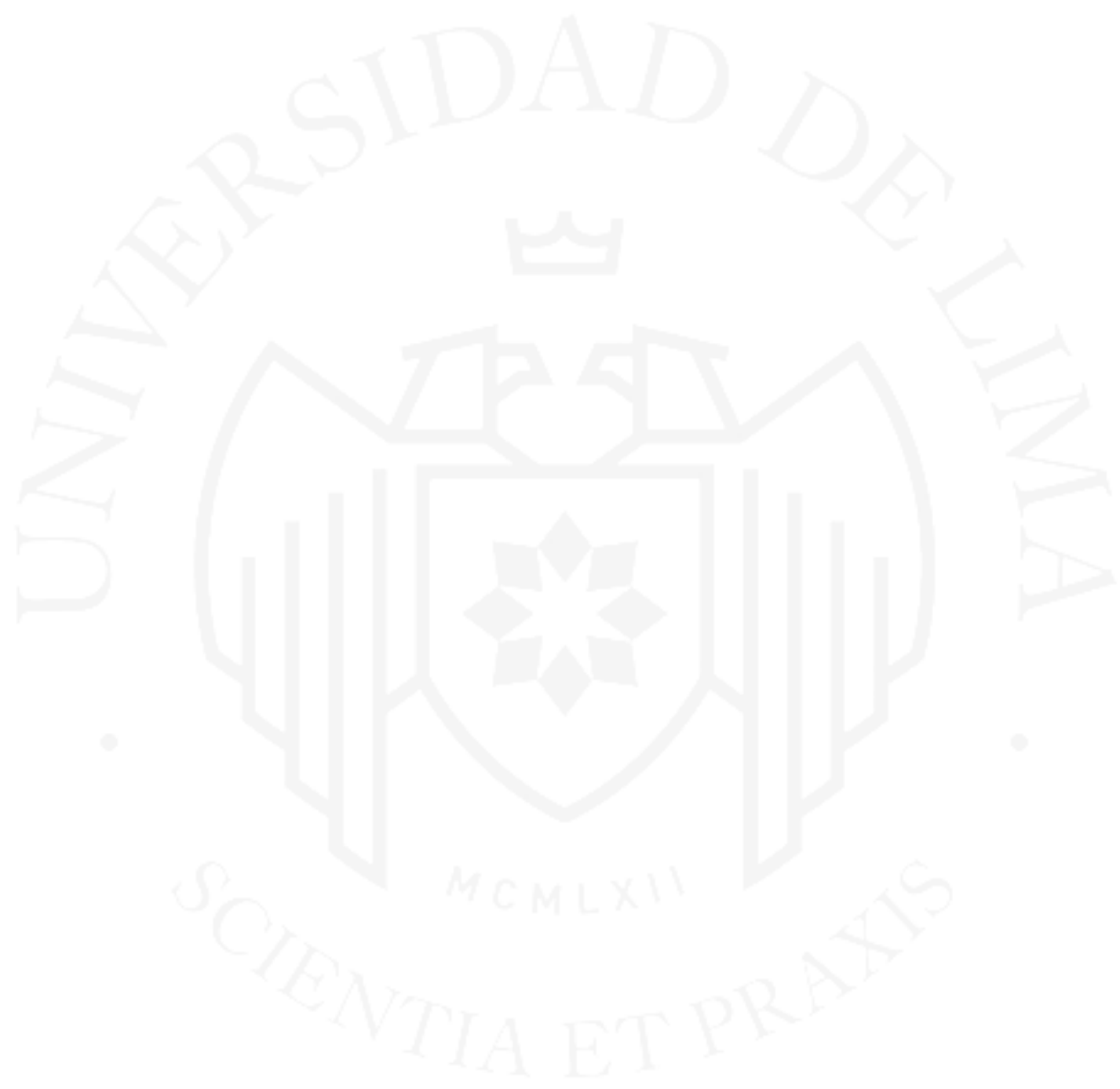




\section{TABLA DE CONTENIDOS}

DIRECCION WEB DE LAS PIEZAS Y PRODUCCIONES DE COMUNICACIÓN PARTE DEL TRABAJO.................................v

RESUMEN

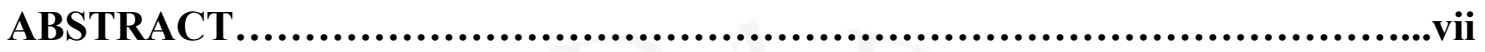

INTRODUCCIÓN.................................................................... 1

CAPÍTULO I: ANTECEDENTES DEL TRABAJO.............................. 2

1. La Fotografía Documental como herramienta.............................. 2

2. La Antropología Visual................................................... 5

3. Puerto Firmeza, esencia shipiba ......................................... 7

4. Investigaciones audiovisuales similares ................................... 12

I. Uchuraccay - Franz Krajnik ............................................ 12

II. Realidad de las comunidades nativas en Loreto, Perú: Yaguas y Kukamas Diego León.................................................................... 15

III. Fotosociales: Retrato de Iquitos 1960-1990 - Augusto Falconi ............... 17

5. Objetivos, materialización y exposición del material fotográfico ............. 19

CAPÍTULO II: REALIZACIÓN Y SUSTENTACIÓN ............................ 24

CAPÍTULO III: LECCIONES APRENDIDAS ............................ 35

CAPÍTULO IV: LOGROS Y RESULTADOS ............................. 37

REFERENCIAS ................................................................ 41

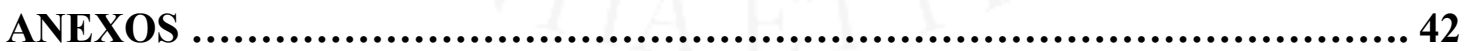

1. Fotos del Primer Viaje ................................................. 42

2. Link de la entrevista en Conectados....................................... 44

3. Fotos de la Galería IMARPU ............................................ 45

4. Fotos del Segundo Viaje ................................................... 67

5. Plano de la Galería Miró Quesada, donde se realizará la exposición ........... 68

6. Bosquejo del recorrido de la exposición ................................... 69 
7. Avance de Fotos Editadas del Tercer Viaje. 


\section{DIRECCION WEB DE LAS PIEZAS Y \\ PRODUCCIONES DE COMUNICACIÓN PARTE DEL \\ TRABAJO}

1. ENTREVISTA PROFESOR DE PUERTO FIRMEZA - TESIS PEDRO HORNA (COMUNICACIÓN

ULIMA):

https://www.youtube.com/watch?v=6qCAIQm1Vm0\&feature=youtu.be

2. SONIDO PUERTO FIRMEZA - TESIS PEDRO HORNA (COMUNICACIÓN ULIMA): https://www.youtube.com/watch?v=B0J6ISUkexc\&feature=youtu.be 


\section{RESUMEN}

El presente proyecto consiste en un ensayo antropológico visual que utiliza la fotografía documental como herramienta para evidenciar la realidad y el modus vivendis de una comunidad Shipibo Konibo pura. De esta manera, se busca desmitificar las ideas preconcebidas que una sociedad metropolitana puede desarrollar sobre agrupaciones sociales similares, propias y -a la vez- foráneas.

\section{PALABRAS CLAVE}

FOTOGRAFÍA - FOTOGRAFÍA DOCUMENTAL - COMUNICACIÓN SELVA - ANTROPOLOGÍA VISUAL 


\begin{abstract}
This project is a visual-anthropological essay that uses documentary photography as its main tool to show a pure Shipibo Konibo community's actual way of life. This way, it is meant to break the pre conceived ideas that a metropolitan society can develop about similar human groups, from their own and -at the same time- foreign ones.
\end{abstract}




\section{INTRODUCCIÓN}

El Perú es un país rico en cultura y tradiciones. Sin embargo, muchas comunidades que aún viven aferradas a sus costumbres son ignoradas tanto por el estado, como por el grueso de peruanos.

Cuando uno habla de una "comunidad Shipibo Konibo pura", el grueso de la gente que vive en sociedades metropolitanas podría pensar de manera automática en gente originaria de la selva que vive con un gran retraso frente al modo de vida occidental. Se suele creer que es gente que está internada en la espesa Amazonía y vistiendo taparrabos y lanzas. Sin embargo, esto está muy alejado de la realidad.

La comunidad de Puerto Firmeza es una de las últimas comunidades Shipibo Konibo puras del Perú. Se ubica a una hora de Yarinacocha, Pucallpa, perteneciente al departamento de Ucayali. Son pobladores que, si bien tienen un arraigo a sus costumbres shipibas, no son seres exóticos. Es una comunidad que, en palabras de sus propios pobladores, busca ser visitada, conocida, y apoyada por el Estado.

La finalidad de este proyecto es mostrar cómo una comunidad nativa de la cultura shipibo Konibo convive en sociedad. Evidenciar que pese a las limitantes a las que el estado los somete debido a la centralización y desinterés de los gobiernos, su estilo de vida es análogo al nuestro. 


\section{CAPÍTULO I: ANTECEDENTES}

\section{La Fotografía Documental como herramienta.}

"Bekanwe" es un ensayo visual que usa como principal herramienta a la fotografía documental. Pero por lo general, no existe una diferenciación clara entre la fotografía documental y la fotografía periodística.

Esta diferencia se encuentra en la intención de la realización fotográfica. La fotografía periodística tiene como principal objetivo el registro de un hecho noticioso. En esta, la misión del fotoperiodista es conseguir una instantánea del evento al que se le comisiona.

En el caso de la fotografía documental tenemos dos vertientes. Una de ellas es más allegada hacia el periodismo, y su realización a modo de registro permite la documentación. Sin embargo, la otra corriente de la fotografía documental, la cual Eugene Smith define como "ensayo fotográfico", coquetea más hacia el lado artístico en los distintos procesos de la producción del trabajo fotográfico, ya sea en la toma de la fotografía, el retoque y/o la materialización del ensayo en un libro, una exposición, o la s distintas plataformas en las cuales se puede publicar un trabajo fotográfico.

Dentro de esta rama de la fotografía existen dos exponentes que han influido de mayor manera en este trabajo, tanto en el estilo fotográfico, los temas que tocan y cómo realizan la producción de sus documentales, siendo de una manera bastante participativa con la comunidad a la que estudian. Ellos son Steve McCurry (EEUU) y Sebastião Salgado (Brasil). Ambos han caracterizado su trabajo (o gran parte del mismo) en la realización de foto documentales en comunidades, con diferentes aristas.

Steve McCurry es mundialmente reconocido por la foto de National Geographic de la niña afgana de los ojos verdes. Pero su trabajo no solo se centra en ese documental. $\mathrm{Su}$ carrera fotográfica arranca a finales de la década del setenta, cubriendo conflictos bélicos en Afganistán. 


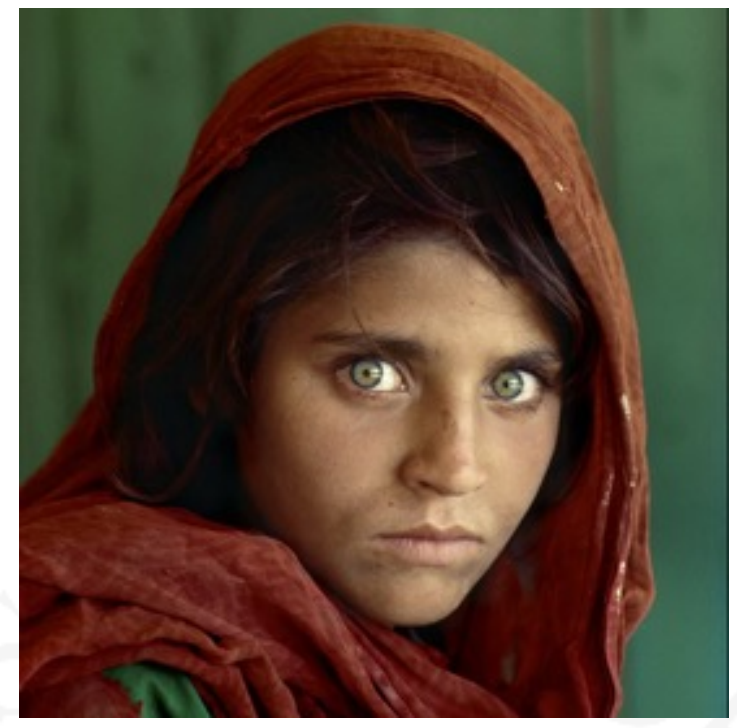

"La Niña Afgana" - Steve McCurry.

Revista National Geographic (1995)

Asimismo, el trabajo de Sebastião Salgado es relativamente similar. Su registro fotográfico tiende hacia el sociodocumentalismo. Entre sus obras, el mayor exponente de esta línea fotográfica es su libro "Éxodos”, en el que captura instantáneas de comunidades en extrema pobreza, sometidas a presión laboral o exiliadas de sus tierras. Entre las fotografías más famosas de este compendio están las de las minas de oro en Serra Pelada. 


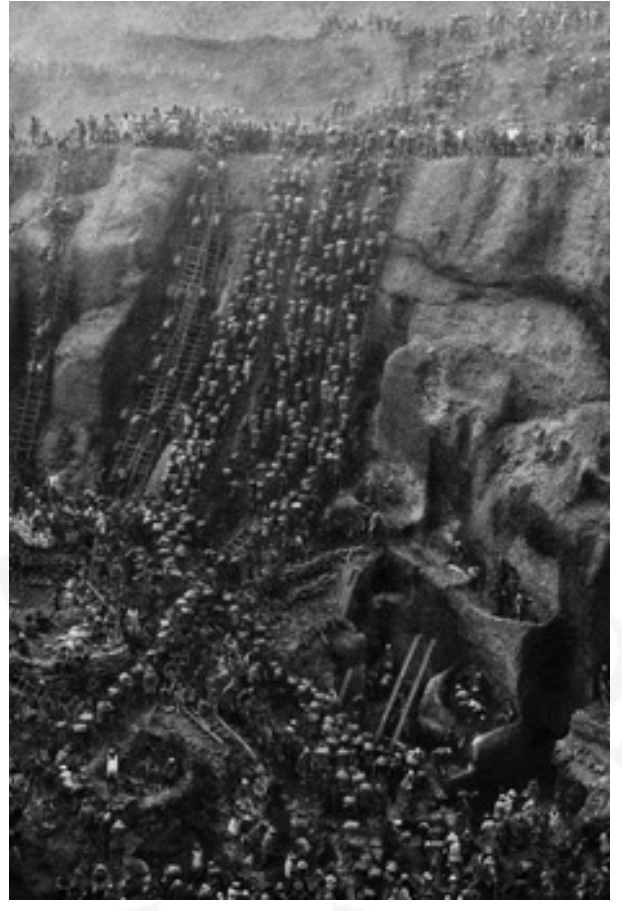

Minas de oro de Serra Pelada - Sebastião Salgado

“Serra Pelada" (1996)

¿Existe un riesgo o una problemática presente dentro de la realización de un ensayo fotográfico documental? Por supuesto. Recordemos que un ensayo fotográfico presenta el punto de vista de su autor. Partiendo de esta premisa, el ensayo fotográfico no busca la objetividad, sino busca la construcción de un discurso por parte del autor. Pero, si se toman en cuenta las bases del lenguaje audiovisual, al decidir un encuadre, el fotógrafo elige una porción de la realidad a registrar, dejando a libertad del espectador la interpretación propia de la imagen. 


\section{La Antropología Visual}

La antropología visual es una disciplina que, en palabras de Jay Ruby, "proviene de la creencia de que la cultura se manifiesta a través de símbolos visibles encajados en gestos, ceremonias, rituales y artefactos situados en entornos naturales o construidos" (Ruby, 1996, p.1). Es válido decir, en consecuencia, que el trabajo de la antropología visual va íntimamente relacionado a los estudios etnográficos, pues esta ultima es una técnica de estudio de la antropología visual.

En el campo, la antropología visual estudia absolutamente todos los ejes de una cultura. Empieza por estudiar aspectos básicos de la sociedad en cuestión, como la comunicación -sea verbal o no verbal-, los ritos, la cotidianidad y llega a analizar elementos tangibles de su cultura, como la materialización del arte y las tradiciones.

Sin embargo, el trabajo del antropólogo visual no puede centrarse netamente en la observación, sino que debe llegar al entendimiento y la reflexión de un hecho o evento del grupo humano estudiado a partir de herramientas visuales.

Para lograr este objetivo, se puede acceder a diversas técnicas. Específicamente dentro del campo de la fotografía, uno puede aplicar numerosas estrategias que lo lleven a un correcto estudio.

Una de estas técnicas, luego de la observación y el registro fotográfico documental es el volver con las fotos impresas a la comunidad y presentárselas a las personas retratadas. Una vez mostradas las instantáneas, se le pregunta al sujeto qué es lo que ve en la fotografía (Fotoelicitación). Eso nos lleva a un primer acercamiento a razonar como el sujeto. Es importante que la persona que realiza el estudio llegue a razonar de esta forma, y no "por" el sujeto, pues se llega a involucrar con la comunidad de una manera errónea y se pueden tergiversar los resultados del estudio. Guber señala en "La Etnografía" (2001) que una investigación de este tipo se debe hacer "con" la comunidad y no "sobre" o "a partir" de la comunidad. De esta manera se logra alcanzar una objetividad, y genera una intimidad que deriva en una relación idiosincrática.

Bajo los conceptos planteados por Rosana Guber, se puede entender que esta investigación en específico es de corte naturalista, pues esta corriente plantea una relación entre el investigador y el sujeto de estudio -en este caso, la Comunidad Nativa Puerto Firmeza-, y pretende generar una interpretación de la cultura. En este proceso, el 
investigador se vincula de una manera más profunda con la comunidad para lograr extraer la información requerida y así aprehender los conocimientos y conceptos bases de la cultura estudiada.

Es por eso que al hablar de generar una "interpretación”, se realiza una reflexión propia de las capturas realizadas durante el trabajo de campo, para entender el contexto, las situaciones y el rol de cada individuo dentro de su grupo humano. Es así, como se llega a tener un análisis connotativo del evento estudiado, como puede ser desde un rito espiritual, hasta un evento deportivo como un partido de fútbol, o situaciones tan cotidianas como la comida.

Además, se debe de entender el funcionamiento de la sociedad desde su cotidianidad, y evitar, precisamente, el mitificar o ver de una manera exótica al sujeto en estudio, pues esto llevaría al error en el momento de generar las conclusiones del trabajo.

Para esto, la técnica utilizada en este trabajo para cumplir con los objetivos de la investigación fue la observación participante. En esta técnica, es vital la convivencia y la participación en las actividades y rituales propios de la comunidad estudiada. Si los pobladores juegan un partido de fútbol, el investigador debe jugar con ellos. Si el poblador come algún plato regional en específico, el investigador también debe de hacerlo. Si se da la oportunidad de ir a una clase en el colegio de la localidad, se debe ir. De esta forma, el observador puede "estar dentro de la comunidad", en palabras de Guber (2001). 


\section{Puerto Firmeza, esencia shipiba}

Puerto Firmeza es una comunidad Shipibo Konibo pura, que se ubica a una hora de camino de la localidad de Yarinacocha, en Pucallpa, Ucayali. Esta comunidad esta aferrada a sus tradiciones shipibas, como la el idioma, los ritos y la vida en comunidad.

Sin embargo, esto no significa que, como el grueso de la gente piensa, sea una tribu de personas con un atraso tecnológico y vivencial que los convierte en no contactados.

Historiadores e investigadores han ubicado geográficamente a la etnia de los Shipibo Konibo en las orillas del río Ucayali, en territorios fronterizos entre Perú y Brasil. El idioma pertenece a la familia lingüística Pano, similar a muchas de las lenguas habladas en las etnias de la región.

Desde el aspecto geográfico, la etnia Shipibo Konibo esta distribuida en gran parte del departamento de Ucayali. Desde mediados del siglo XVII, misioneros Franciscanos y Jesuitas organizaron y evangelizaron a las comunidades amazónicas no contactadas. Sin embargo, la pobre red de comunicación e infraestructura vial siempre significaron un gran problema tanto para los evangelizadores, como para las personas oriundas del territorio.

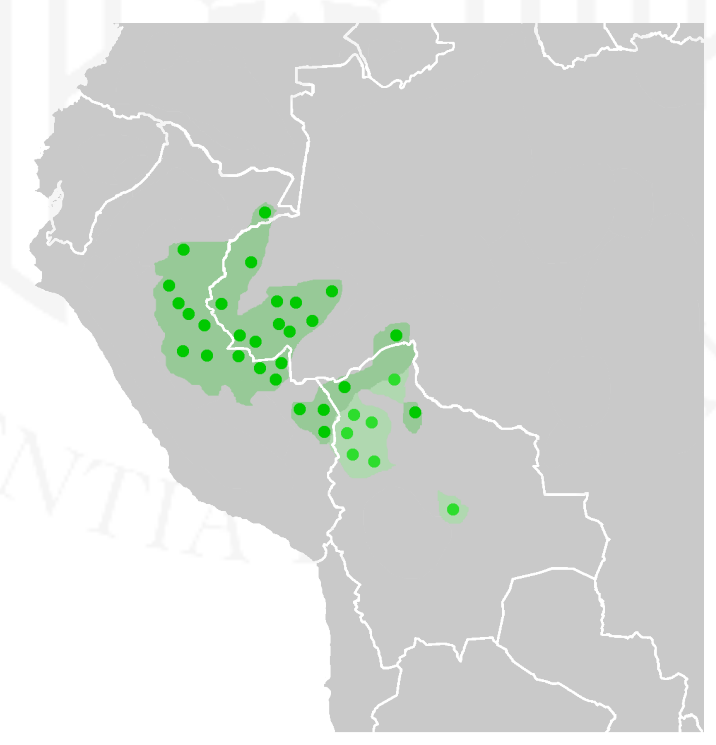

Ubicación Geográfica de la etnia Shipibo Konibo. 
A inicios del siglo XX, y debido al abandono de las órdenes católicas encargadas de la evangelización de la zona, los protestantes y adventistas de la Iglesia del Séptimo Día se dedicaron a instaurar su religión en las tribus del sector. Esto, añadido al inicio del desarrollo comercial y metropolitano de Pucallpa como capital del departamento de Ucayali (la construcción del aeropuerto a mediados de siglo y el desarrollo portuario), el crecimiento de la población citadina (de mil pobladores en 1940, a cincuenta mil en 1960), y a su vez, el relego de las comunidades nativas. Esta distancia influye en la falta de conocimiento de las personas que viven en ciudad, sobre el verdadero modo de vida de las comunidades nativas. Asimismo, la presencia de estos nuevos misioneros impacto en las creencias religiosas actuales en las comunidades.

Según Pablo Ramírez, jefe de la comunidad, Puerto Firmeza es una de las últimas comunidades shipibo Konibo puras. El esquema político de esta lo encabeza Ramírez, seguido por una junta directiva de la población. Él se encarga de velar por la correcta convivencia y la subsistencia de Puerto Firmeza, así como fungir de vínculo entre su gente y las autoridades del distrito de Yarinacocha. Esto se facilita gracias a que Ramírez trabaja en la oficina de Registros de la Municipalidad de Yarinacocha. Además, estos puestos no son fijos, sino que la misma comunidad elige a sus representantes cada cierto tiempo.

La comunidad guarda tradiciones muy arraigadas, entre las que están costumbres shipibas como el compartir todo alimento con las casas inmediatamente colindantes a la propia. Si alguien consigue pescado, lo hace para su casa y sus vecinos inmediatos.

La comunidad cuenta con 2 iglesias: una adventista, ubicada en la plaza central de Puerto Firmeza; y una evangelista, a diez minutos a pie desde el centro de la comunidad. Sin embargo, a pesar de ser cristianos no dejan de tener cierto culto a divinidades de la selva, y temor a ciertos espíritus. Es decir, así como la gente en localidades de Cusco se define como adeptos a la religión católico-andina (puesto que siguen los mandatos de Roma, pero tienen cultos hacia la Pachamama y los Apus); la localidad de Puerto Firmeza, bajo la misma premisa, sería una comunidad cristianaamazónica, puesto que mantiene vivas sus creencias en la Luna y los distintos espíritus de la selva como el Tunche y el Chuyachaqui.

En la misma línea religiosa encontramos que el poblador de Puerto Firmeza considera tanto al pastor como al chamán como líderes religiosos. El primero enseña la 
doctrina cristiana, y el segundo mantiene vivos rituales como las curaciones mediante frotaciones con hojas de plantas y el famoso Ayahuasca, ritual en el que se ingiere un extracto de la raíz de la planta con el mismo nombre y, bajo la guía del maestro chamán, tiene un viaje en el que, se supone, encuentra tanto respuestas a inquietudes sobre el futuro, como la sanación de enfermedades y malestares.

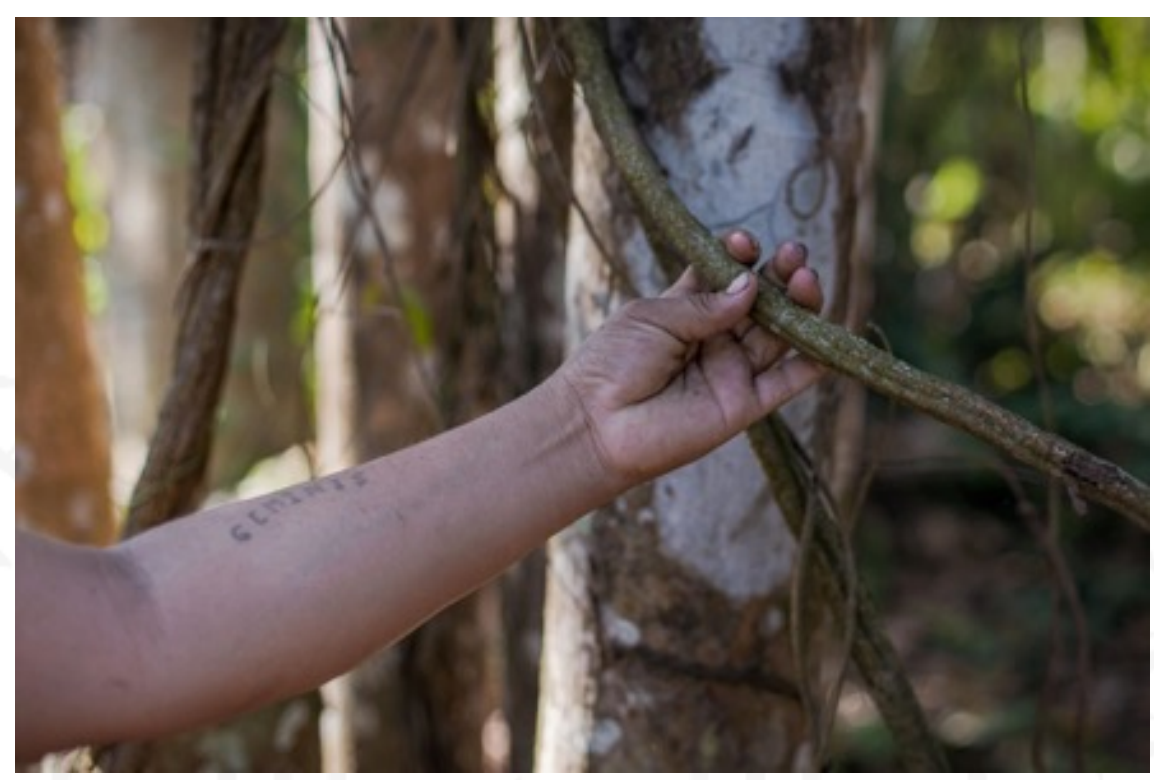

Raíz del Ayahuasca - Pedro E. Horna Horna (2019)

Puerto Firmeza, Pucallpa

La comunidad basa su sustento económico principalmente en la venta de sus propias cosechas. Entre ellas se encuentran el cultivo de yuca, maíz y plátano. Así mismo, el consumo de pescado es fundamental en su dieta diaria, y son ellos mismos los que salen en búsqueda de estos a las cochas (lagunas) cercanas. En su mayoría, el pescado más consumido es la carachama. Ellos mismos elaboran sus redes, sus remos y botes para navegar en las vertientes de la laguna de Yarinacocha y así obtener sus alimentos. Tradicionalmente, los hombres shipibos son quienes se dedican en su mayoría a la caza, pesca y cultivo. Por el contrario, las mujeres se dedican por sobre todo a la elaboración de telares, artesanías y el cuidado del hogar. Los primeros suelen ser elaborados en tocuyo, una tela bastante gruesa en la que bordan diseños y motivos relacionados a sus creencias. Las artesanías son elaboradas a manera de pintura en caparazones de tortuga, adornados con huairuros y escamas de paiche. 


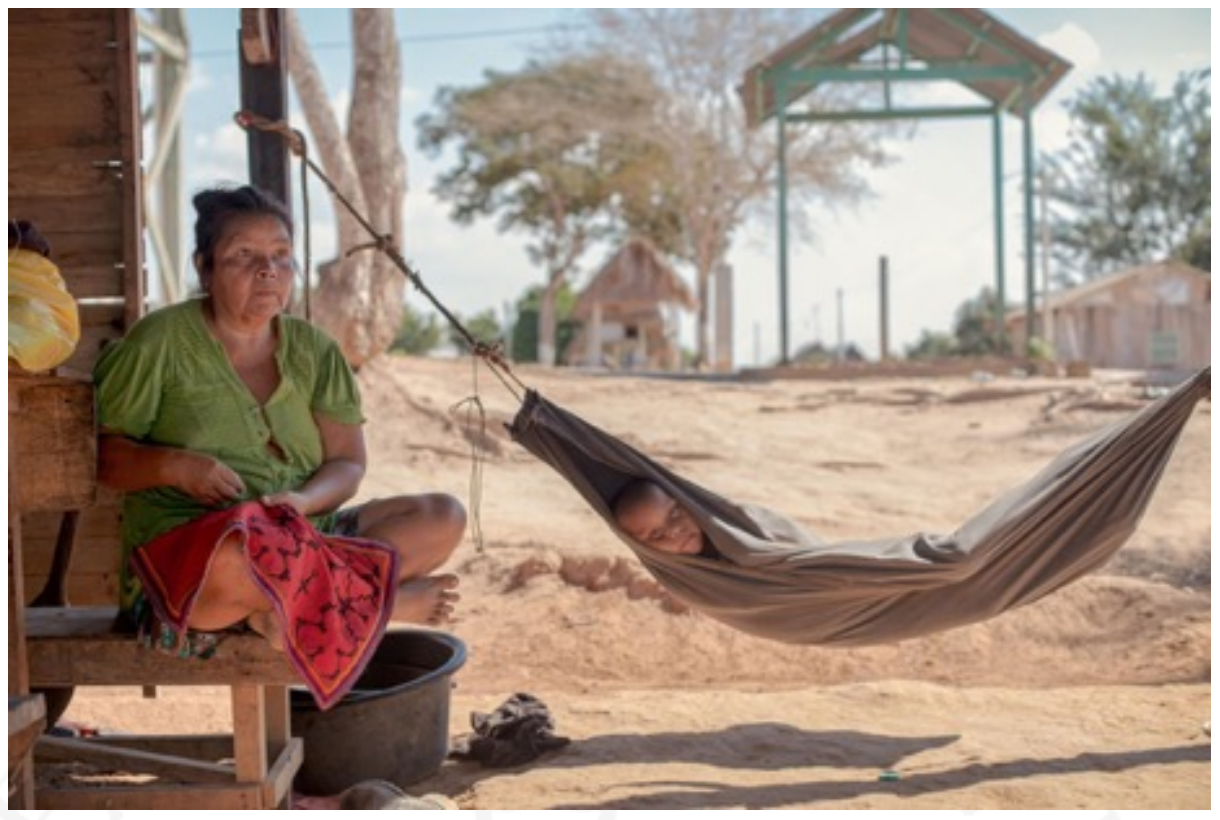

Mujer artesana - Pedro E. Horna Horna (2019)

Puerto Firmeza, Pucallpa.

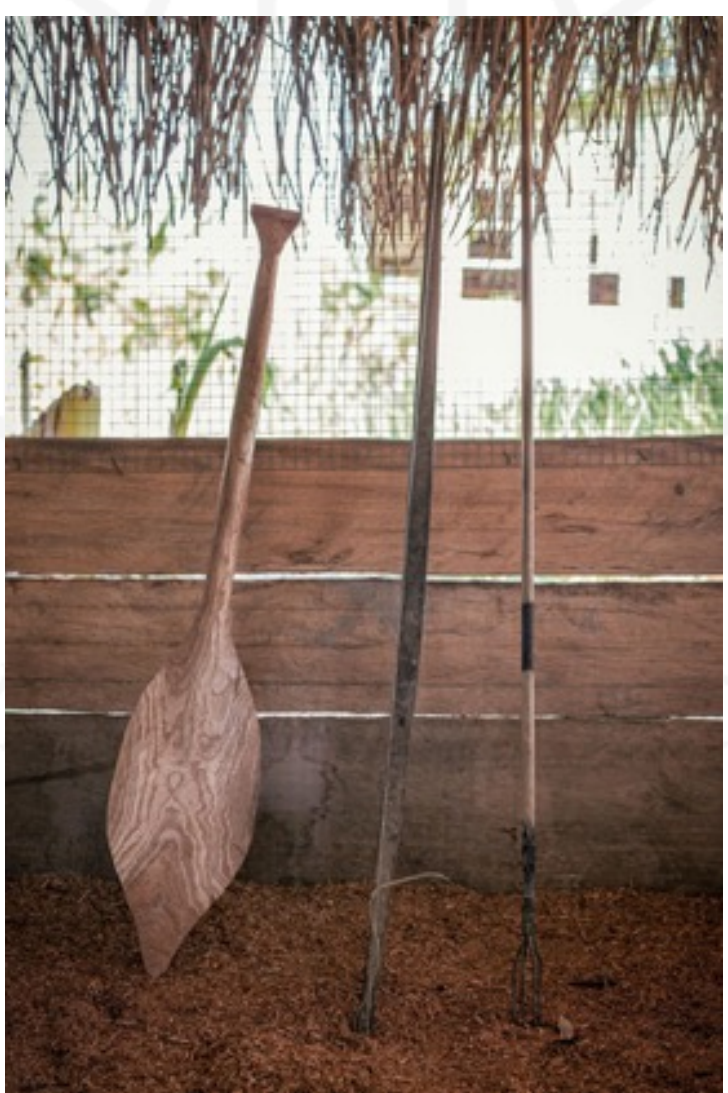

Remo, arco y arpón elaborados por los pobladores

para las labores de pesca - Pedro E. Horna Horna (2019)

Puerto Firmeza, Pucallpa. 
Dentro de las principales vicisitudes que atraviesan diariamente los pobladores de Puerto Firmeza se encuentran la falta de rutas pavimentadas que faciliten el ingreso a la localidad, el deficiente abastecimiento de luz, restringido servicio de agua potable y la falta de servicios de desagüe. A esto se añade que, en días lluviosos, el trayecto desde Yarinacocha hasta Puerto Firmeza -que es principalmente tierra y trocha- se torna muy resbaladizo, por lo que los vehículos no llegan hasta la comunidad. Esto implica que los maestros del colegio no lleguen a dar las clases, perjudicando el desarrollo integral de los niños y jóvenes.

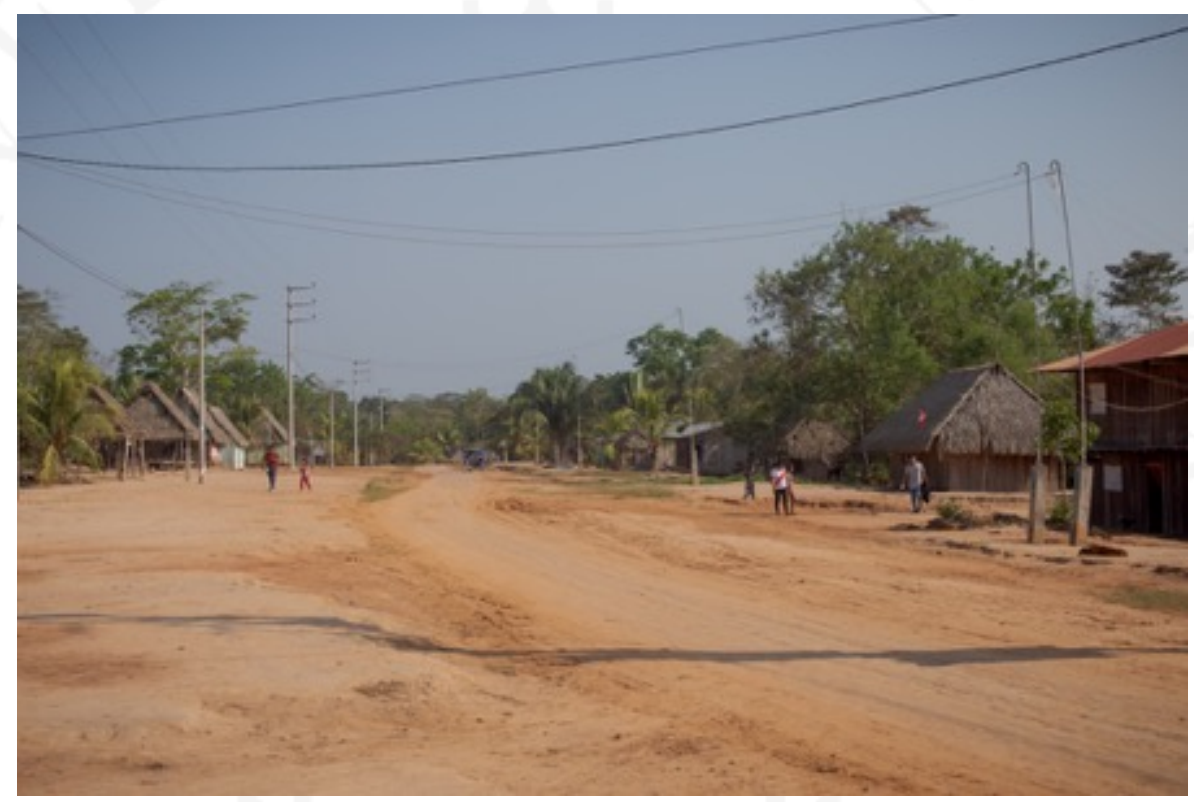

Ruta de entrada a Puerto Firmeza - Pedro E. Horna Horna (2019) Puerto Firmeza, Pucallpa.

En cuanto a las clases en el colegio, están distribuidas las aulas y los materiales de estudio. En el nivel primario las clases se dictan en el idioma Shipibo Konibo, como un esfuerzo para preservar la lengua. Los niños, además, llevan un curso de castellano básico. La secundaria sí se dicta en castellano. 


\section{Investigaciones audiovisuales similares.}

\section{Uchuraccay (Krajnik, F. 2018)}

Uchuraccay es un trabajo de fotografía documental realizado por Franz Krajnik. El trabajo se centra en el pueblo homónimo al proyecto, en el departamento de Ayacucho, donde 135 campesinos residentes de la localidad fueron muertos por Sendero Luminoso y las Fuerzas Armadas tras el asesinato de los ocho periodistas, un guía y un traductor a manos de los terroristas.

Krajnik decide plantear el proyecto como un documental de memoria, en el que retrata una comunidad que fue azotada por un evento catastrófico en una era de violencia y terror en su máxima expresión. Su intención es retratar en estas fotos cómo influye el paso del tiempo en esta sociedad andina (Krajnik, F., 2017). Asimismo, logra plasmar en imágenes la concepción de la cosmovisión andina, el paralelismo entre esta y la visión del mundo que existe en una sociedad occidental. Parte importante del análisis recae también en el documentar ritos de la comunidad, en los que la gente se congregue para un evento importante, como un matrimonio, un carnaval, o un entierro. Finalmente, consigue capturar en sus instantáneas la percepción de la muerte en esta sociedad.

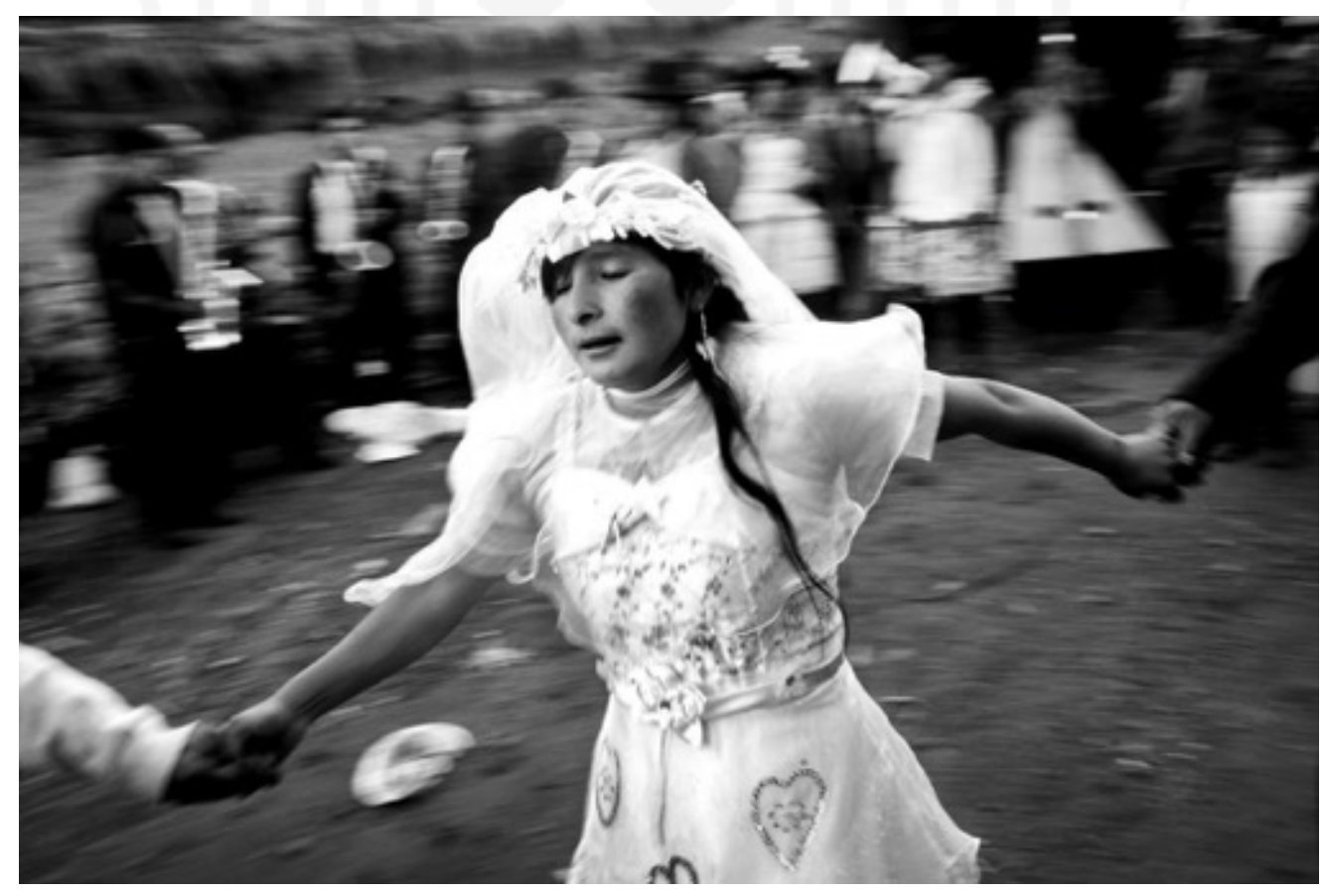

Foto a una novia - Franz Krajnik (2018)

Uchuraccay, Ayacucho. 
Sin embargo, lo más remarcable en su trabajo es que retrata este renacer de la comunidad; una nueva generación de personas que viven hoy en Uchuraccay, que han perdido hijos, padres y/o hermanos en esta época de violencia política que perpetuó el grupo terrorista Sendero Luminoso, y que han vuelto, reunidos como sociedad, a vivir bajo sus costumbres y tradiciones.

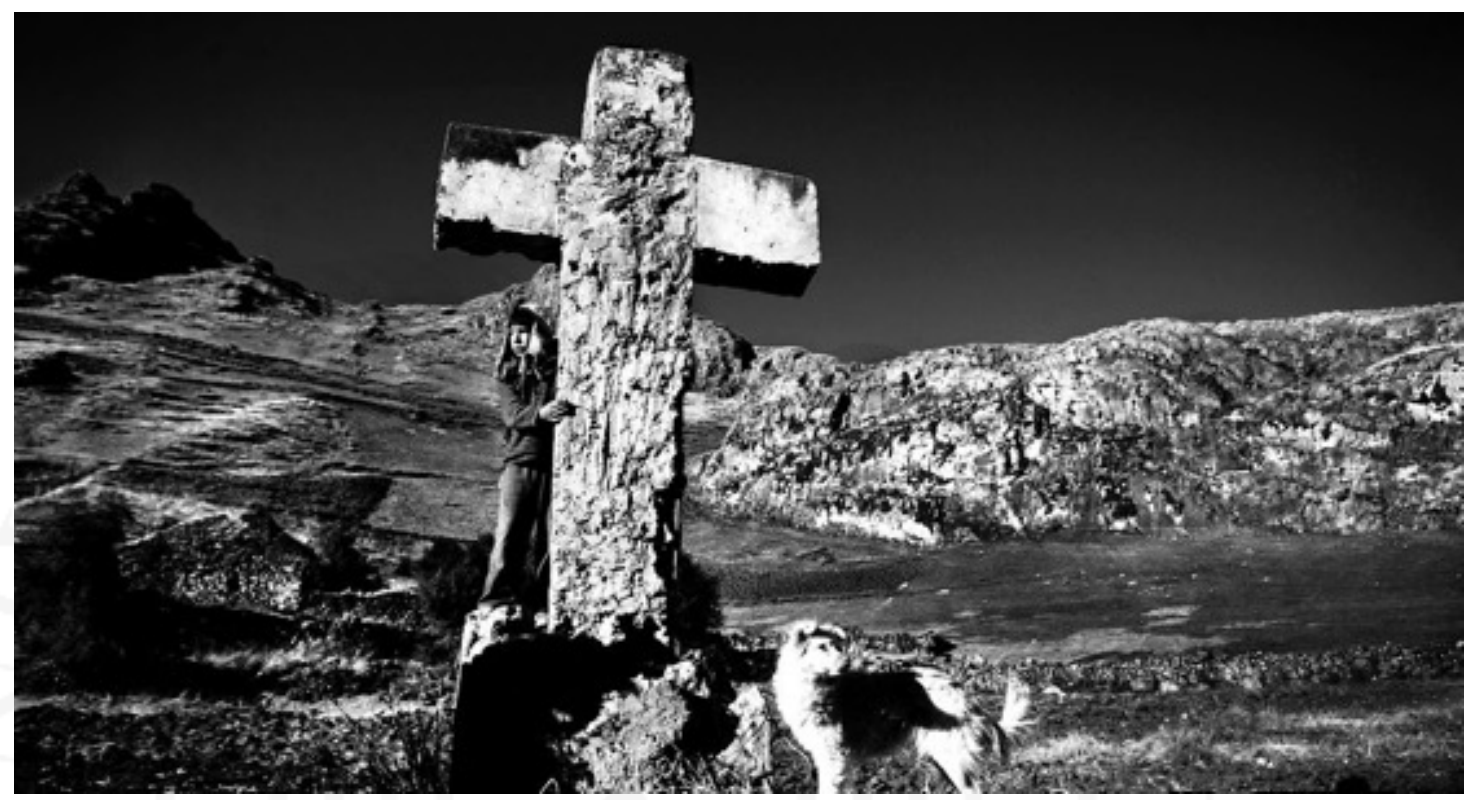

Foto en el cementerio - Franz Krajnik (2018)

Uchuraccay, Ayacucho.

En el trabajo presentado por Krajnik se evidencia el impacto de los eventos mencionados en la memoria del poblador de Uchuraccay. Por ejemplo, Krajnik cuenta en su libro "Uchuraccay" (2018) que, tras la matanza de los 135 campesinos, muchos de ellos no pudieron ser sepultados en el cementerio, y sus tumbas son hoy la única prueba de su existencia y su memoria (Krajnik, F. 2018).

Entre otras cosas, el proyecto también muestra, hoy en día, la vida en comunidad, lo que respondió, según el propio autor, a una necesidad propia de sentirse parte de un grupo de gente y cumplir un rol.

Esto evidencia el trabajo antropológico-visual del proyecto, pues cada una de las fotos implicó una reflexión para Krajnik, lo que supuso una explicación de un trasfondo poco evidente a simple vista.

Este trabajo es una de las principales referencias para este proyecto, puesto que el enfoque hacia la comunidad, los rituales propios de la misma y la vida en comunidad se 
tratan de una manera similar a lo que se busca en el ensayo fotográfico de Puerto Firmeza. Asimismo, el análisis entorno a los ejes antropológico visuales en el proyecto de Uchuraccay sirven como inspiración y como un sólido antecedente para poder llevar a cabo una correcta reflexión sobre el material fotográfico recabado en la comunidad nativa. 


\section{Realidad de las comunidades nativas en Loreto, Perú: Yaguas y Kukamas}

(León, D. 2019)

Diego León, egresado de la Universidad de Lima, realizó un trabajo documental de corte similar al planteado en esta tesis. Se adentró con las comunidades de los Yaguas de Santa María y los Kukamas de Loreto, para fotografiar y entender la supervivencia de estos dos pueblos nativos. Se trató de su trabajo para sustentar el grado de Licenciado en Comunicación.

León también optó por realizar un proyecto bajo la estrategia de la observación participante, conviviendo con las comunidades durante semanas, en el período de un año y medio que demoró en culminar el proyecto, realizado para presentarse en el soporte de un fotolibro.

La intención de Diego fue retratar la cotidianidad de las comunidades nativas, las cuales él considera casi olvidadas por el estado (León, D., 2019). De esta forma, y como resultado de este trabajo, quedaría un registro histórico sobre su existencia, costumbres y modo de vida.

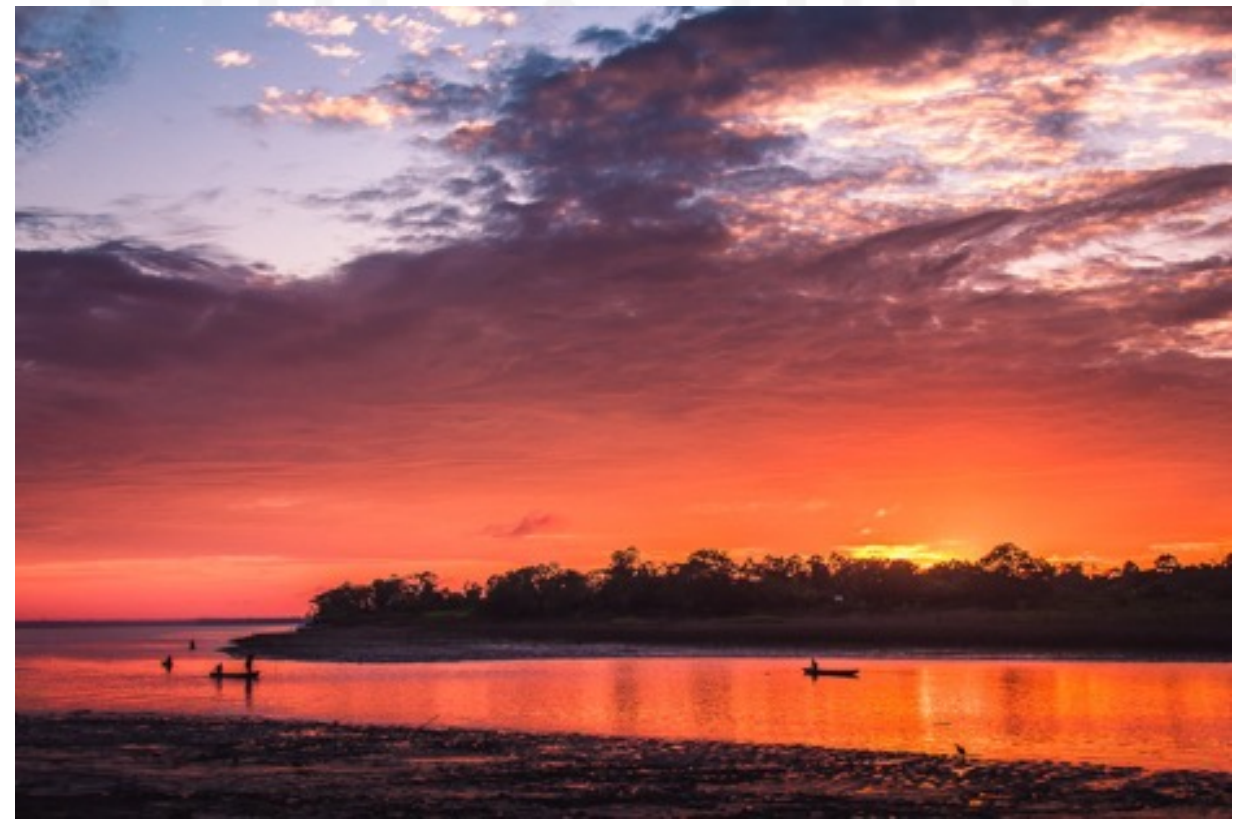

Fotografía realizada en el Río Amazonas - Diego León Garrido-Lecca Pescadores en sus labores diarias.

El trabajo de León representa una gran guía para la elaboración de este proyecto, puesto que contempla un acercamiento a unas comunidades nativas de la selva, que 
comparten rasgos similares en cuanto a cultura y modo de vida. Asimismo, dentro de estas comunidades se presenta el mismo problema que en Puerto Firmeza: las dificultades para poder acceder a recursos económicos, debido a que son consideradas poblaciones en extrema pobreza. Además, se comprarte el objetivo de evidenciar y concientizar a la población metropolitana sobre el estilo de vida y las condiciones en las que viven los nativos de la Amazonía peruana.

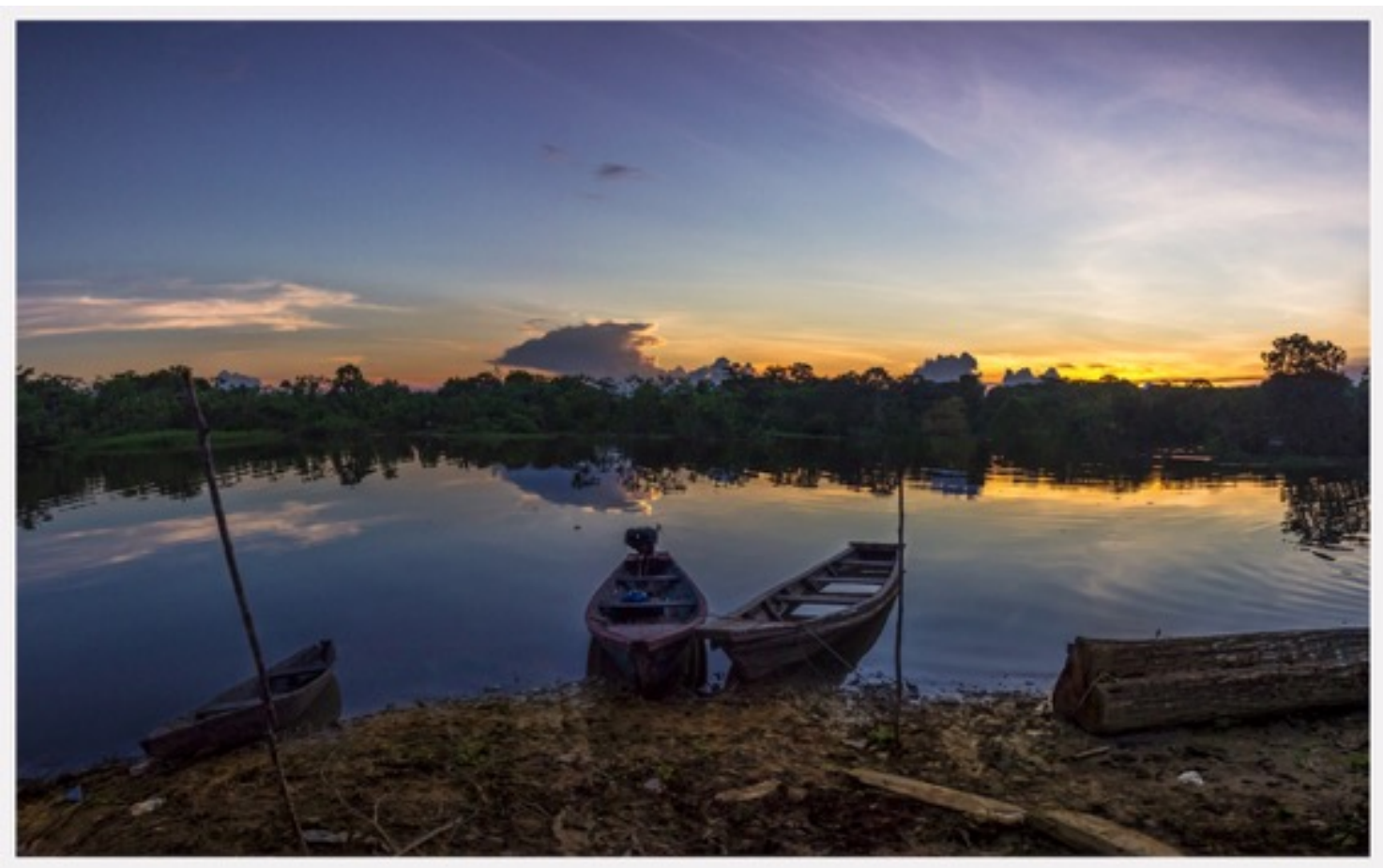

Amanecer en la comunidad de los Kukamas Kukamira - Diego León Garrido-Lecca Loreto, 2019 


\section{Fotosociales: Retratos de Iquitos 1960-1990 - Augusto Falconi}

Durante la época del "boom" del caucho, la fotografía se dedicó en gran forma a satisfacer los pedidos de los empresarios que se dedicaron a explotar a los pobladores amazónicos. La intención seguía siendo la de exotizar al poblador de la Amazonía, y mostrar como el "empresario" llegaba a la selva y llevaba el desarrollo.

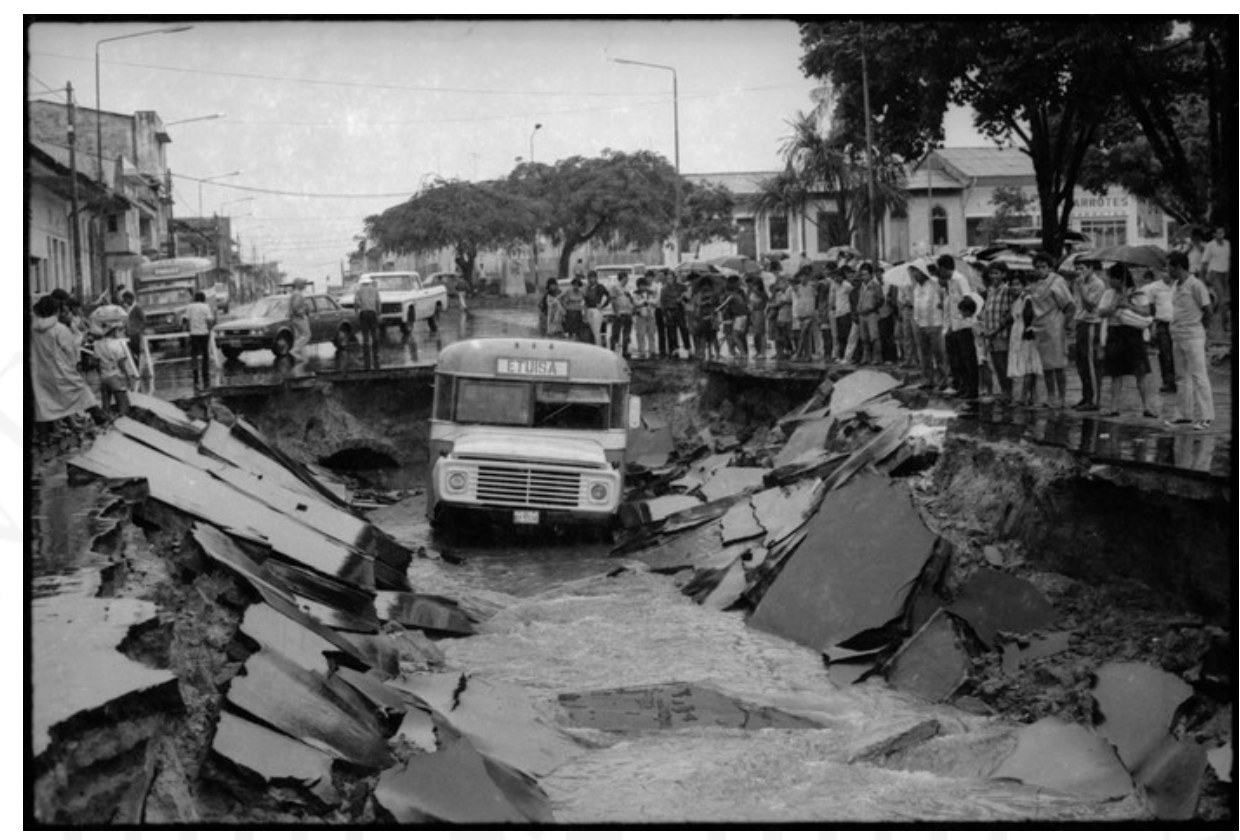

Augusto Falconi - FOTOSOCIALES (1960-1990)

Sin embargo, llegados los años 40, la fotografía buscó dignificar y reivindicarse con el poblador de la selva que había sido denigrado en épocas anteriores por este mismo arte visual. Es en este contexto que nace el proyecto de Augusto Falconi, que mediante de la fotografía busco evidenciar el verdadero rostro cotidiano de Iquitos. Logró, a lo largo de tres décadas, volverse una suerte de "cómplice" del iquiteño de a pie y ser participe activo a la hora de denunciar las injusticias que los aquejaban mediante el uso de la fotografía. Así es que nace su posición como el "Fotógrafo Social por excelencia de Iquitos", según cuenta Christian Bendayán, curador de su exposición "Fotosociales". 


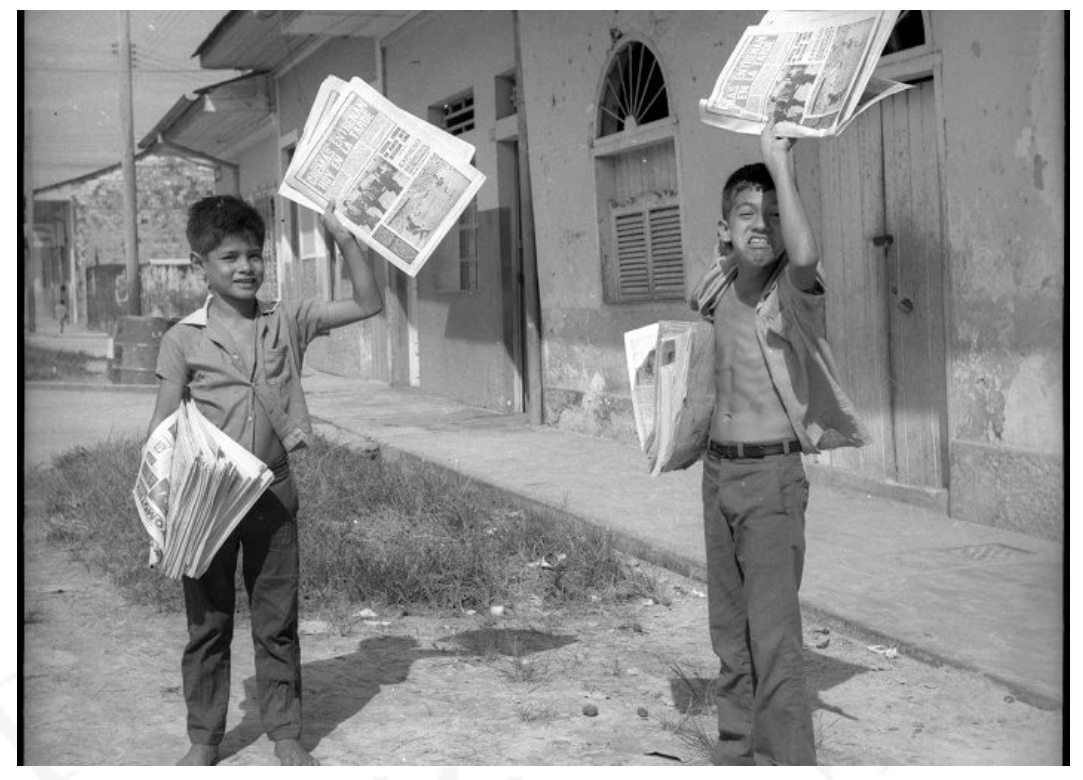

Augusto Falconi - FOTOSOCIALES (1960-1990)

El trabajo de Falconi sirve como una gran referencia para el proyecto "Bekanwe", puesto que, de cierto modo, este ultimo busca también reivindicar y mostrar la realidad de una comunidad amazónica, y evidenciar su verdadero modo de vida, denunciando sus carencias y mostrando su verdadero rostro. 


\section{Objetivos, materialización y exposición del material fotográfico.}

Este ensayo no busca quedarse como un registro más de una sociedad, sino que busca generar un impacto en sociedades metropolitanas. El objetivo central de esta tesis es evidenciar el modus vivendis de una comunidad Shipibo Konibo pura y retratar su cotidianidad, y de esta forma romper ideas pre concebidas por sociedades de ciudad sobre su cultura, entre las cuales está la idea de que los pobladores nativos son "salvajes" o personas pertenecientes a "tribus no contactadas" sin ningún tipo de occidentalización.

Para esto, me valdré de la plataforma en la que se mostrará el material fotográfico. El proyecto tiene como finalidad culminar en una exposición fotográfica altamente sensorial para el espectador. Esto se logrará con la materialización de las fotografías.

Un cierto número de fotos serán impresas en hojas de Bijao, una planta oriunda de la selva, conocida por ser esencial para la preparación de comidas regionales como el juane. Para este proceso, se trabajará de la mano con Manuel Limay, especialista en el proceso de impresión en plantas con clorofila. 


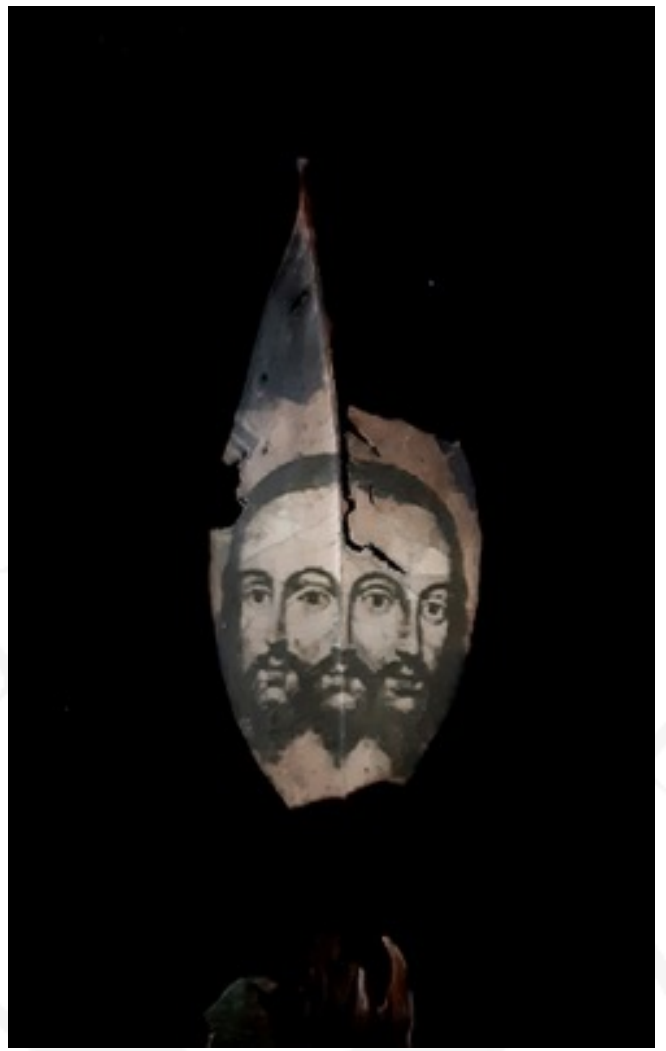

Impresión en hojas de plantas por Manuel Limay Incil Cajamarca, Perú.

Asimismo, se imprimirán térmicamente retratos de la comunidad en gasa, y se colocará detrás materia prima para la elaboración de bordados y telares que realizan las mujeres en Puerto Firmeza para generar texturas. 


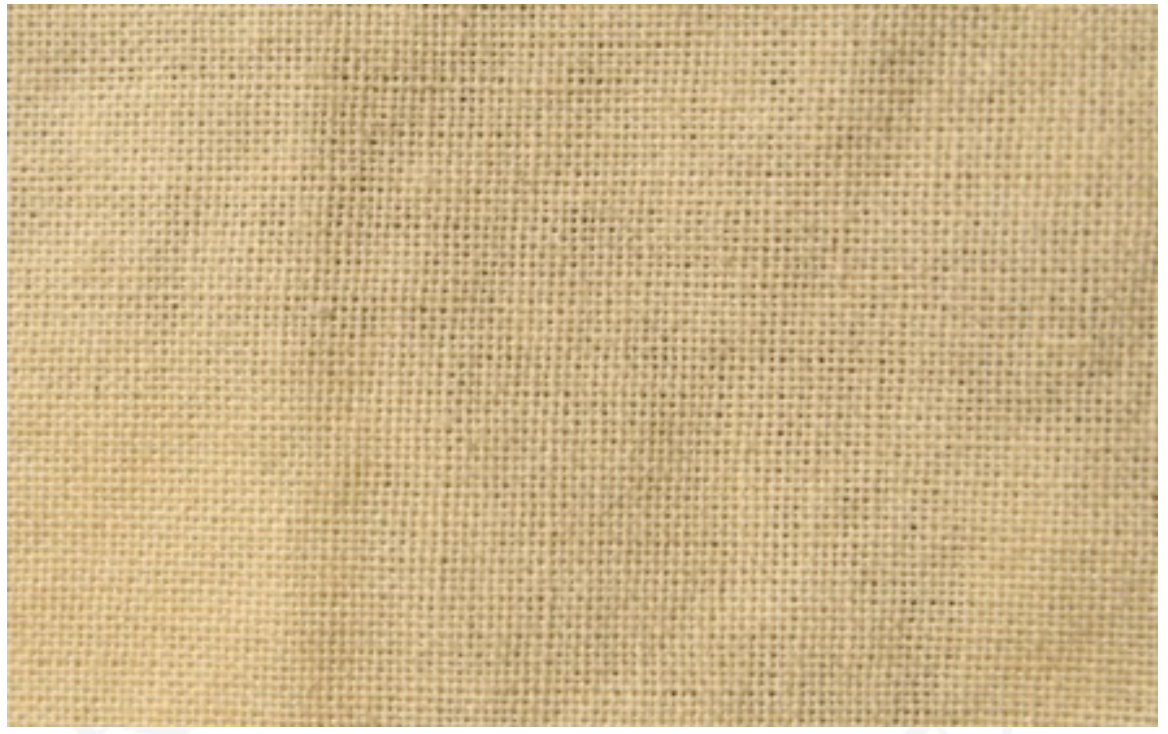

Telar de Tocuyo, esencial para el bordado de piezas típicas de la comunidad.

Asimismo, se realizará serigrafía en un corte transversal a un tronco de árbol de dimensiones de por lo menos un metro de diámetro, impregnando en él el rostro de uno de los niños de Puerto Firmeza.

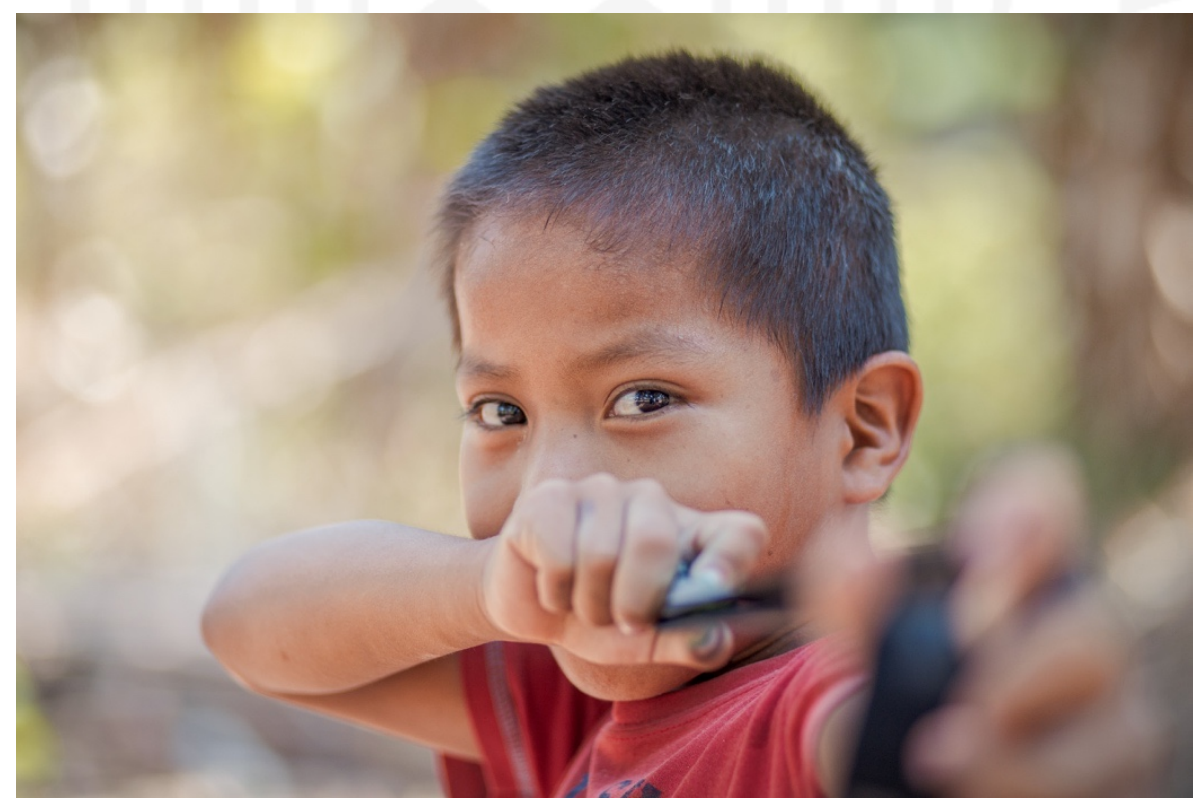

Juego de niños - Pedro E. Horna Horna (2019)

Puerto Firmeza, Pucallpa. 
Por otro lado, se ha grabado sonido ambiental en la selva durante el día, la noche y los "ícaros" o cantos de una chamán durante el ritual del Ayahuasca. Este material ha pasado por un proceso de post producción en el cual se han juntado todos los audios. Esto sirve para que, durante la muestra, se reproduzca el archivo en "loop" todo el tiempo, y de un contexto sensorial al visitante.

La finalidad de este proyecto es que sea, mas que una exposición, una experiencia fotográfica, y permita que la persona que asiste a la muestra tenga un viaje a través de los sentidos a Puerto Firmeza y pueda ser testigo de su cotidianidad. Y este viaje sensorial al que será expuesto el espectador de la muestra tendrá como referencia las distintas texturas, sonidos y, principalmente, experiencias visuales que tuve mientras realizaba el trabajo de campo. Las fotos serán plasmadas en distintos materiales que son abundantes en la comunidad como madera, hojas y tela con la textura de los telares de la comunidad, y esto será un remitente directo a Puerto Firmeza.

Este proyecto nace a partir de la necesidad personal de mostrar la realidad de comunidades y sociedades distintas a la propia. En el caso en específico de este proyecto, busco romper con la idea de que una comunidad nativa de la selva es un grupo de aborígenes no contactados que visten taparrabos y cazan en lianas con lanzas. El estilo del trabajo se inspira mucho en las obras de Steve McCurry, Sebastião Salgado y Franz Krajnik, en el sentido de la inmersión y la convivencia con la comunidad estudiada, en el intentar ver "como ellos", y no "por ellos", aspecto fundamental en el corte de antropología visual del proyecto.

Sin embargo, este proyecto no niega la existencia de grupos de personas que viven en comunidades no contactadas y rechazan la occidentalización. Un claro ejemplo de esto es el trabajo de Daniel Silva para la revista Cometa (2011), en el cual realiza un reportaje fotográfico a una familia de cazadores nómades de la selva del Cusco. Este grupo de personas si es completamente aislado y rechazan al hombre blanco, por el temor que les genera el recuerdo de la llegada de enfermedades y la explotación que sufrían las personas de su región en la época del caucho. En contraposición, este proyecto fotográfico busca mostrar cómo vive actualmente una Comunidad Nativa.

Si bien es cierto que estas fotos son pertenecientes a un ensayo fotográfico, y están compuestas bajo mi punto de vista, el proyecto tiene una relevancia más allá de lo personal. La muestra de estas fotografías permite que personas que nunca han tenido la 
oportunidad de conocer una comunidad nativa aprendan sobre el modo de vida de las mismas, y así rompan los mitos que existen entorno a ellos. Es decir, este trabajo contribuye a observar la vida cotidiana de un poblador de una comunidad nativa de la selva sin "exotizarlo". 


\section{CAPÍTULO II: REALIZACIÓN Y SUSTENTACIÓN}

A la fecha se han realizado dos viajes a la comunidad de Puerto Firmeza. El primer viaje se dio en el período comprendido entre el 1 y el 5 de agosto del 2019. Durante este primer viaje se realizó una labor de exploración y búsqueda de contactos que faciliten el trabajo. Se contactó a Cristofer Queque, estudiante de la carrera de Turismo en el Instituto "TEC" de Pucallpa. Él se dedica principalmente a la promoción e incentivo de turismo no convencional, en especial a la comunidad de Puerto Firmeza, con su marca Ucayali Adventure. Cabe resaltar que esta comunidad no es una comunidad que pueda basar su subsistencia en la mencionada actividad. Esto se debe a que la comunidad de San Francisco (a 4,4km de distancia) ha monopolizado el turismo en Pucallpa, y debido a su mayor cercanía a la ciudad, los visitantes no llegan a puerto Firmeza.

Queque cumple el rol de informante clave en toda la investigación. Él facilitó el acceso a la comunidad en el primer viaje. Sin embargo, en enfoque de nuestro interés por la comunidad es esencialmente distinto. Su afán porque la comunidad de Puerto Firmeza sea conocida es el incentivar el turismo no convencional/vivencial en la localidad. Él encontró provechoso el hecho de que yo visite el poblado de Puerto Firmeza porque, al ser realizador audiovisual, podía generar contenido para la página en Instagram que él maneja (@ucayaliadventure) en la cual fomenta el interés por Pucallpa como espacio turístico. Fue esencial, para el poder generar y mantener una buena relación, el poder realizar, a la par de mi trabajo documental, un trabajo de corte publicitario que, mediante planos distintos, puedan ser aprovechados por Queque para fines turísticos.

Viajamos el día 2 de agosto. Ese fue el primer contacto presencial con la comunidad. Ese día recorrimos los senderos donde están ubicadas las casas y cosechas en esta comunidad. Se realizaron algunas fotografías tanto a las personas que se encontraban cumpliendo sus actividades cotidianas, como la pesca y la cocina.

Esta primera visita tuvo como objetivo principal el contacto con el jefe de la comunidad. Sin embargo, por temas de trabajo el líder se encontraba de viaje. De igual forma, el segundo día (3 de agosto), volvimos a la comunidad y seguimos con el trabajo de observación. 
Estos dos primeros días en Puerto Firmeza fueron clave para analizar la viabilidad del proyecto. En esta primera fase de observación, analizamos de manera un poco más superficial el modo de vida de la población. Encontré que las casas están construidas en materiales precarios, como madera y plástico. Asimismo, la gran mayoría de techos son "malokas" -un conjunto de ramas secas y hojas, tejidos entre sí para evitar el paso del agua en época de lluvias-. La gran mayoría de las viviendas son de un solo piso, y el suelo de las casas es netamente la misma tierra.

Un aspecto que resalto de la comunidad es la práctica del fútbol. Todas las tardes, los niños, jóvenes y adultos, indistintamente de su sexo, juegan al fútbol (y de una manera muy aguerrida). El deporte es la actividad que más une a la comunidad como tal, y cuentan inclusive con un equipo de fútbol femenino.

Debido a que los últimos dos días que estuve en la ciudad de Pucallpa hubo vientos huracanados y malas condiciones meteorológicas, no se pudo volver a la comunidad de Puerto Firmeza. Sin embargo, habiendo realizado algunas fotos en los días que sí pudimos acceder a la localidad (fotos del primer viaje en anexos).

Lamentablemente, llegando a la ciudad de Lima, el disco duro donde se almacenaban las fotos del primer viaje sufrió una caída, perdiendo así gran cantidad de fotos, tanto en raw como en JPG. Se logró salvar por otros medios algunos archivos editados, pero no los raw.

Posteriormente, del 12 al 20 de setiembre, retorné a la ciudad de Pucallpa, para internarme desde el 13 en la comunidad. Para este viaje, Cristofer Queque coordinó con el supuesto jefe de la comunidad (Sandro López Ahuanari) nuestra estadía. Al llegar a la comunidad, nos ubicó en un salón del colegio durante tres días. Luego de esto, Sandro se trasladó a Yarinacocha. Pocos días después nos enteraríamos que él no era el líder de la comunidad, puesto que hubo un cambio de mando, y que el nuevo jefe era Pablo Ramírez.

Durante estos días participé en las distintas actividades de la comunidad, como la pesca, la agricultura, la cosecha, el deporte, y la comida. Asimismo, registré un ritual de ayahuasca. El corte de estas fotos fue lo menos intervencionista posible. No modificaba en lo absoluto la escena observada, sino que se registraba tal cual se encontraba. Esto con la intención de no alterar en lo absoluto la realidad encontrada y que las instantáneas cuenten con la mayor objetividad posible, para que facilite la reflexión. 
Llegado el lunes, mi intención era fotografiar las aulas de clase del colegio ubicado en la comunidad. Sin embargo, mi sorpresa fue grande cuando la profesora tocó la puerta del lugar donde yo dormía -y que ignoraba que era un aula de clases-. La maestra me invitó a retirarme y sacar mis pertenencias del salón. Sin embargo, esto fue de gran ayuda, pues una de las señoras de la comunidad, al percatarse de la situación, me invitó a quedarme con ella en su casa. Así, mi convivencia con los shipibo fue mucho más intima.

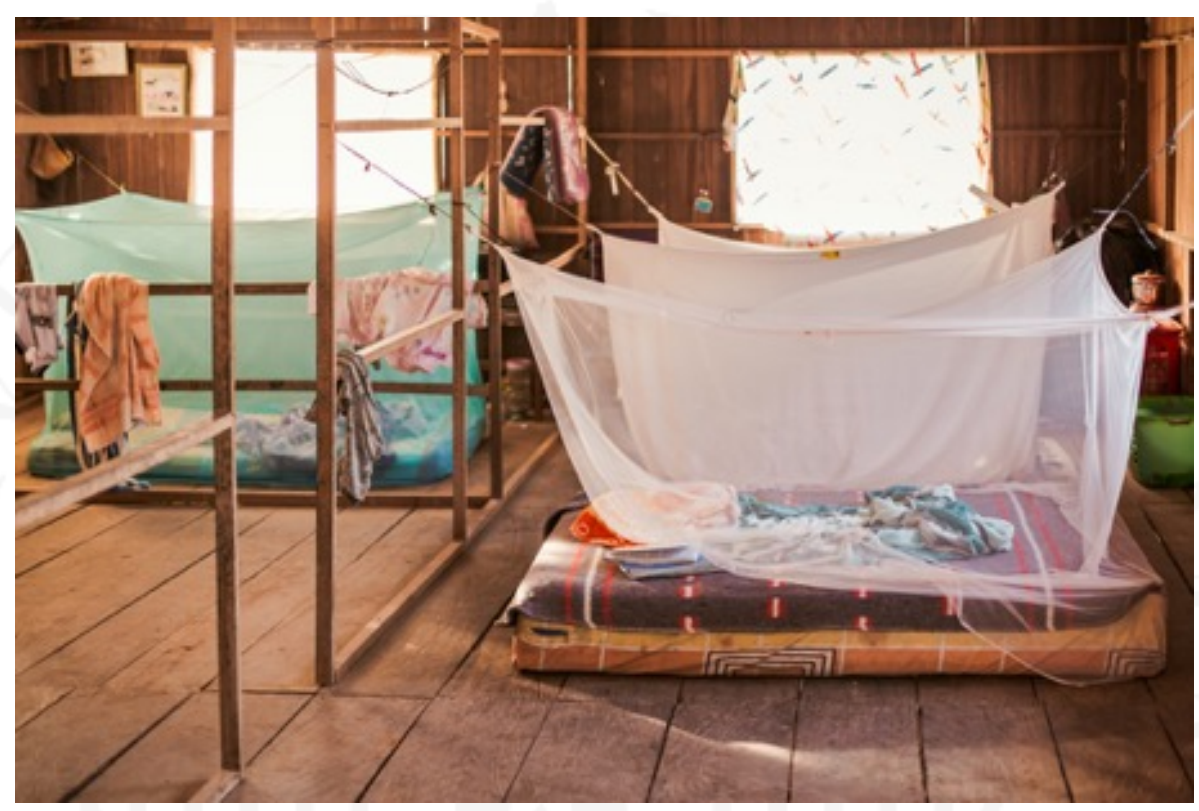

Dormitorios dentro de una casa Shipibo - Pedro E. Horna Horna (2019) Puerto Firmeza, Pucallpa 


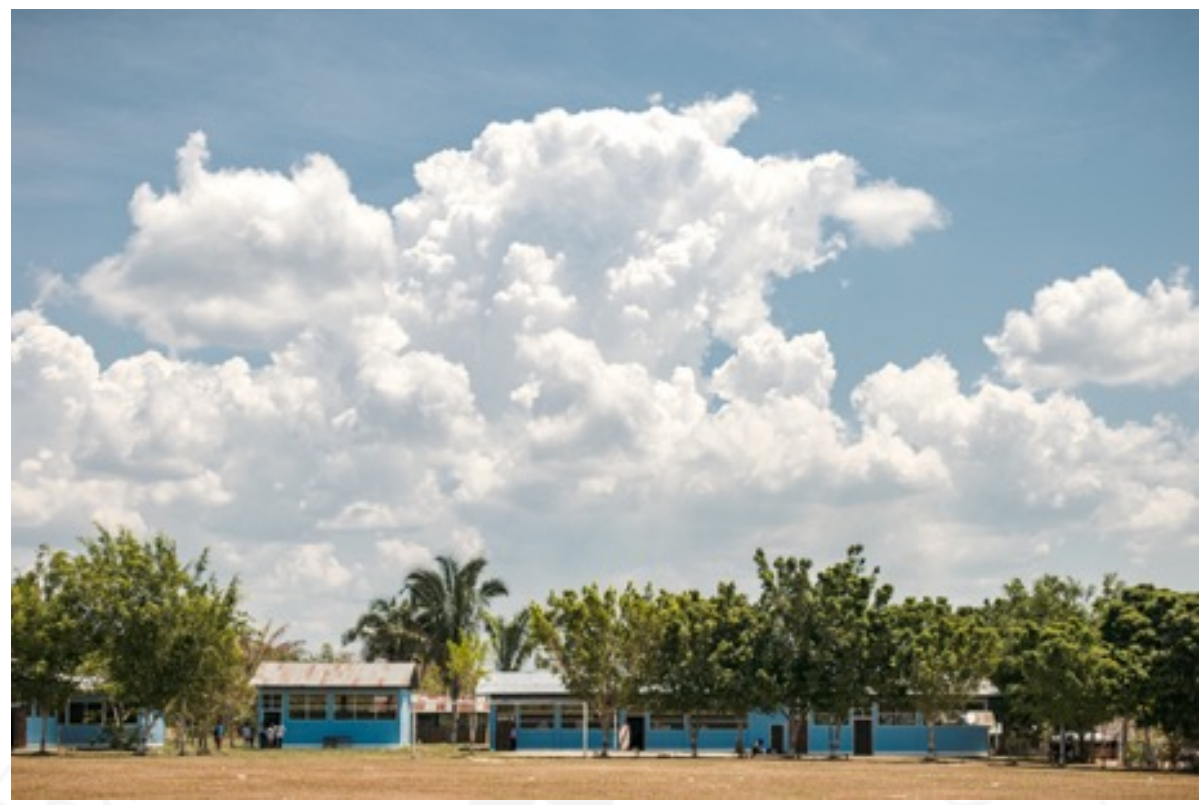

Colegio de Puerto Firmeza - Pedro E. Horna Horna (2019)

Puerto Firmeza, Pucallpa.

Una vez reinstalados pudimos ingresar a las aulas del colegio, con el permiso del director de la institución. Vimos salones bastante precarios, con infraestructura un poco maltratada por los años. Sin embargo, el entusiasmo de los niños al estar en clases era inmenso.

Nos enteramos que las clases en el nivel primario se dictan en el idioma Shipibo, y cuentan con un curso de Castellano Básico. En el nivel secundario, los alumnos si estudian netamente en español. Así, se preserva el idioma y los niños y adolescentes terminan el colegio siendo bilingües. 


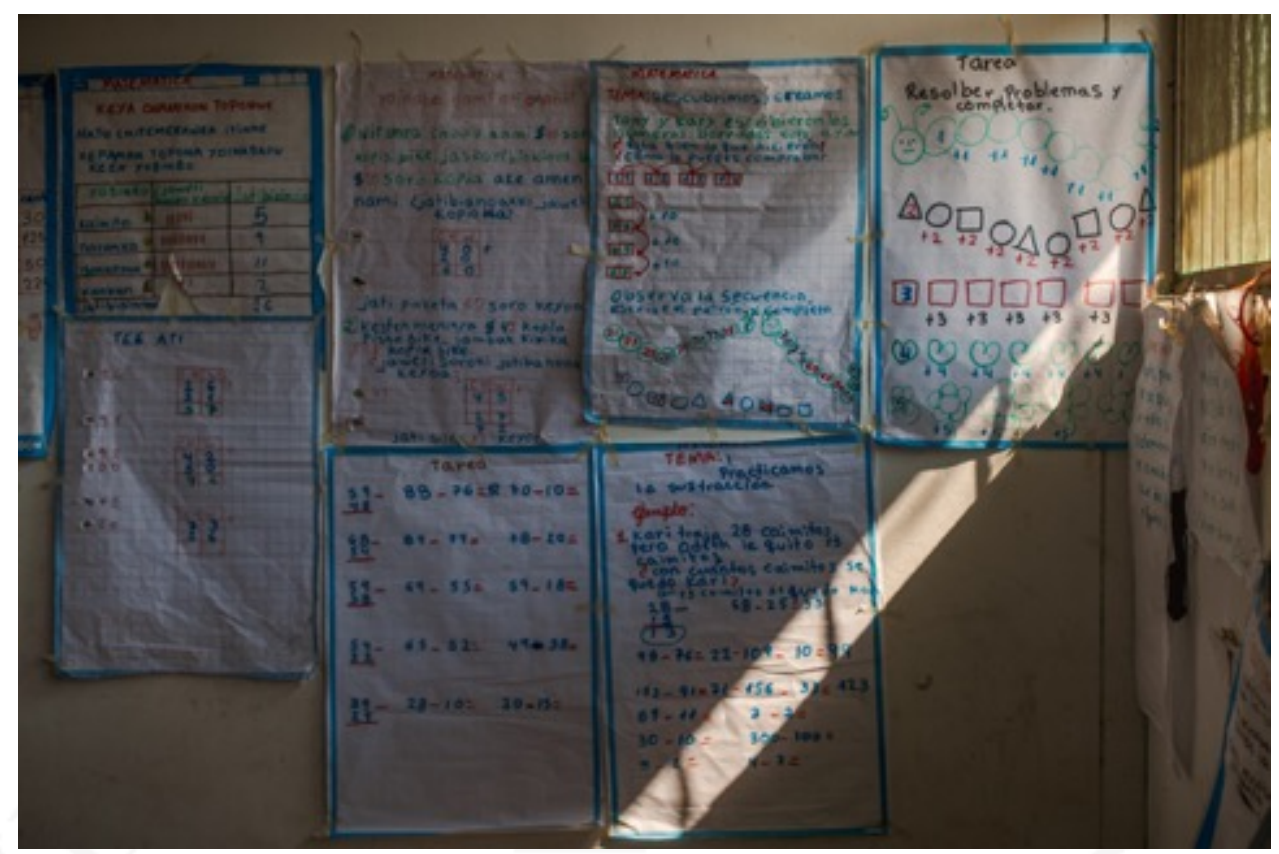

Trabajos de clase realizado por alumnos de primaria - Pedro E. Horna Horna (2019) Puerto Firmeza, Pucallpa.

Regresé a Lima el 21 de setiembre, debido a una cancelación de vuelo por parte de LATAM. Traje conmigo alrededor de dos mil fotos. Pocas semanas después, me reuní con mi asesor, Franz Krajnik -foto documentalista y docente de la Universidad de Limay revisamos el material.

Del total de fotos, decidimos seleccionar 146 fotografías que iban más acorde al tema de este trabajo: la vida cotidiana como evidencia de cómo vive la comunidad shipibo de Puerto Firmeza. Posteriormente, se imprimieron estas 146 fotos en tamaño jumbo y se realizó una segunda selección. Quedaron seleccionadas 46 fotos que pasaron por un proceso de retoque fotográfico.

En el mes de enero del año 2020 se realizó un tercer viaje a la comunidad nativa, en el que permanecí durante cuatro días en Puerto Firmeza, con un gran inconveniente por delante. Viajé entre el 12 y el 16 de enero, y la ONPE había programado las Elecciones Congresales Extraordinarias para el 26 de enero, lo que significó que al llegar a Puerto Firmeza me encuentre con muy pocos pobladores, en su mayoría niños, puesto que la mayoría de los adultos se encontraban realizando sus tramites de regularización de papeles para poder ejercer su derecho al sufragio, lo que en parte señala que es un poblado políticamente activo. 
Frente a esta dificultad la decisión tomada fue aprovechar los días en tomar fotografías que generen en su mayoría texturas, un tanto más conceptuales. La finalidad de estas fue fungir como una conexión entre los diversos "capítulos" que tendrá la exposición (como, por ejemplo: la vida cotidiana, la infancia, el hogar, la escuela, etc.). Sin embargo, se logró realizar también un trabajo de retratos y algunas otras instantáneas con los niños de Puerto Firmeza.

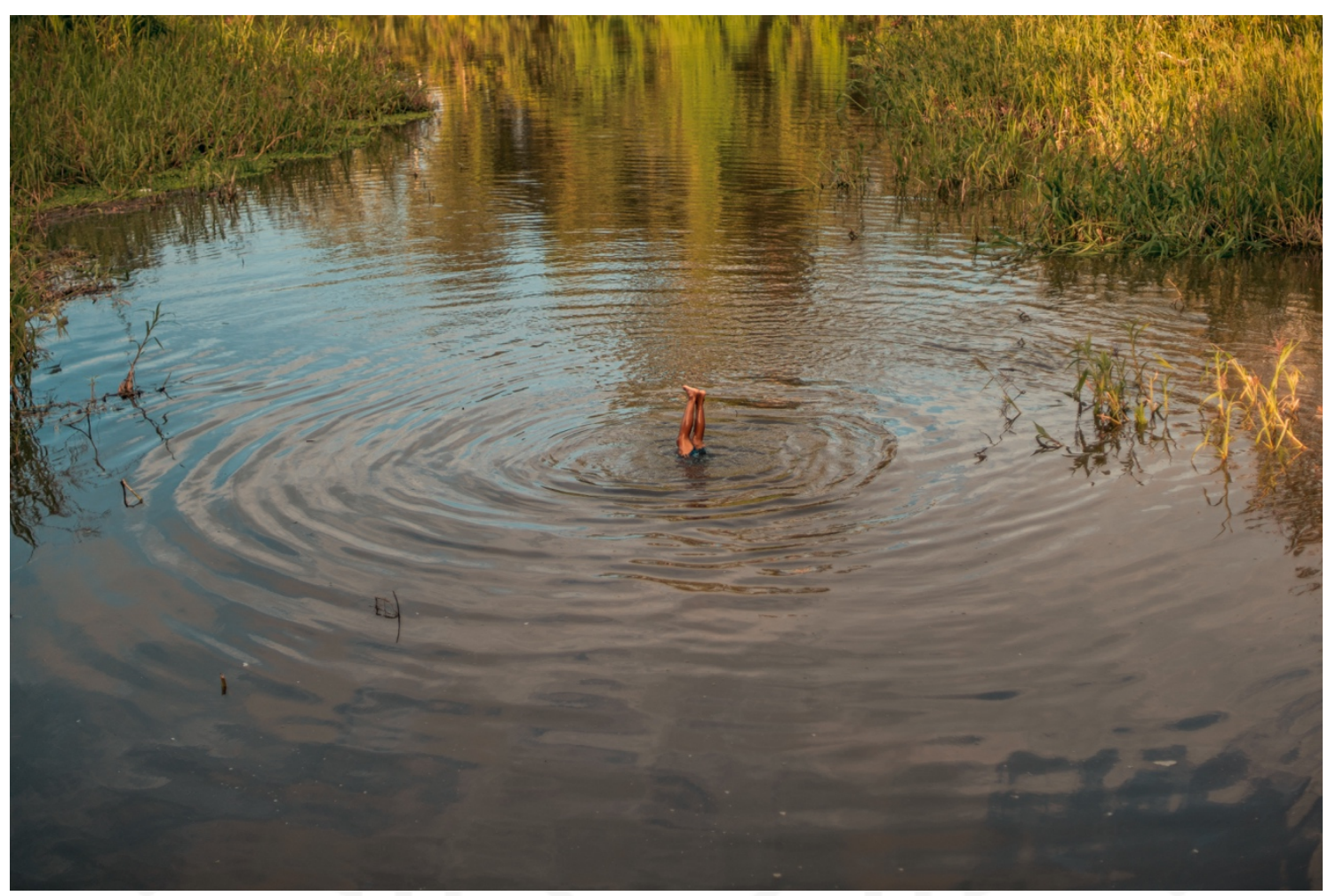

Infancia - Pedro E. Horna Horna (2020)

Puerto Firmeza, Pucallpa. 


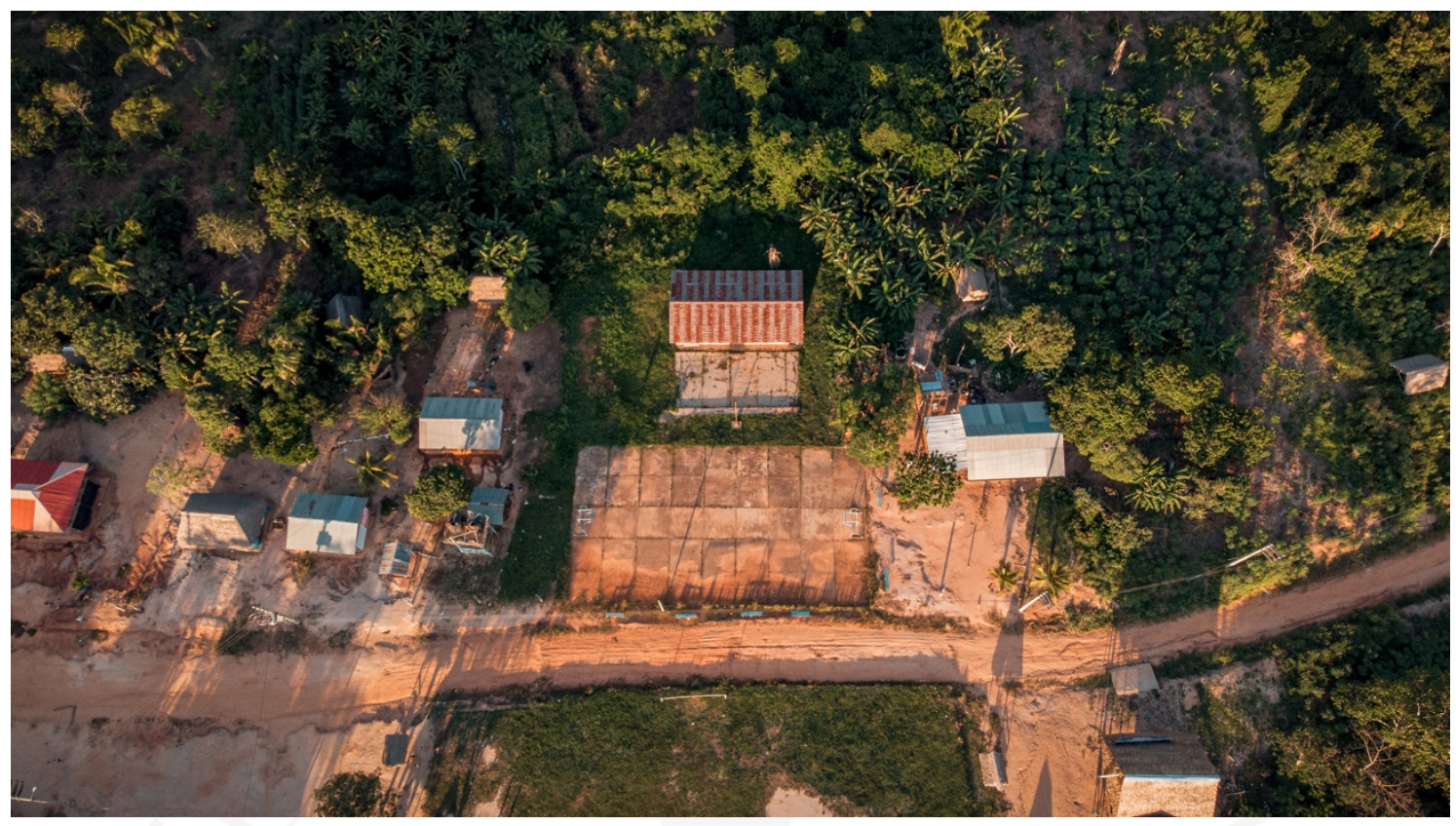

Infancia - Pedro E. Horna Horna (2020)

Puerto Firmeza, Pucallpa.

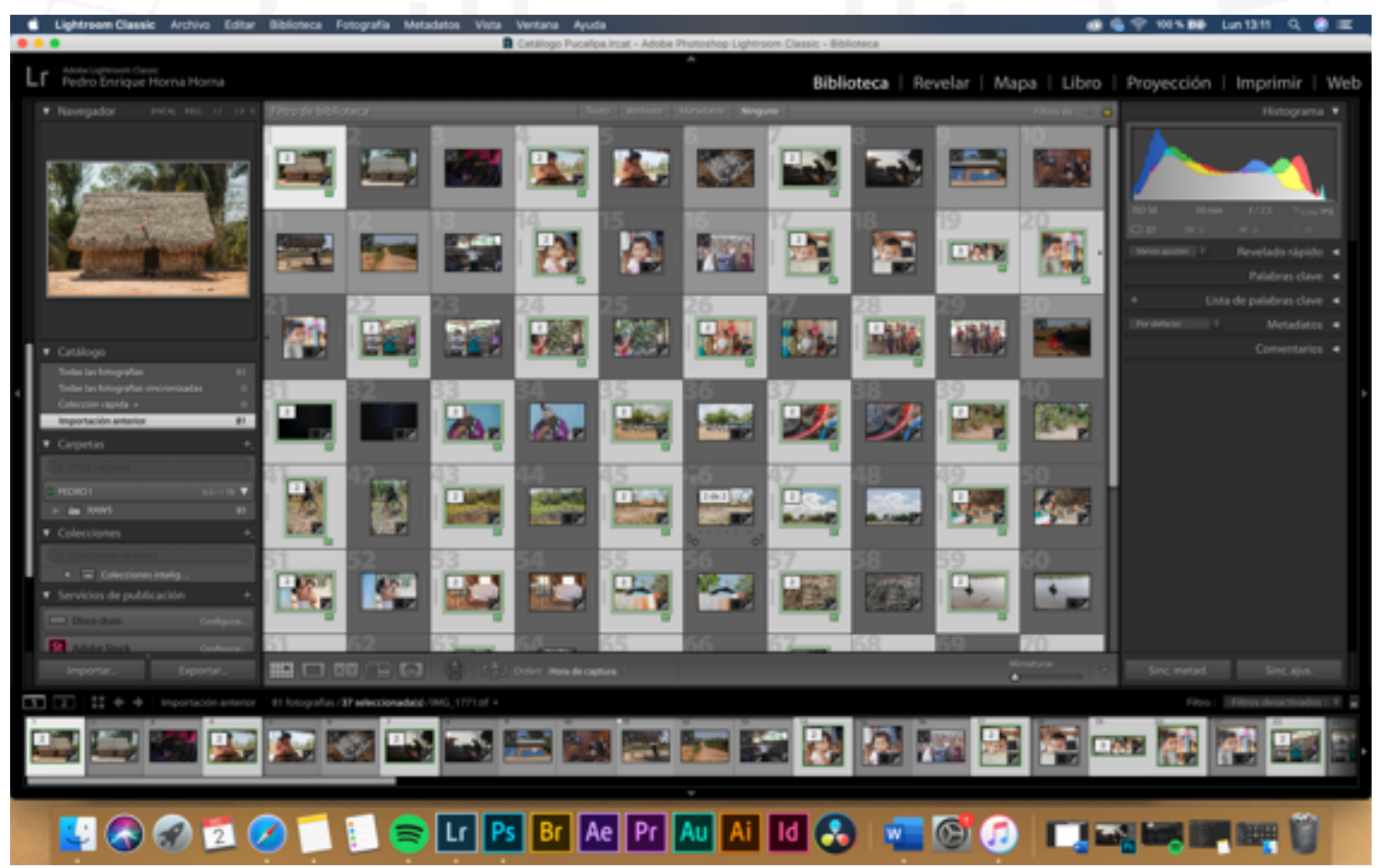

Fotos elegidas para retoque. 
El tipo de retoque que se realizó fue netamente el proceso de calibración de luz y realce de color, mas no hubo alteración o intervención de la fotografía, puesto que lo que se evita es justamente alterar la realidad vivida en la localidad. El proceso de calibración se realizó en Adobe Lightroom, y el proceso de edición de color en Adobe Photoshop. Se decidió virar los colores hacia tonos terrosos/cálidos, puesto que, desde la perspectiva propia, sentí que me remitía directamente a dos aspectos esenciales de Puerto Firmeza: El calor y sequía de la selva peruana, y la calidez de la gente de la localidad al recibirme y abrirme las puertas de su casa.

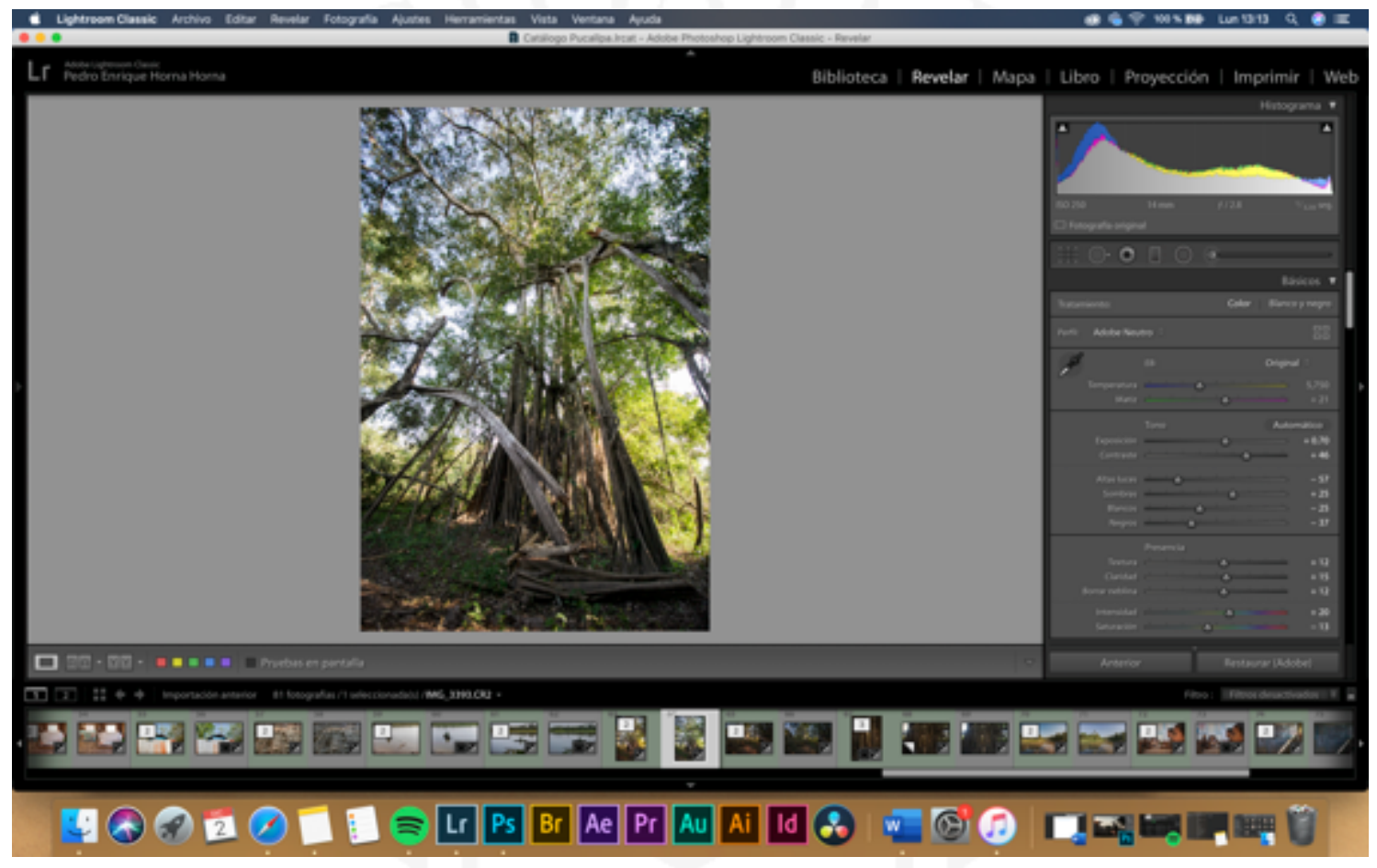

Proceso de calibración 


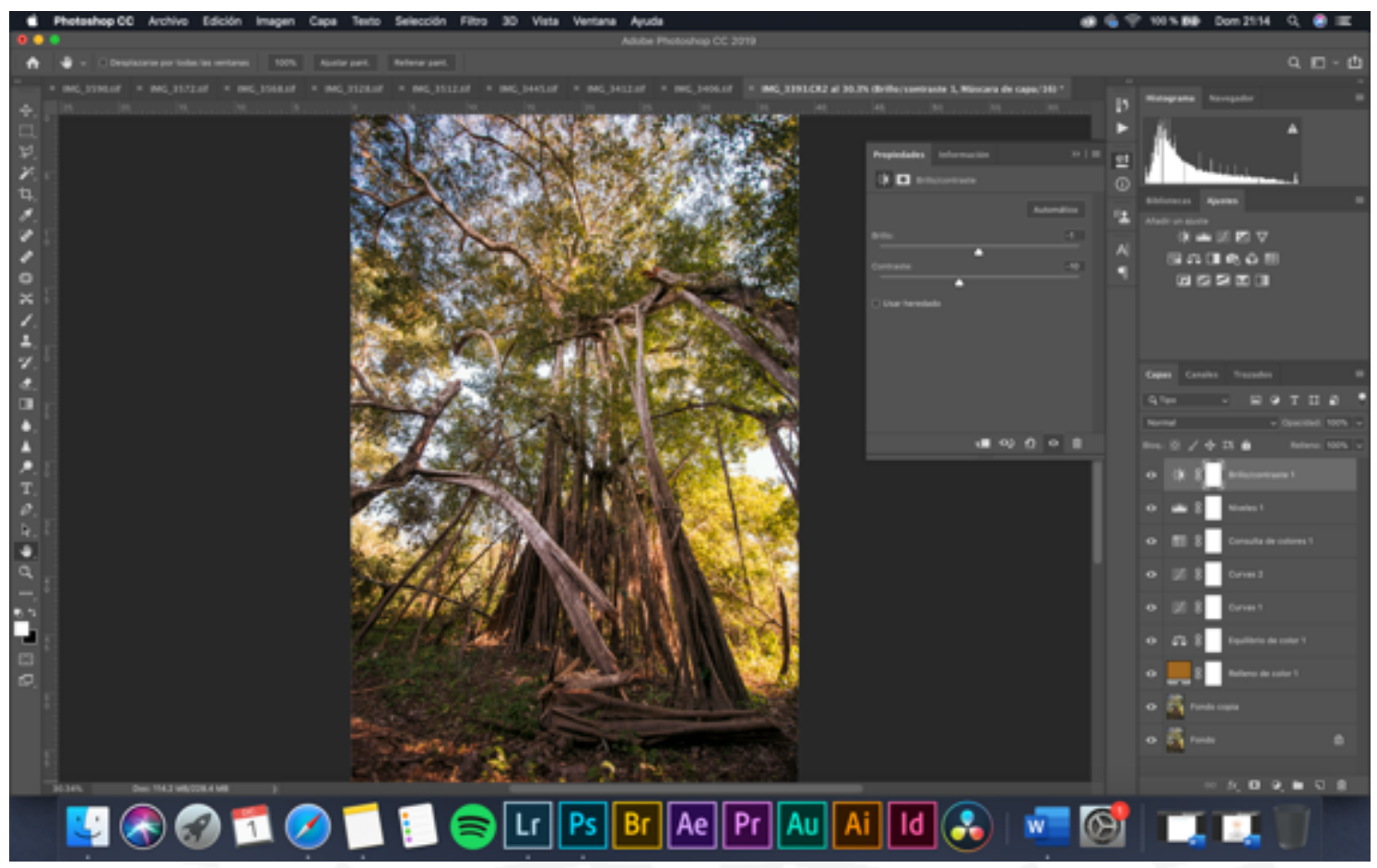

Proceso de edición de color

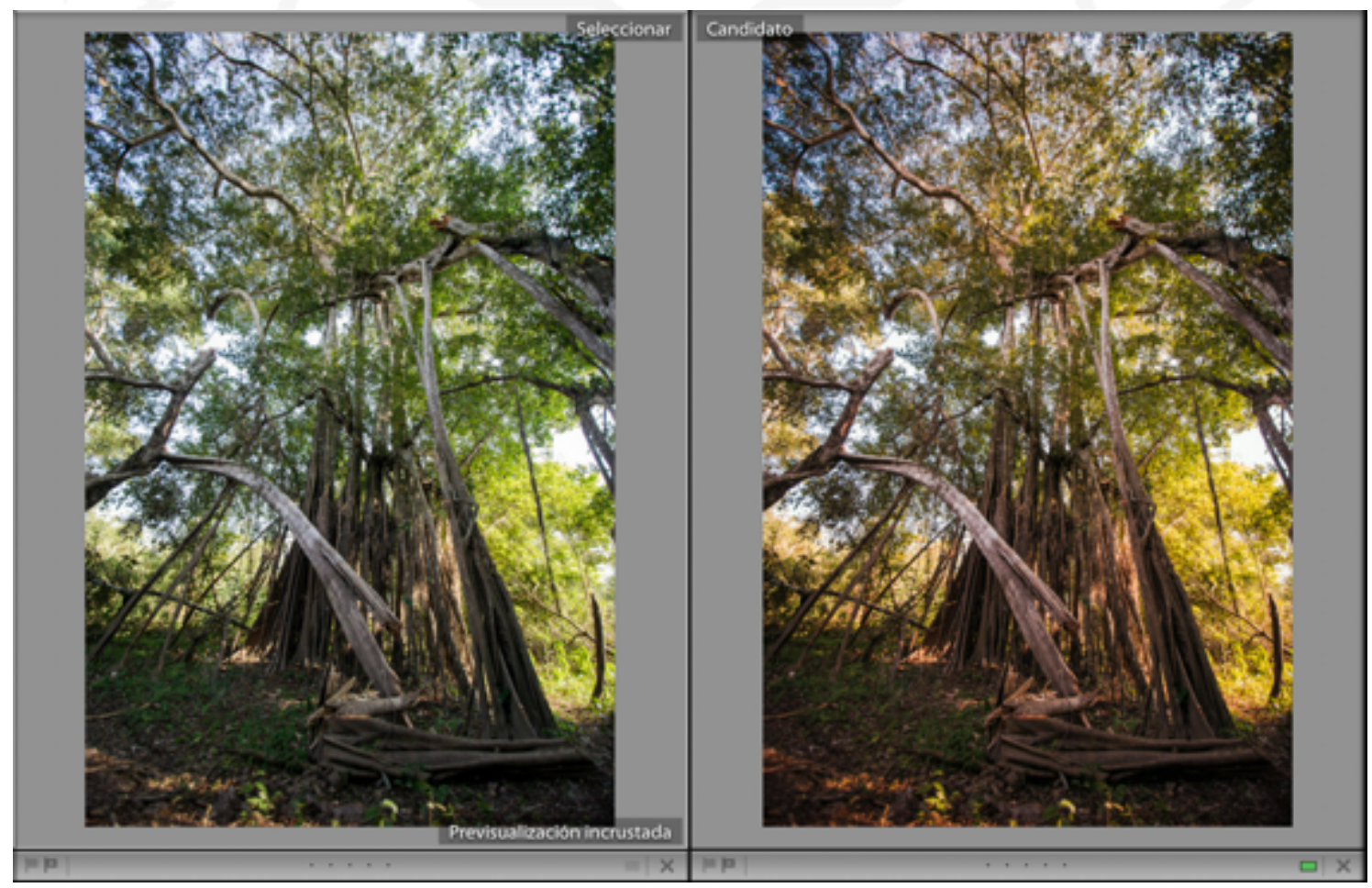

Antes y después del proceso de retoque

Asimismo, dado que estas fotos están siendo trabajadas para una futura exposición fotográfica, se conversó acerca de los formatos en los cuales se presentarían las fotos. La decisión cerró en que, si bien la gran mayoría sería impresa en papel fotográfico, muchas 
de estas serán materializadas en hojas de bijao, una planta común en la localidad. Asimismo, se imprimirá en gasa y se jugará con las texturas del tocuyo, material usado para realizar bordados. Esto para que el visitante a la exposición tenga una experiencia más sensorial que permita una mayor conexión con el tema expuesto.

Al revisar todo el material fotográfico recabado en la investigación, adicionalmente al testimonio del maestro del colegio de Puerto Firmeza, es posible generar una reflexión acerca del sentido de comunidad que tienen los habitantes. En primer lugar, tienen los roles de tareas diarias bien definidos por género. Asimismo, si bien no tienen un gran apoyo por parte del estado y de los gobiernos regionales, los pobladores de Puerto Firmeza, y sobre todo los niños de la comunidad, tienen un gran orgullo y sentido de pertenencia a este grupo humano. Defienden mucho su lengua y su cultura, y tienen esta inocencia propia de la infancia, y se las ingenian para seguir siendo niños, disfrutando de su infancia pese a la carencia en la que se ven sometidos.

En un principio fue bastante complicado empezar a generar relaciones con los pobladores. Sin embargo, estos mismos niños fueron un gran camino para llegar a los padres. E irónicamente, esto se logró al permitirle a los niños tomar algunas fotos con una cámara análoga, y permitirles jugar con esta. Muchos niños, que al principio se mostraron reacios a ser retratados, luego de prestarles la cámara, perdieron el miedo a esta y se pudo hacer un mejor registro tanto de ellos, como de sus familias.

Las fotos fe paisaje nos dan un contexto del lugar en el que esta Puerto Firmeza, sobre todo las tomadas con drone, que nos permite ver a Puerto Firmeza en relación al espacio en la selva. Y es interesante tener a una persona en estos paisajes, pues te da la sensación de inmensidad que tiene el monte y no vulnerable que puede ser el ser humano en ese estado, $\mathrm{y}$, sin embargo, no se ve amilanado por el espesor de la selva porque lo siente como lo que es, su hogar.

La foto de el niño en la hamaca, a mi parecer, explica de gran manera lo que busca este proyecto. Es un niño, envuelto en la hamaca, con la mirada hacia el horizonte, y la interpretación que uno le puede dar, en relación a este proyecto, es la de un niño, mirando hacia un posible futuro cercano, pero envuelto en sus tradiciones shipibas, de las cuales se abraza. Y es algo que en campo me dejaron en claro todos los niños: están orgullosos de ser shipibos, de hablar shipibo y de llevar su cultura fuera de la comunidad. Y frente 
a la adversidad que afrontan, sobre todo a nivel de infraestructura y equipamiento para la educación, todos tienen ese deseo de asistir a cada una de sus clases.

La cotidianidad de la comunidad podría parecer monótona, pero en el momento que ves el sincretismo cultural que existe entre los shipibos y la ciudad, ves el concepto de modernidad en su estilo de vida. Ves ese occidentalismo entrando a la comunidad: antenas de Direct TV, cabinas de internet, e incluso el mismo hecho de que exista un colegio, denota modernidad. Por ejemplo, vemos que cada una de las casas en toda la comunidad cuenta con radio y televisor. 


\section{Capítulo III: Lecciones Aprendidas}

Este proyecto no fue sencillo de realizar. Durante todo el proceso de producción se presentaron numerosas dificultades, desde el mismo proceso de llegar a la comunidad, hasta el almacenamiento del material fotográfico.

Durante el primer viaje, mi informante, Cristofer Queque, me llevó a la comunidad a buscar a quien se suponía era el jefe, Sandro López. Sin embargo, no se encontraba en la comunidad y se mostraba esquivo a nuestras llamadas. Lo encontramos en el segundo viaje y nos instaló en un salón del colegio - no sabía que era un salón-, y llegado el día lunes, los profesores, con un justificado mal humor, nos hicieron retirarnos del aula. Es en ese momento en el que nos enteramos que Sandro no era más el jefe de la comunidad, sino Pablo Ramírez. A partir del incidente, entablamos mejores relaciones con el nuevo jefe, y nos facilitó mucho el trabajo. Esto nos enseña que el generar un contacto con la máxima autoridad de la comunidad es clave para el desarrollo de un proyecto de esta envergadura.

Además, el informante necesitaba el material para incentivar el turismo en la comunidad, por lo que me pedía que elabore fotos cuya composición y enfoque no iba de acorde a los principios de la fotografía documental, sin embargo, se realizaron las tomas solicitadas, y de esta forma, el informante y yo nos vimos beneficiados de esta incursión en la comunidad.

Otra de estas lecciones aprendidas -pese a que es un proceso básico y muchas veces pasado por alto por muchos realizadores visuales- es el realizar numerosas copias del material recabado. Poco después de haber regresado de Puerto Firmeza en el primer viaje, el disco duro donde tenia almacenado el material sufrió una caída y los RAW de esta primera incursión se perdieron, junto con una gran cantidad de material fotográfíco realizado en los últimos cinco años. Con las facilidades que brinda la tecnología hoy en día, la lección es realizar como mínimo tres copias de seguridad del material -una en el disco duro principal, una en un disco duro de back up, y una última en la nube-, para así evitar cualquier tipo de pérdida. 
Finalmente, otro aspecto clave a tomar en cuenta es el cuidado y preparación de equipos. Considerando que el servicio de luz es un poco deficiente, no podía darme el lujo de cargar baterías muchas veces al día, Esto demuestra que es vital el llevar gran cantidad de baterías cargadas y memorias para la cámara, pues esto facilitará el proceso y no nos quedaremos con la cámara muerta durante horas, arriesgándome a perder fotos valiosas. 


\section{Capítulo IV: Logros y Resultados}

Dentro del período en el que se llevó a cabo la producción, selección y retoque fotográfico del material obtenido en este ensayo, se presentaron oportunidades en las que se pudo analizar la respuesta y recepción del público frente a algunas de las instantáneas realizadas en Puerto Firmeza.

El primero de ellos fue la obtención del primer puesto en la categoría Selva, del concurso organizado por Columbia Sportswear Perú, en el que se participó con una fotografía realizada en la laguna de Yarinacocha durante el primer viaje realizado a Pucallpa. La foto tuvo muy buena recepción por parte del jurado y la gente que pudo verla.

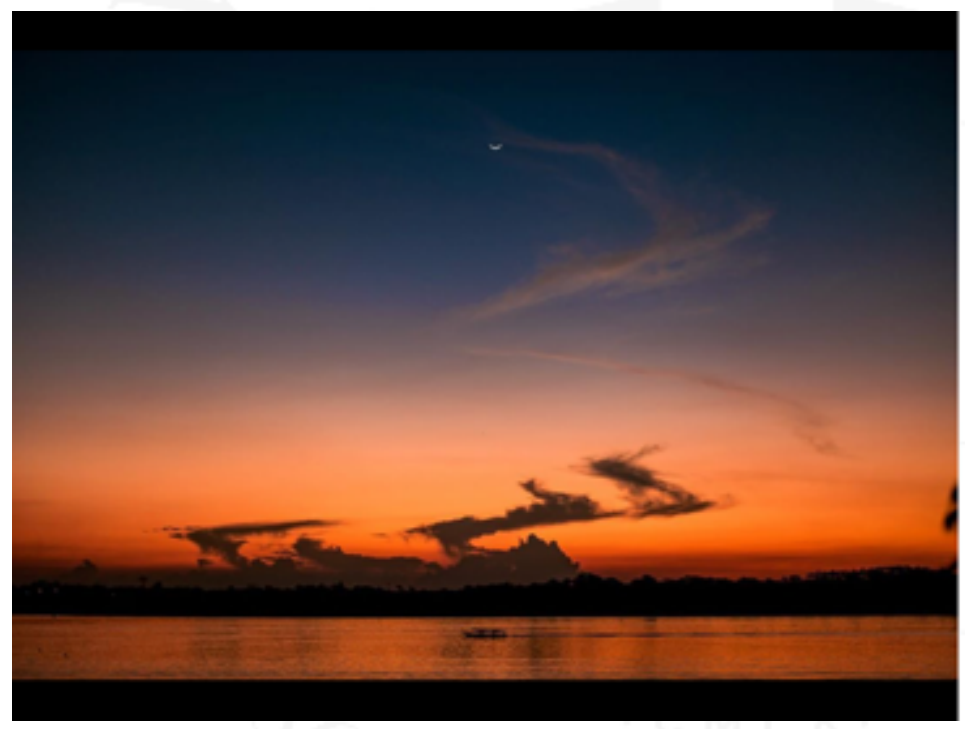

columbiasportsweat * Siguiendo

columbiasportswear_peru Felicitamos al PRIMER PUESTO en la categoría SELVA.

Pedro Enrique Horna Horna Qhornapedro

Foto tomada en la Laguna de Yarinacocha, Pucallpa

¡Gracias por participar!

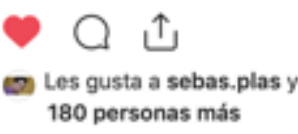

Posteriormente, el 3 de setiembre del 2019, se presentó la foto bautizada como "Capullo", al primer concurso de Fotografía "EnFoco", organizado por la Facultad de Ciencias de la Comunicación de la Universidad de Lima, en conjunto con Sony. Esta foto fue galardonada con el Primer Puesto del concurso, escogida entre 19 fotos finalistas. El jurado estuvo compuesto por dos fotógrafos peruanos, pertenecientes a las ramas de la fotografía de modas y publicitaria, y un representante de Sony USA. La Universidad de Lima premió con un trofeo de Primer Puesto, y en conjunto con Sony, se otorgó un vale de $50 \%$ de descuento en cámaras Sony. Posteriormente, el boletín "Conectados" de la Facultad de Comunicación elaboró una nota que tuvo gran respuesta e interacción por los 
lectores, quienes presentaron un gran interés por el trabajo documental en Puerto Firmeza.

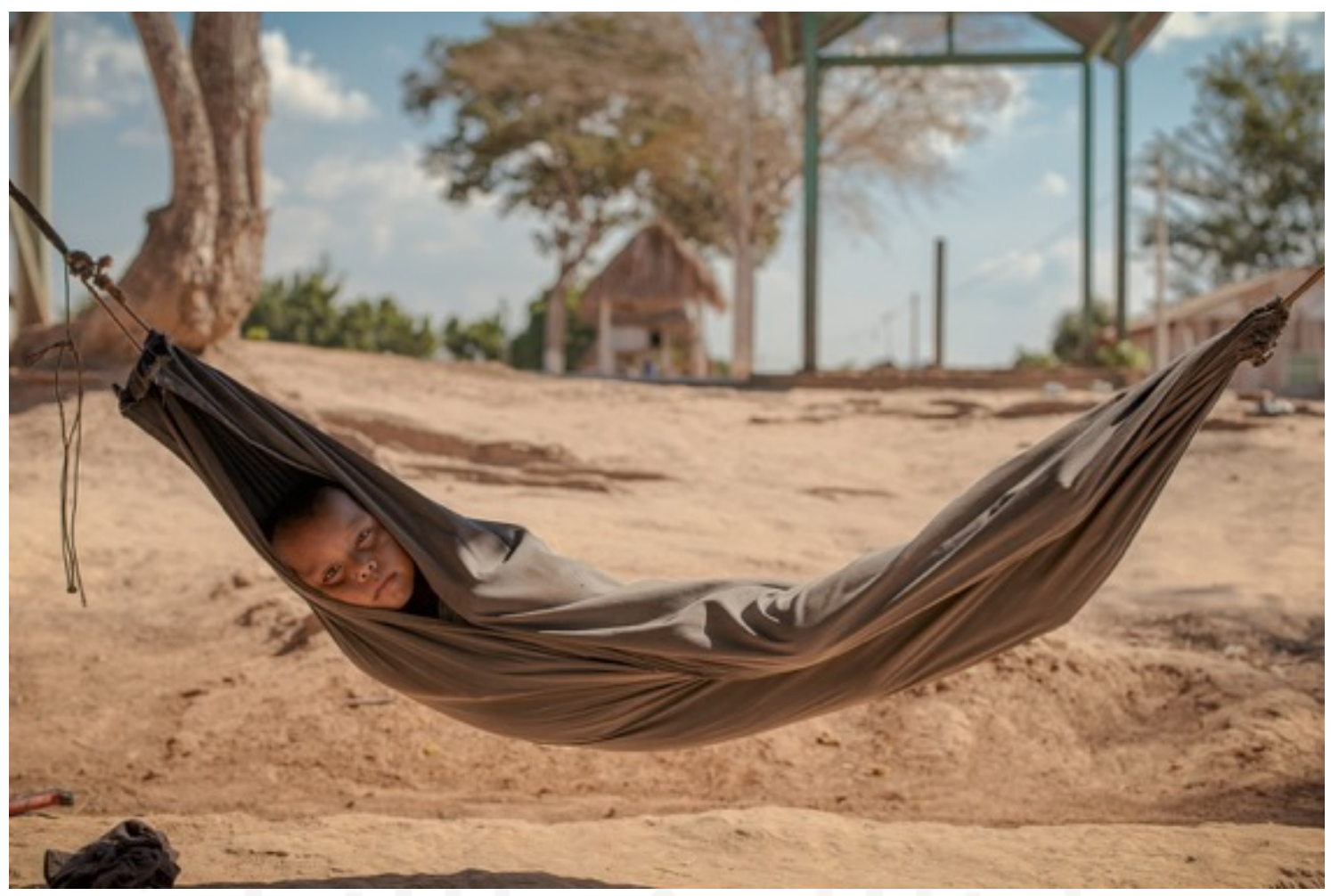

Capullo - Pedro Enrique Horna Horna (2019)

Puerto Firmeza, Pucallpa.

Ganadora del Primer Concurso de Fotografía

Universidad de Lima.

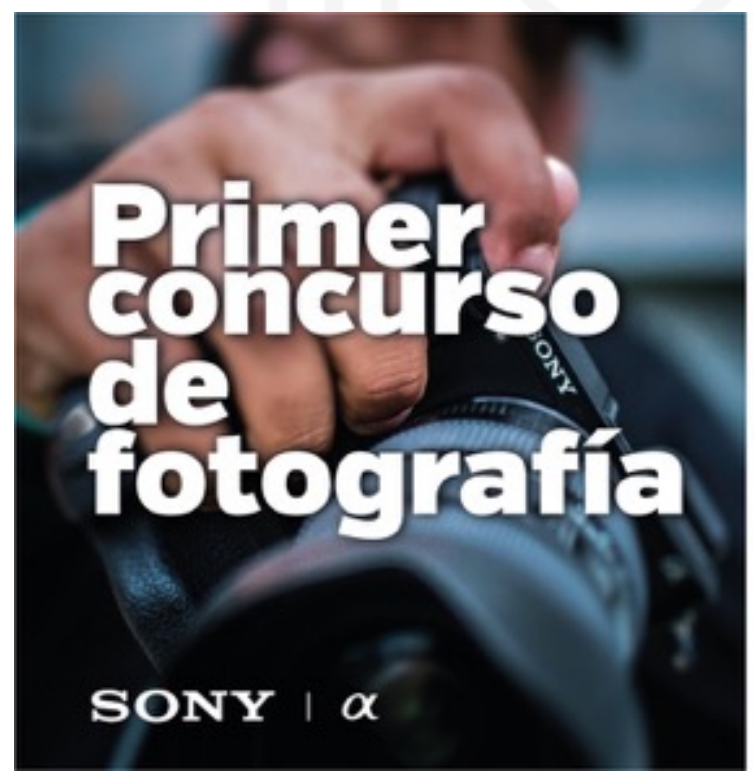

\section{Finalistas}

Marla Albornoz

Luis Barzola

Renzo Cahuana

Jose Cartbajal

Ursula Coello

Alejandra del Águlla

Pedro Horna

Maria Fernanda Infantas

Carlos Medina

Muries Novoa

Sebastián Plascencia

Gonzalo Portilla

Josefina Rivadeneyra

Janet Roca

Franccesca Seminario

Finalistas del concurso EnFoco 2019 
Una experiencia como proyecto de tesis

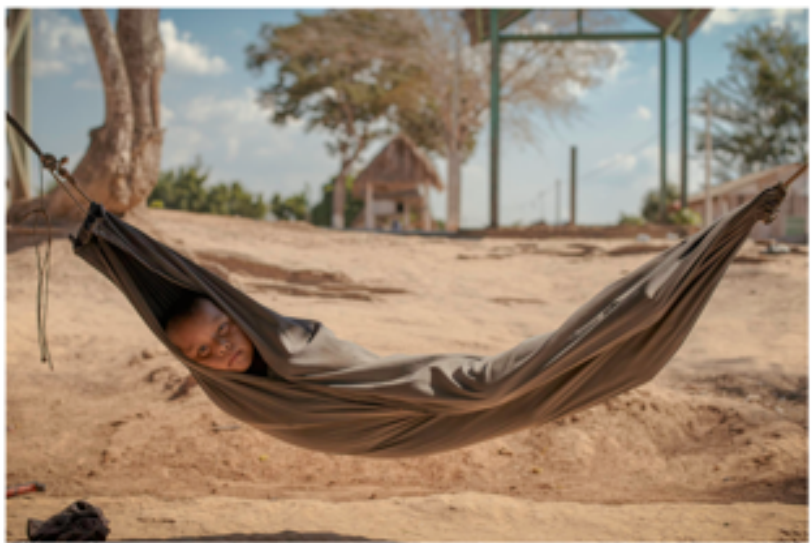

Diarios de fotografia

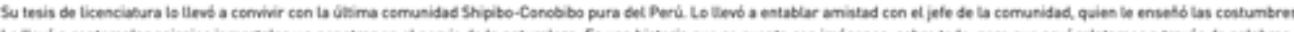

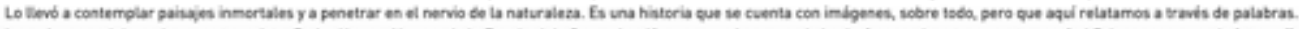

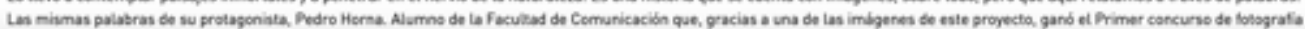

Nota del Boletín "Conectados" de la Universidad de Lima Link en Anexos.

Finalmente, a raíz de este trabajo se me convocó a participar en una exposición colectiva denominada "Todo Pasará", organizada y curada por Fernando Dolorier, en la Galería IMARPU (Jr. Soledad 489, Lince), donde se expuso "Capullo" junto con tres fotografías más, presentes en el proyecto (ver fotografías en anexos).

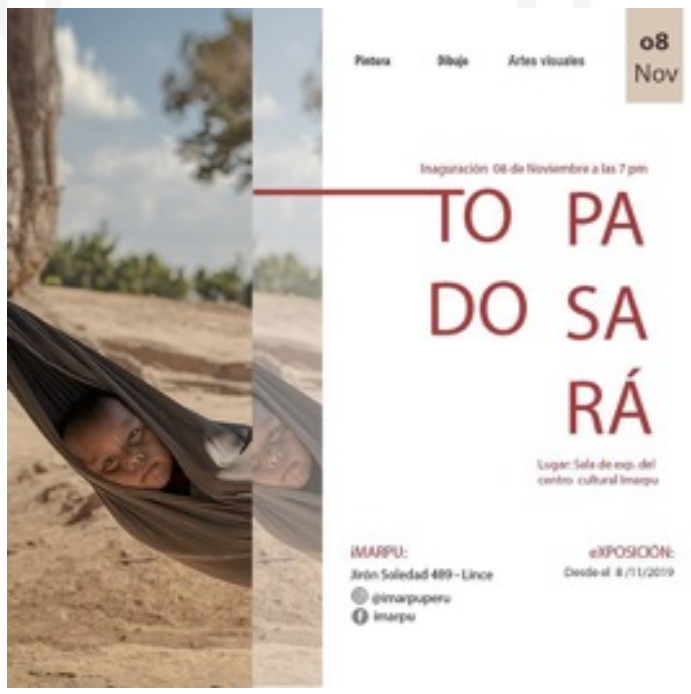

Publicidad de la Exposición Colectiva "Todo Pasará" 


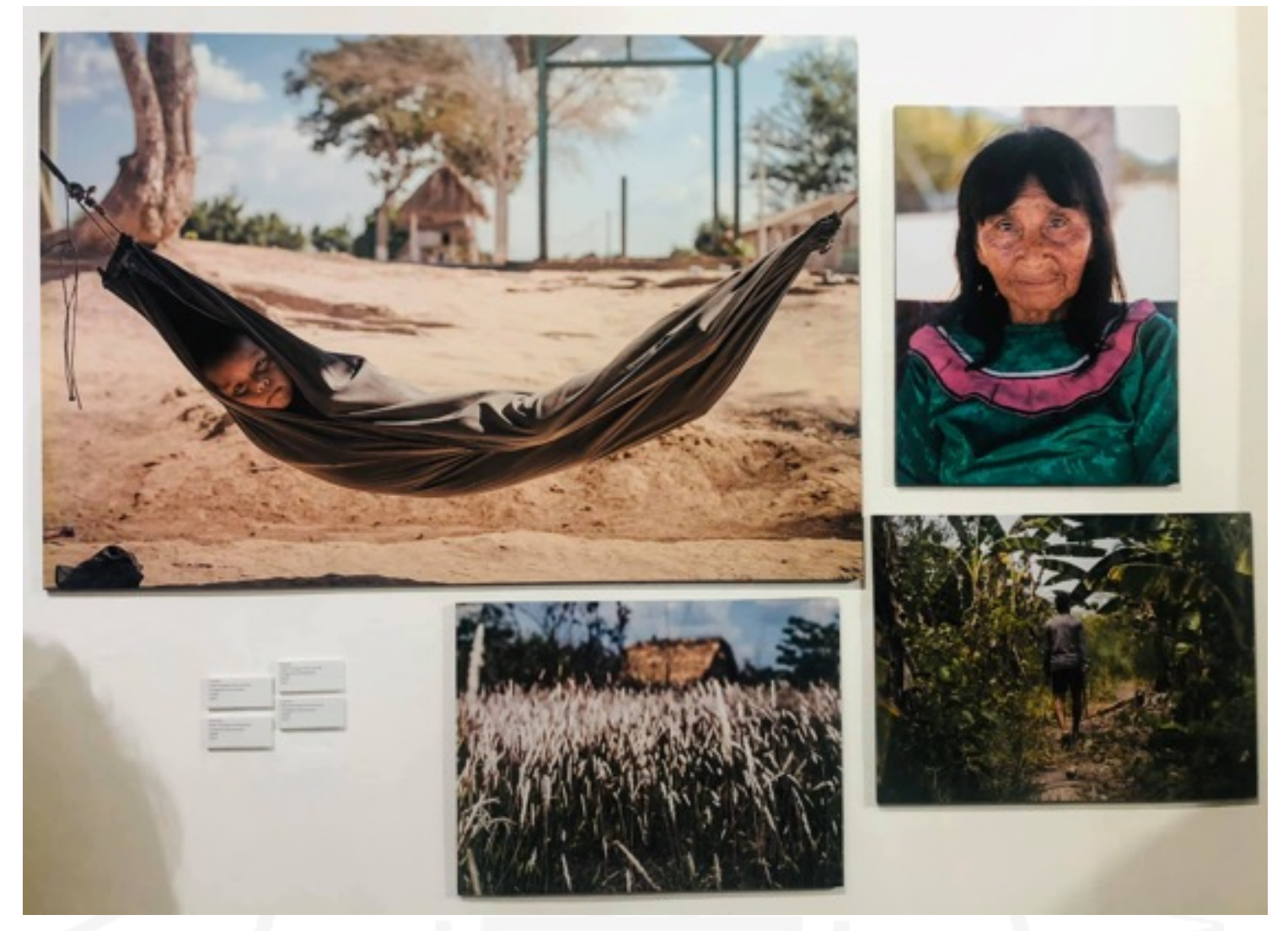

Distribución de las fotografías del proyecto en la exposición "Todo Pasará"

Durante la inauguración de la exposición, y en las semanas que estuvo montada, las fotos despertaron un gran interés en el público que fue a ver la muestra. Sin embargo, tratándose de una galería donde la mayoría de las piezas eran collages y pintura, se pudo percibir - según el encargado de la galería IMARPU- que las fotos del documental no llamaron la atención como el resto de cuadros. Eso hace reflexionar en que, para la exposición central de este proyecto se debe definir bien el público para quienes está dirigida esta muestra. 


\section{REFERENCIAS}

CARTIER-BRESSON, Henry (2003). Fotografiar del natural (1952). Editorial Gustavo Gili, Madrid.

COMAROFF, JL (2009). Ethnicity, Inc. The University of Chicago Press, Chicago. FONTCUBERTA, Joan (1997). El Beso de Judas. Editorial Gustavo Gili, Barcelona. GEERTZ, Clifford (1989). El antropólogo como autor. Paidós Ibérica, Barcelona.

GUBER, Rosana (2001). La Etnografía, método, campo y reflexividad. Grupo Editorial Norma, Bogotá.

JARA LÓPEZ, Emilio (2005). La Fotografia como Documento Histórico-Artístico y Etnográfico: Una Epistemología. Revista de Antropología Experimental, 5, 1-24.

KRAJNIK, Franz (2018). Uchuraccay. Editorial UPC, Lima.

KRAJNIK, Franz. (2017). Uchuraccay. La transtemporalidad del dolor desde el ensayo fotográfico documental (Tesis de maestría). Pontificia Universidad Católica del Perú, Lima.

LEÓN, Diego (2019). Realidad de las comunidades nativas en Loreto, Perú: Caso Yaguas y Kukamas. (Tesis de pregrado). Universidad de Lima, Lima.

RUBY, Jay (1996). Antropología Visual. En Enciclopedia de Antropología Cultural (4, 1345-1351) Nueva York: Henry Holt \& Cía.

SILVA, Daniel (2011). Contactados. Amor y sangre en el Lote 88. Revista Cometa, $1,1-78$.

TROYA, María Fernanda (2009). Del documento fotográfico a la Fotografía Documental. Revista Ecuatoriana de Historia, 29, 121-131.

MORIN, Françoise (1998). Los Shipibo Conibo. En Guía Etnográfica de la Alta Amazonía (275-478). Balboa, Panamá: Smithsonian Tropical Research Institute/Ediciones Abya-Yala. 


\section{ANEXOS}

1. Fotos del primer viaje
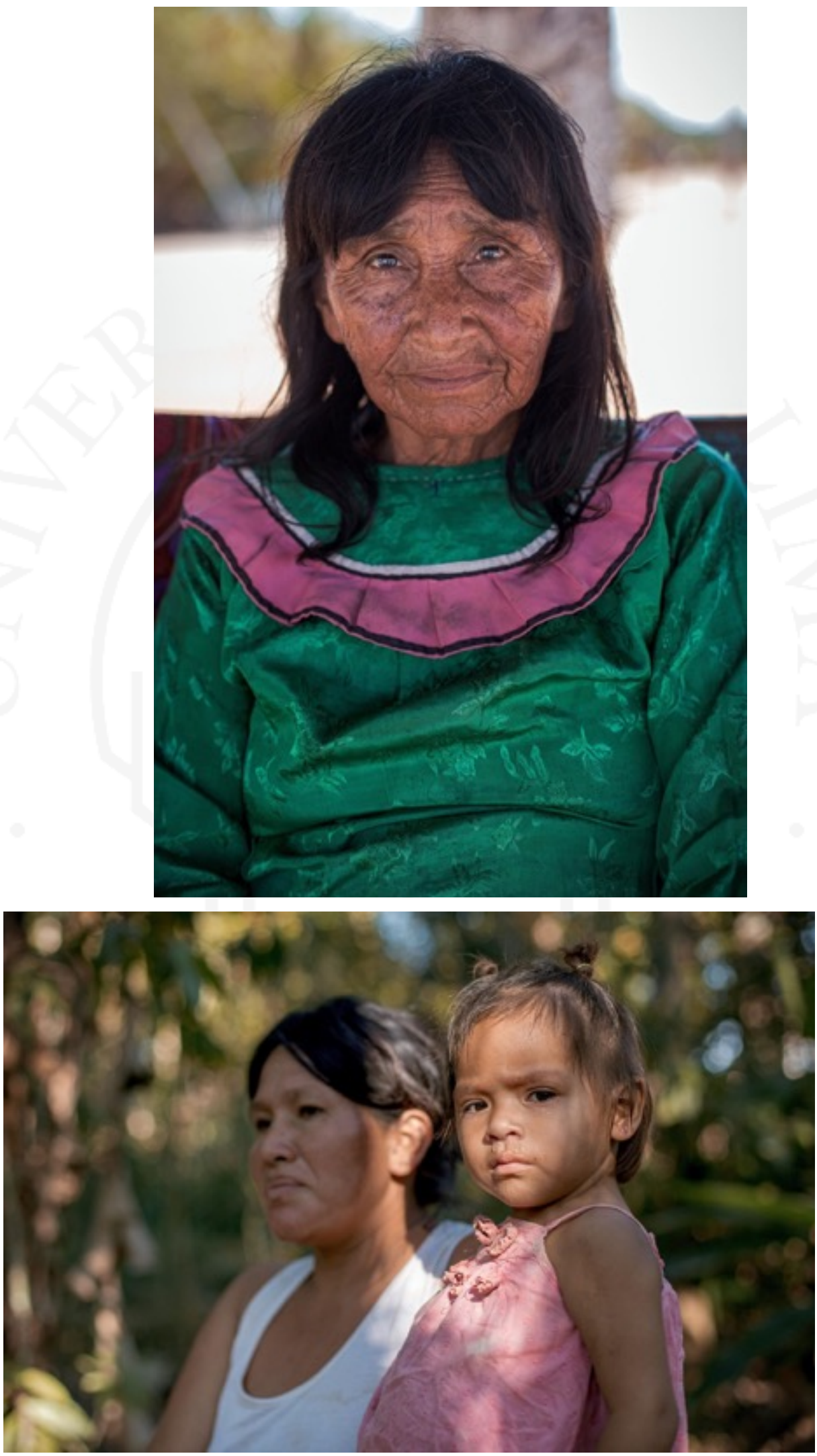

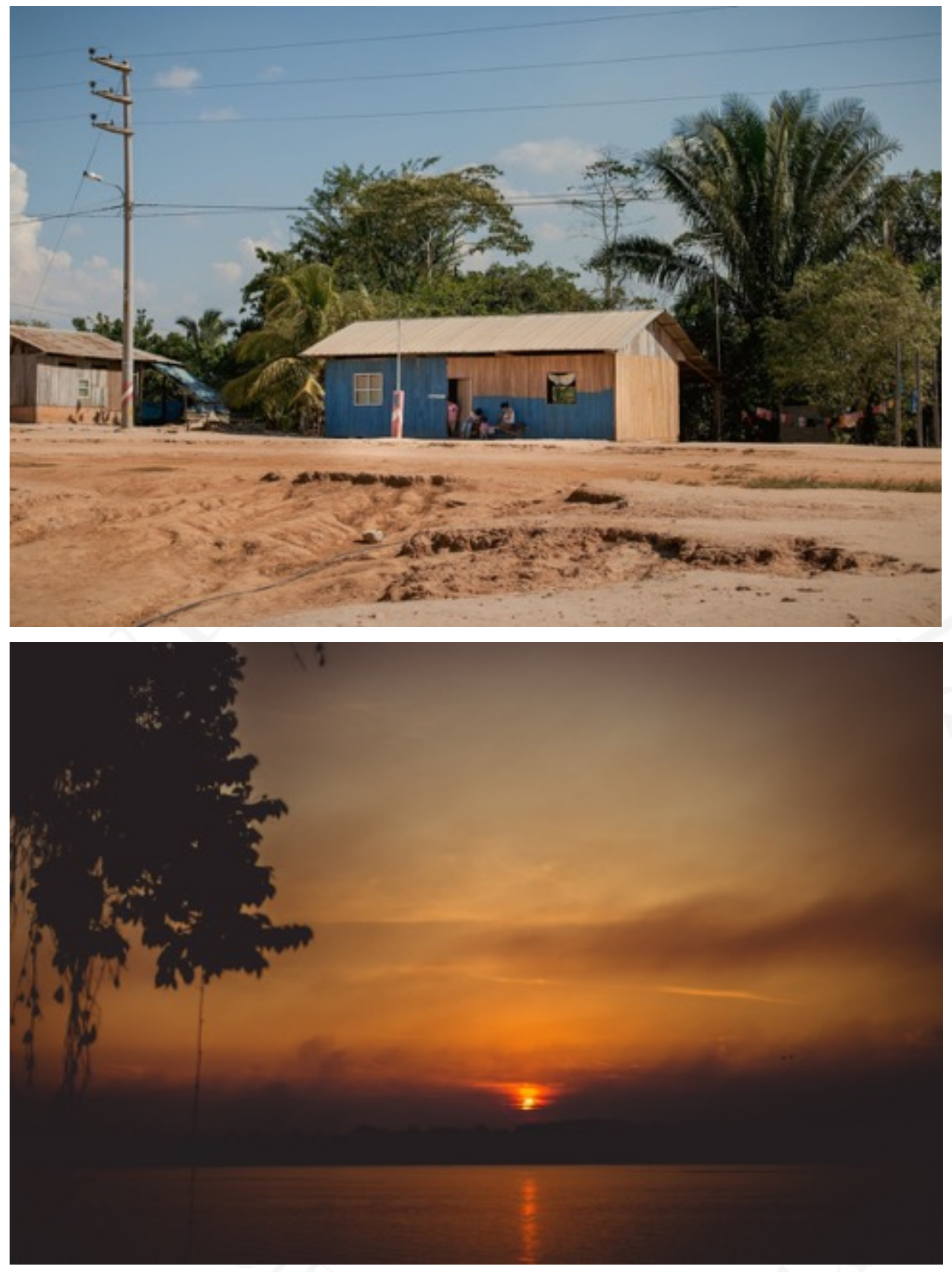


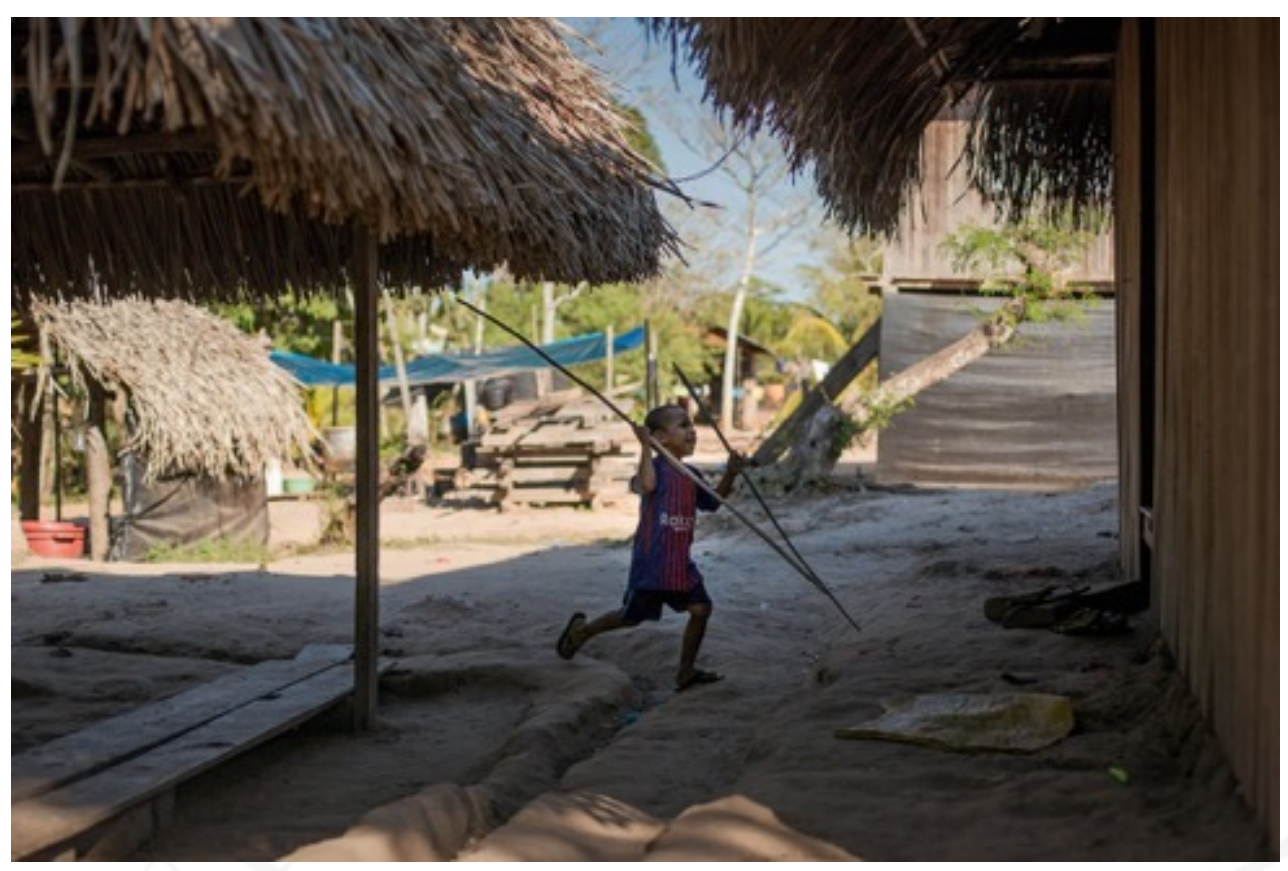

2. Link de la entrevista en Conectados

http://conectados.ulima.edu.pe/una-experiencia-como-proyecto-detesis/?fbclid=IwAR07rKjDstwFEMzPMs-

5zpxcj5RSW3U9qXCYCasVKEIo5IgMfdPIdn1PXIU 


\section{Fotos de la galería IMARPU}
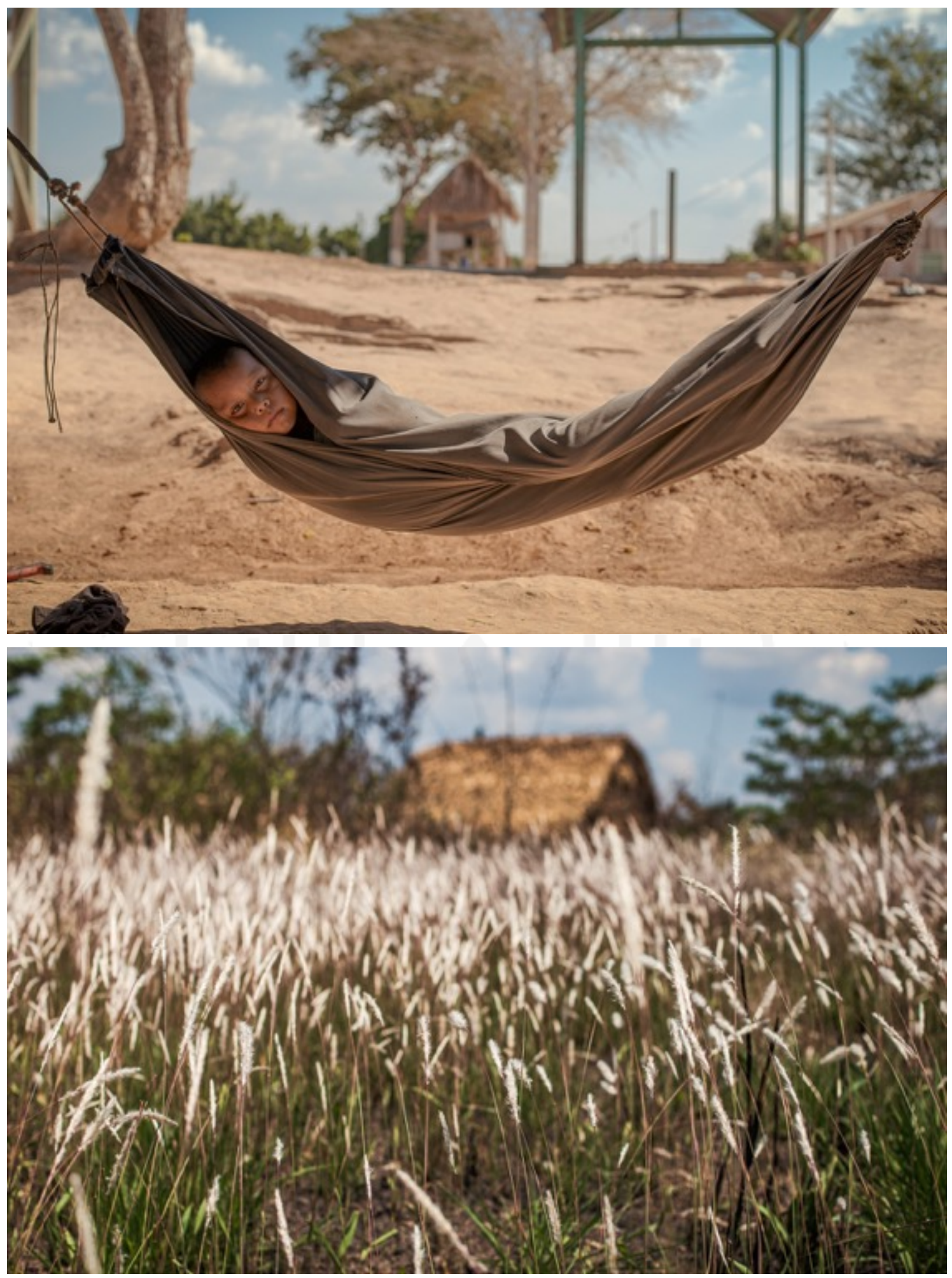

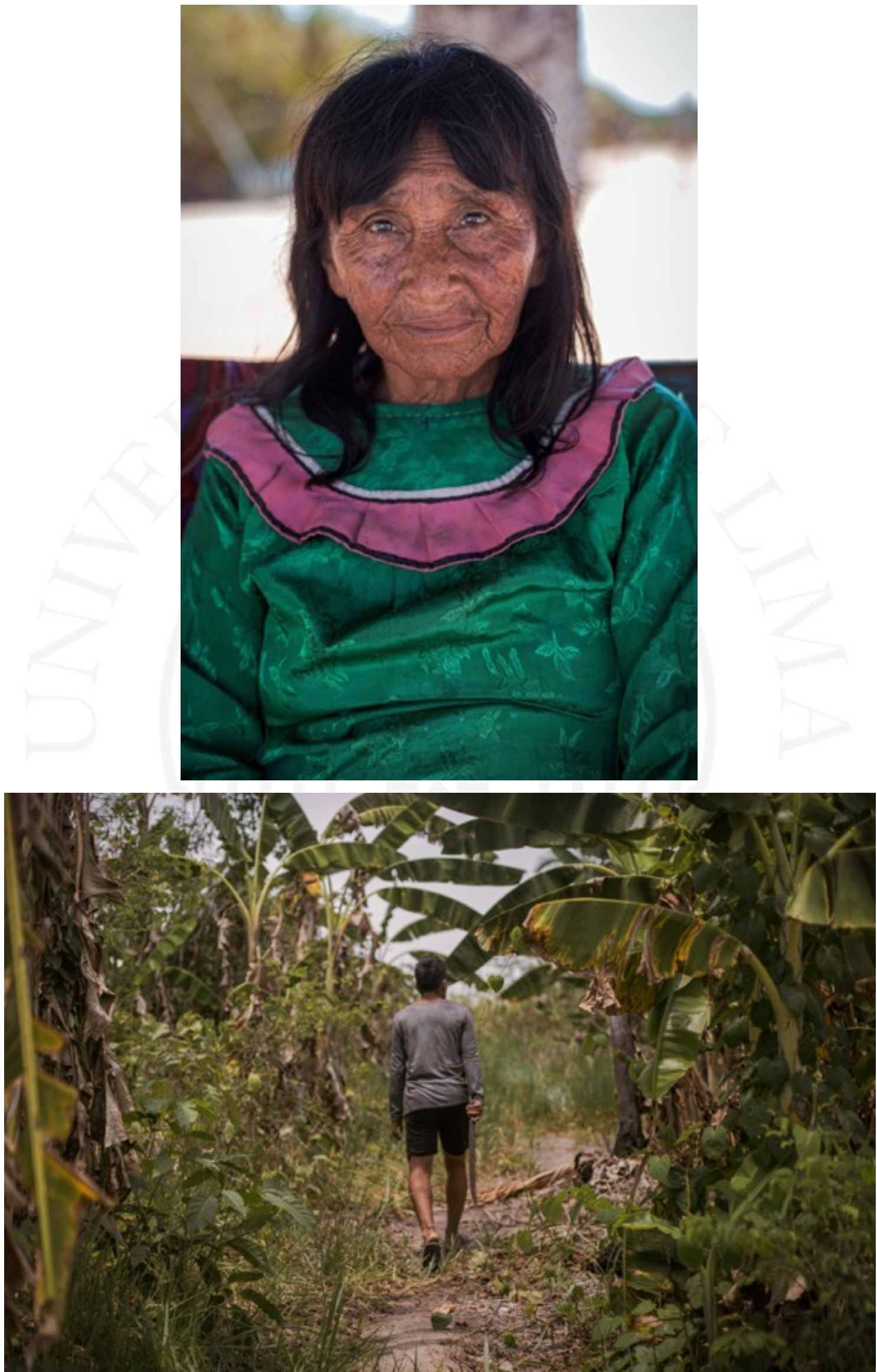


\section{Fotos del segundo viaje}
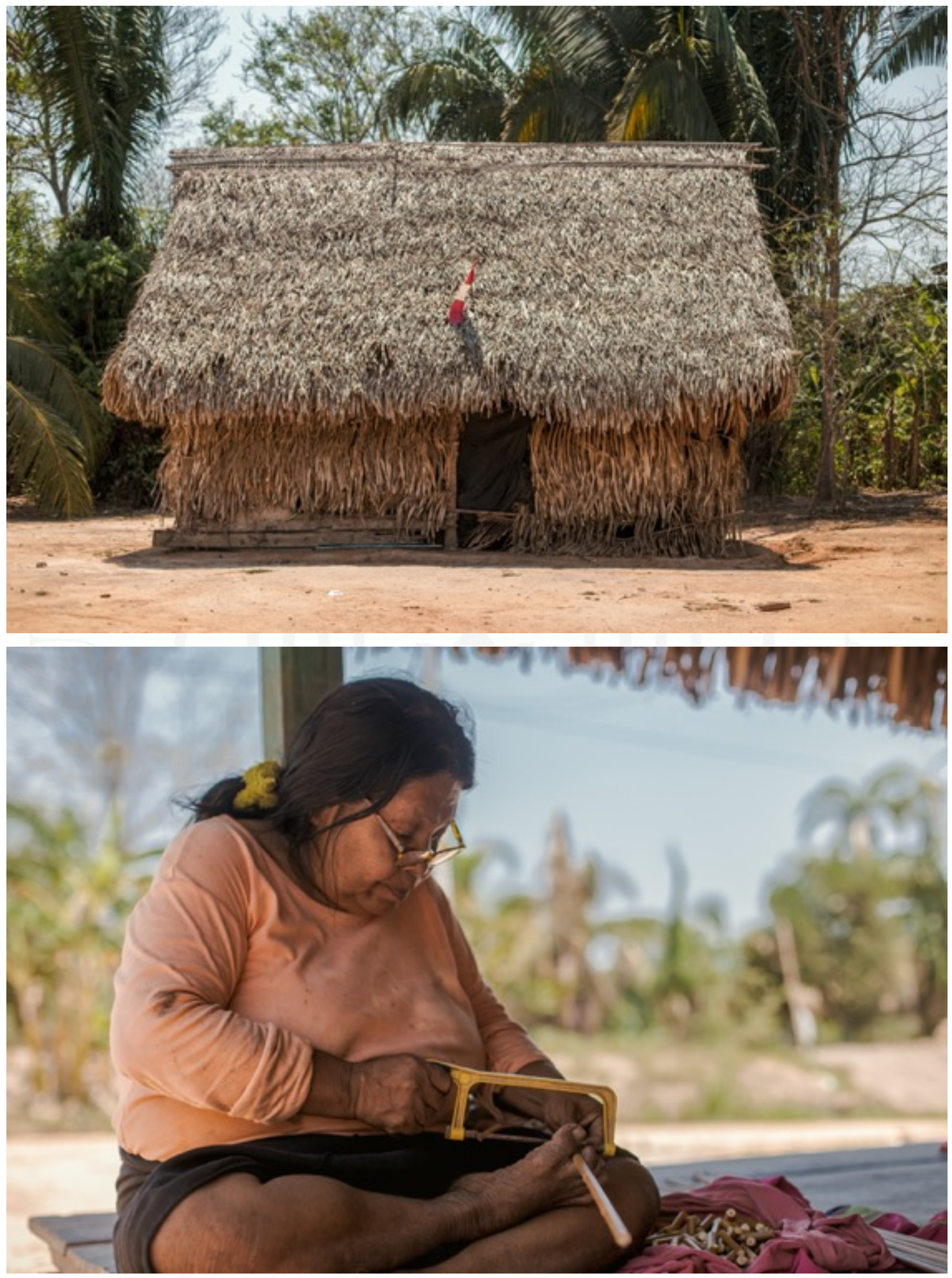

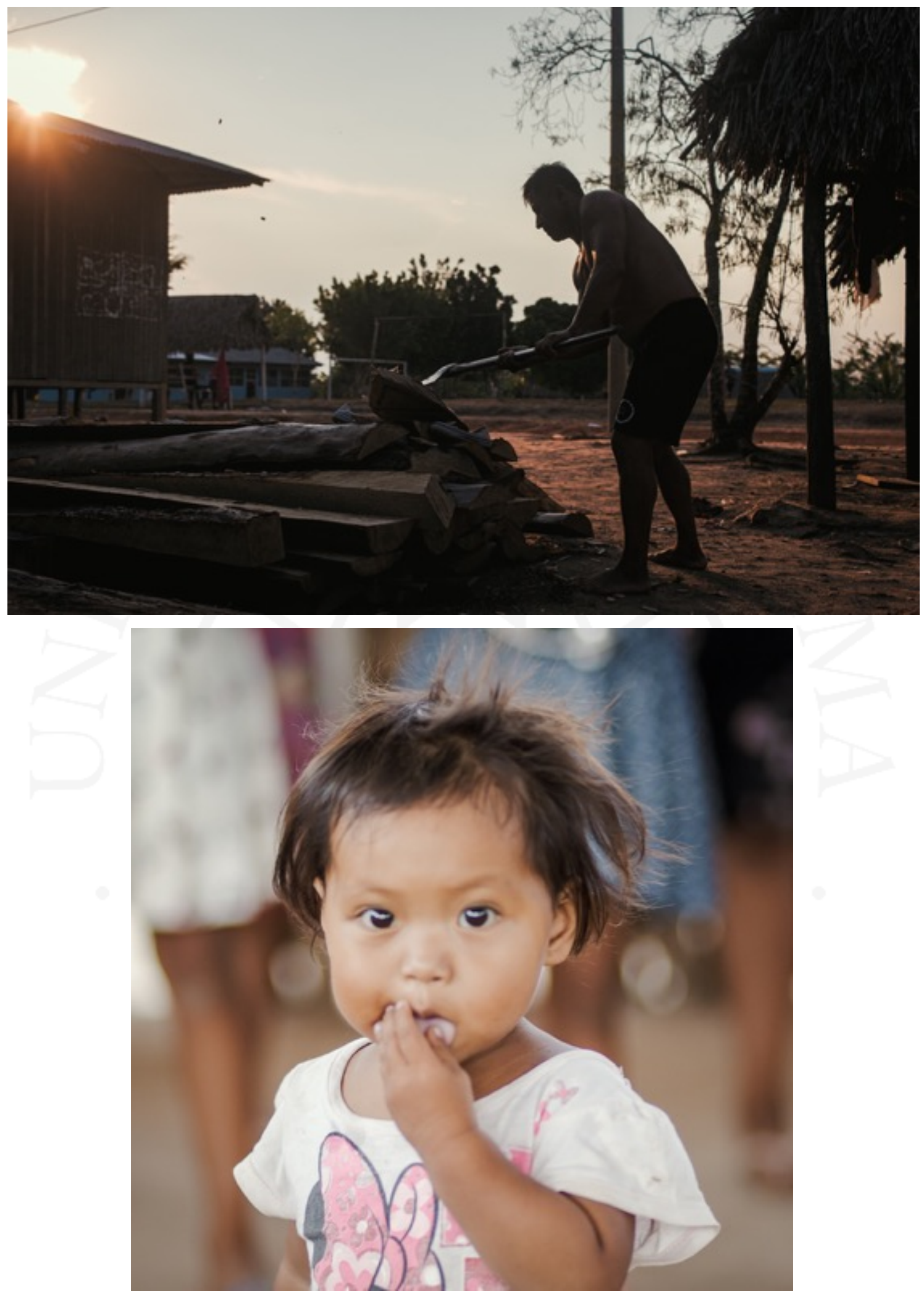

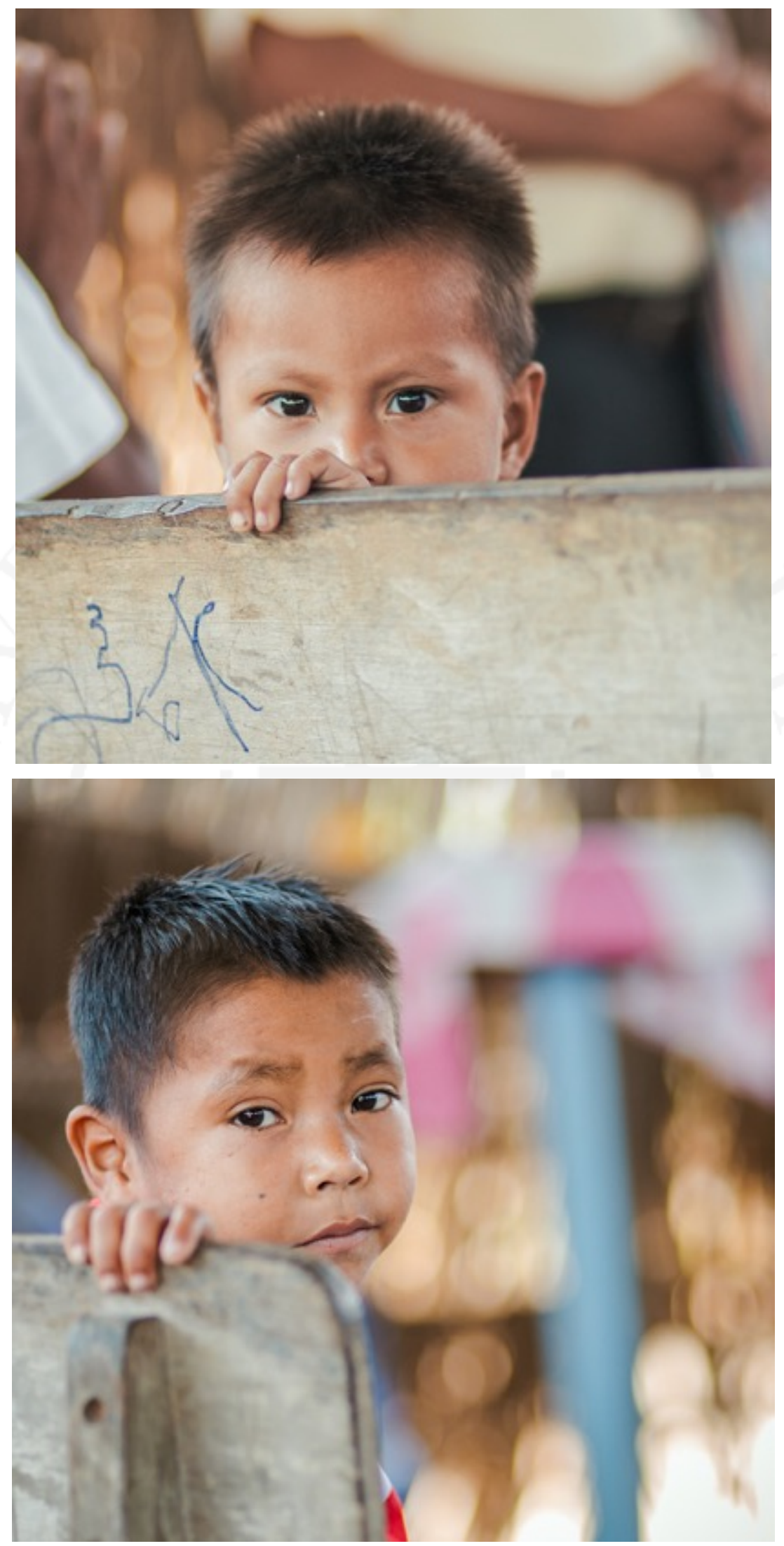


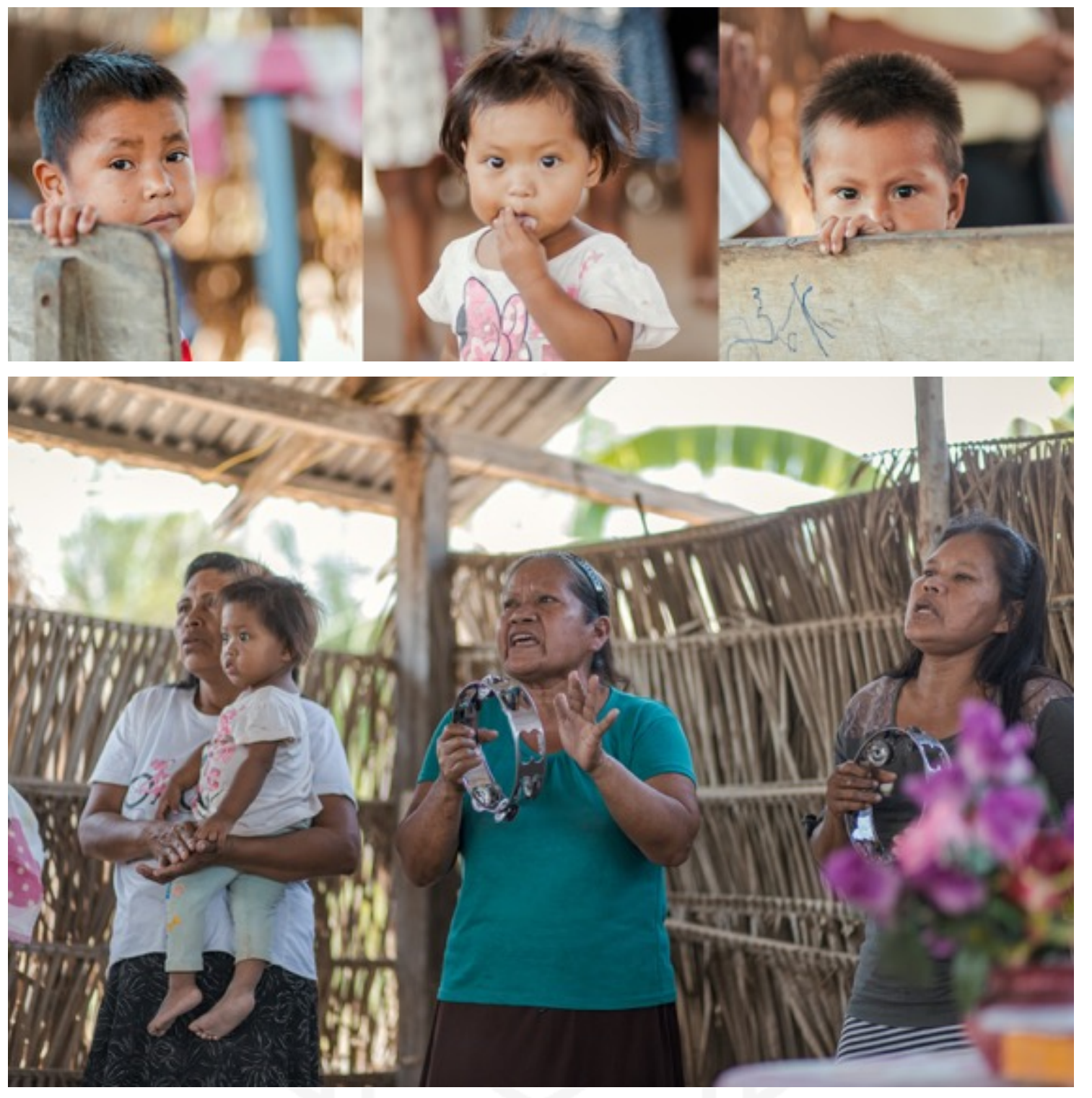



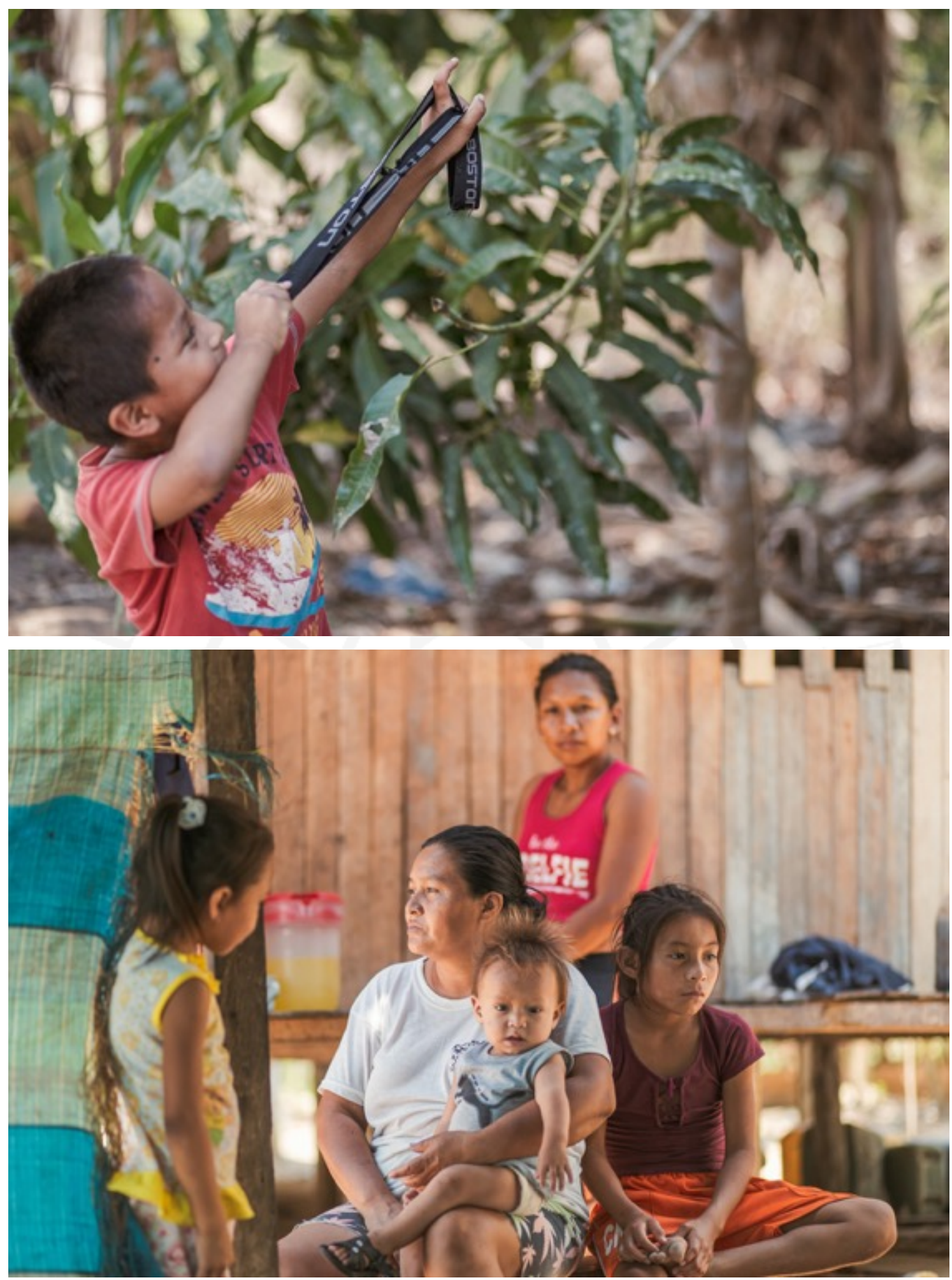

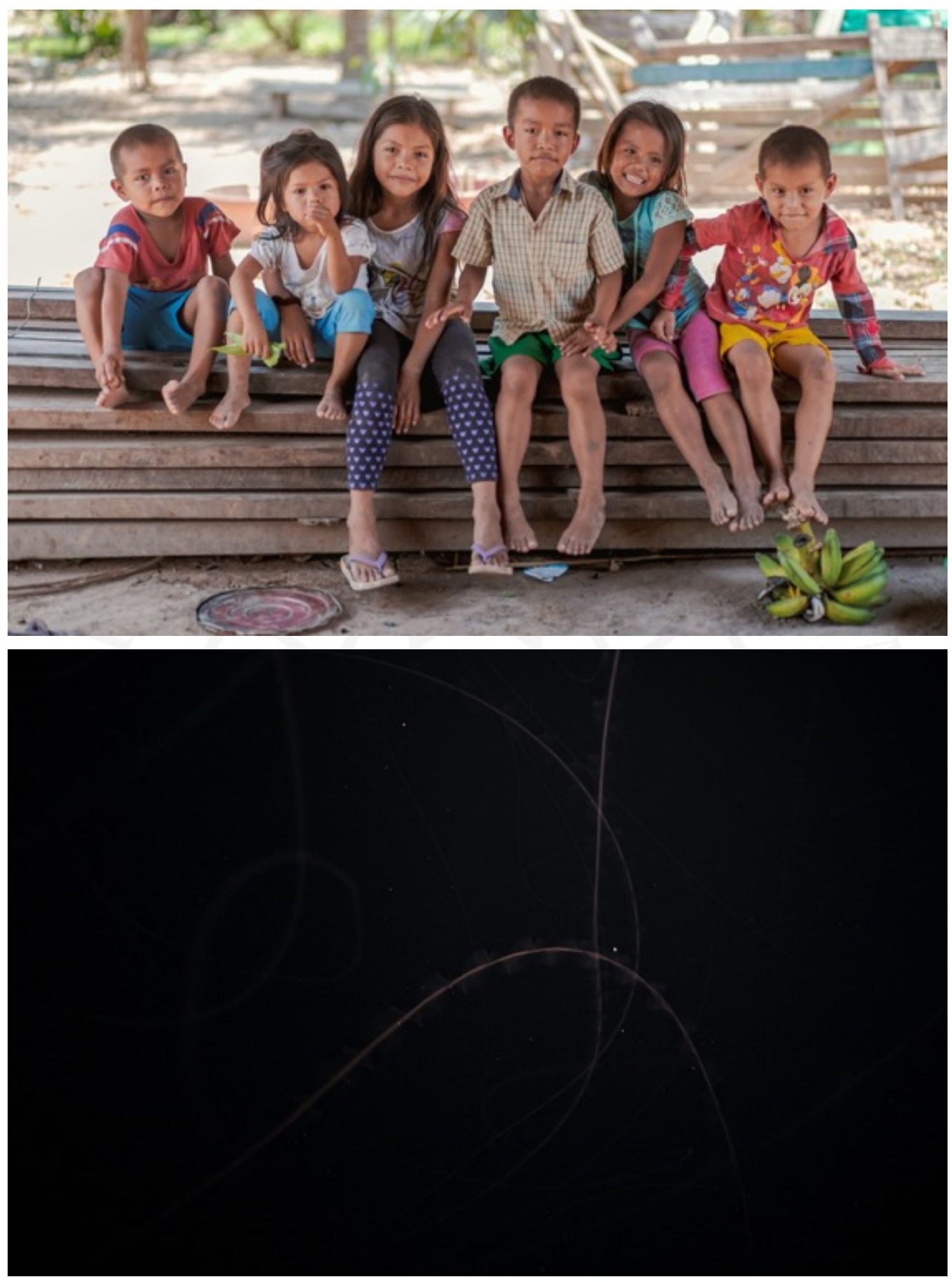

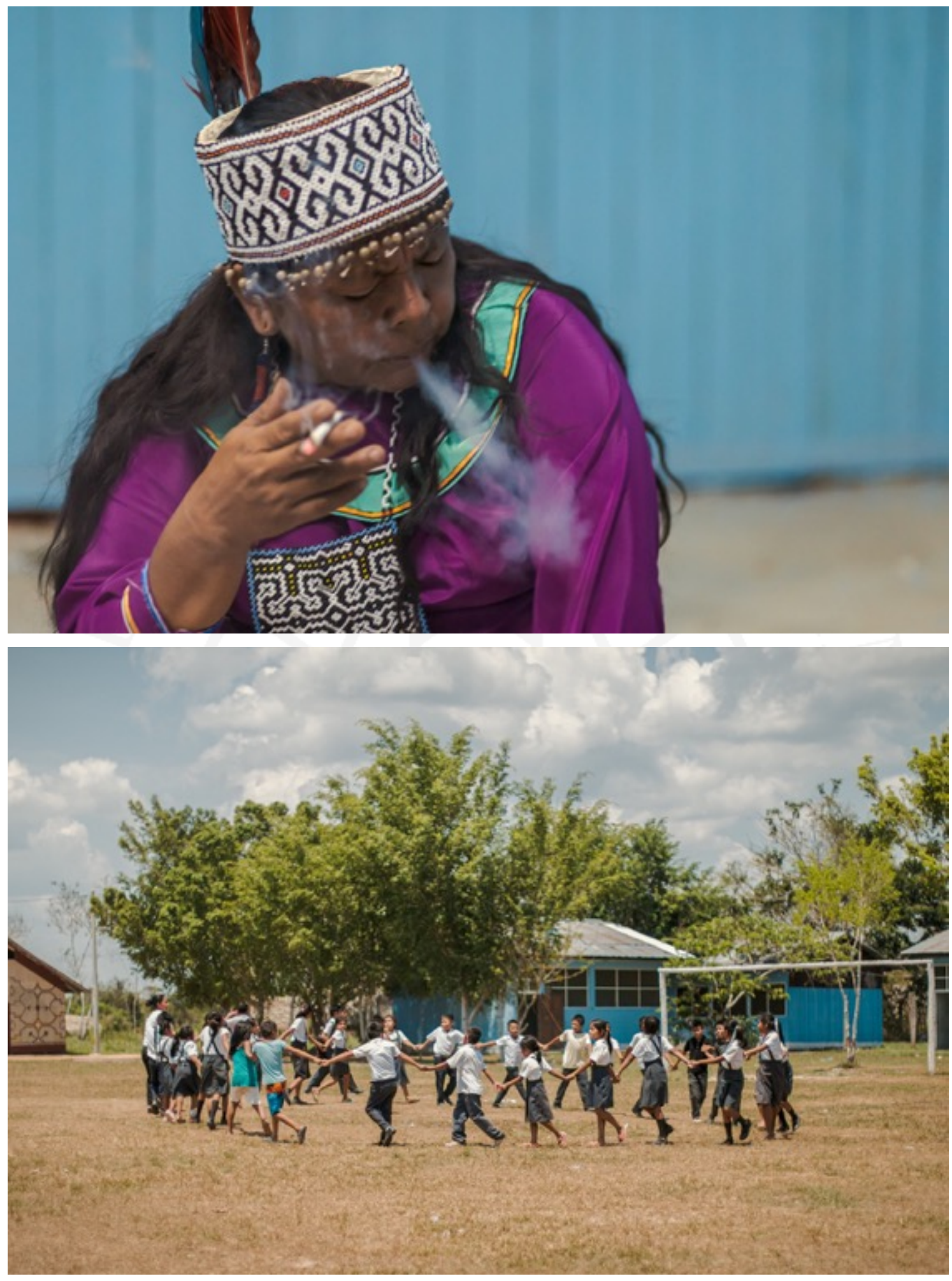

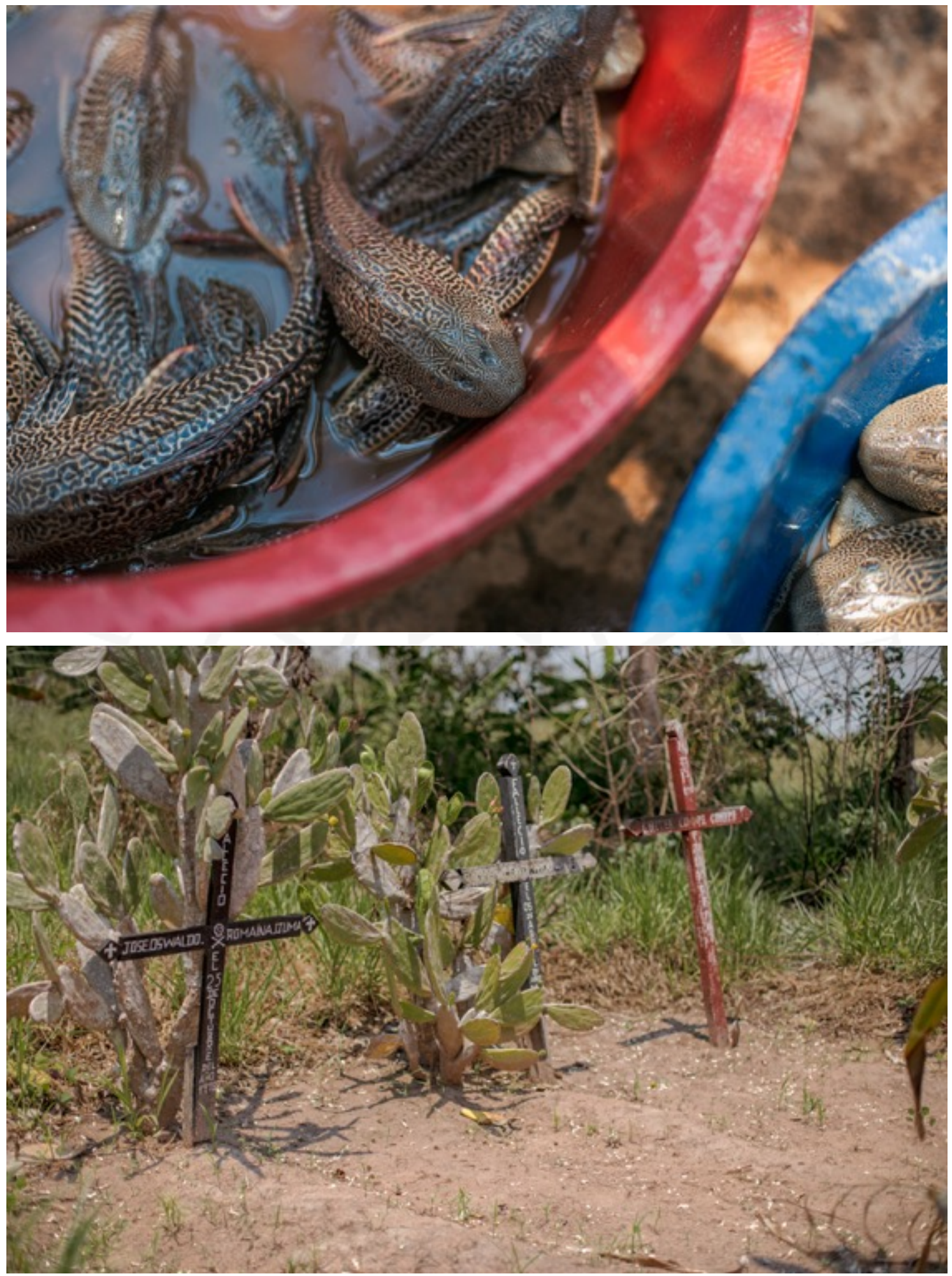


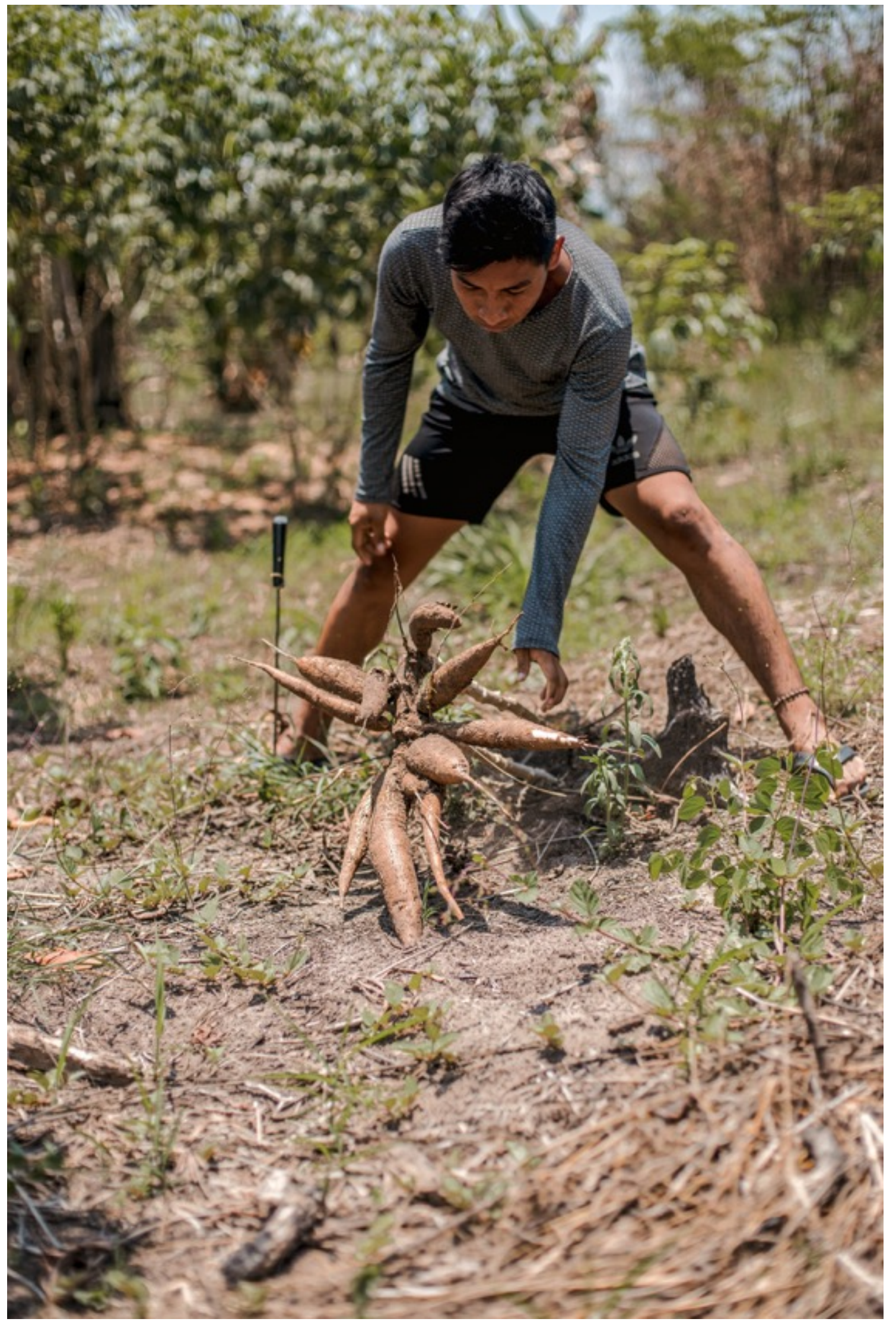



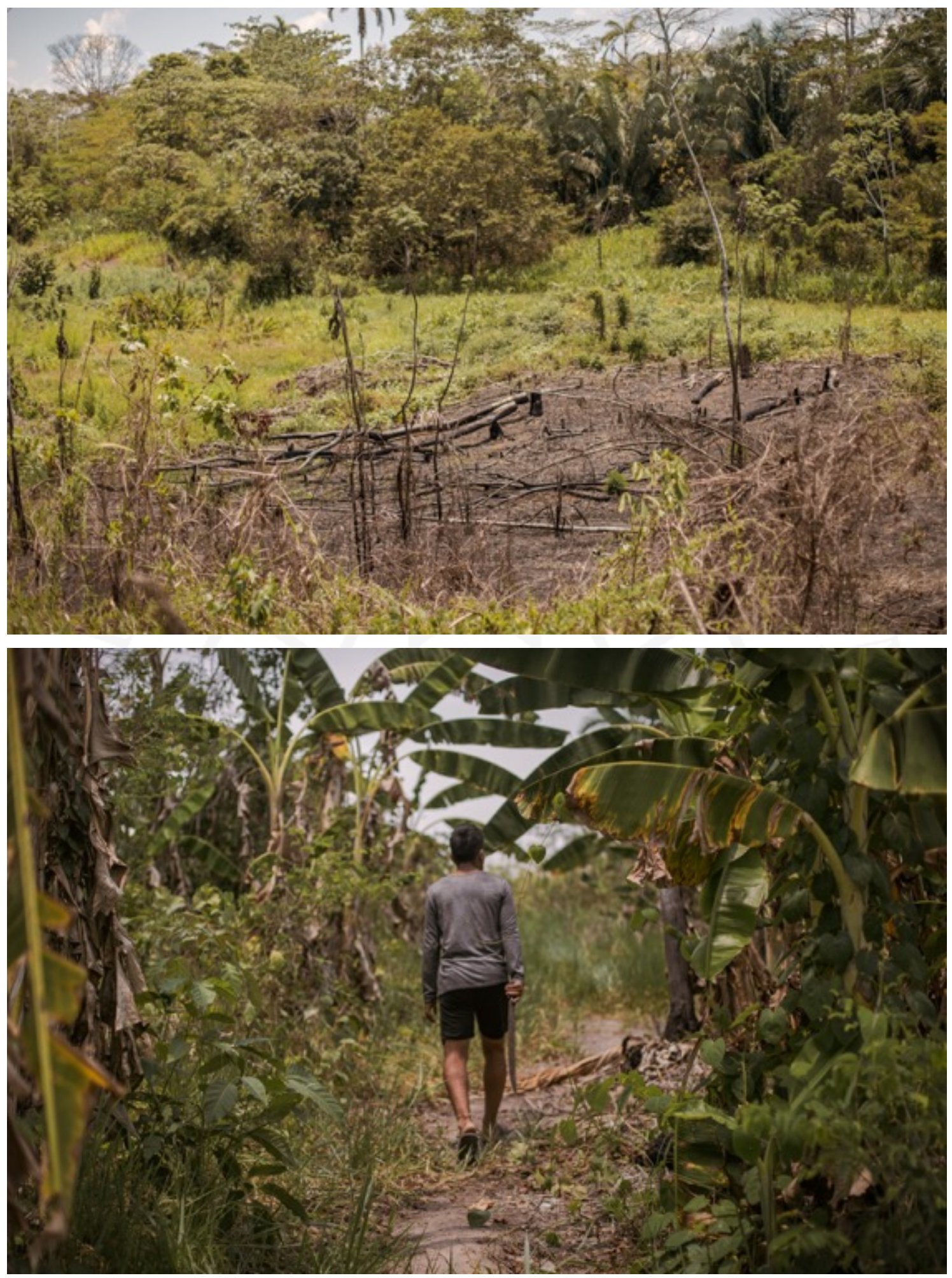

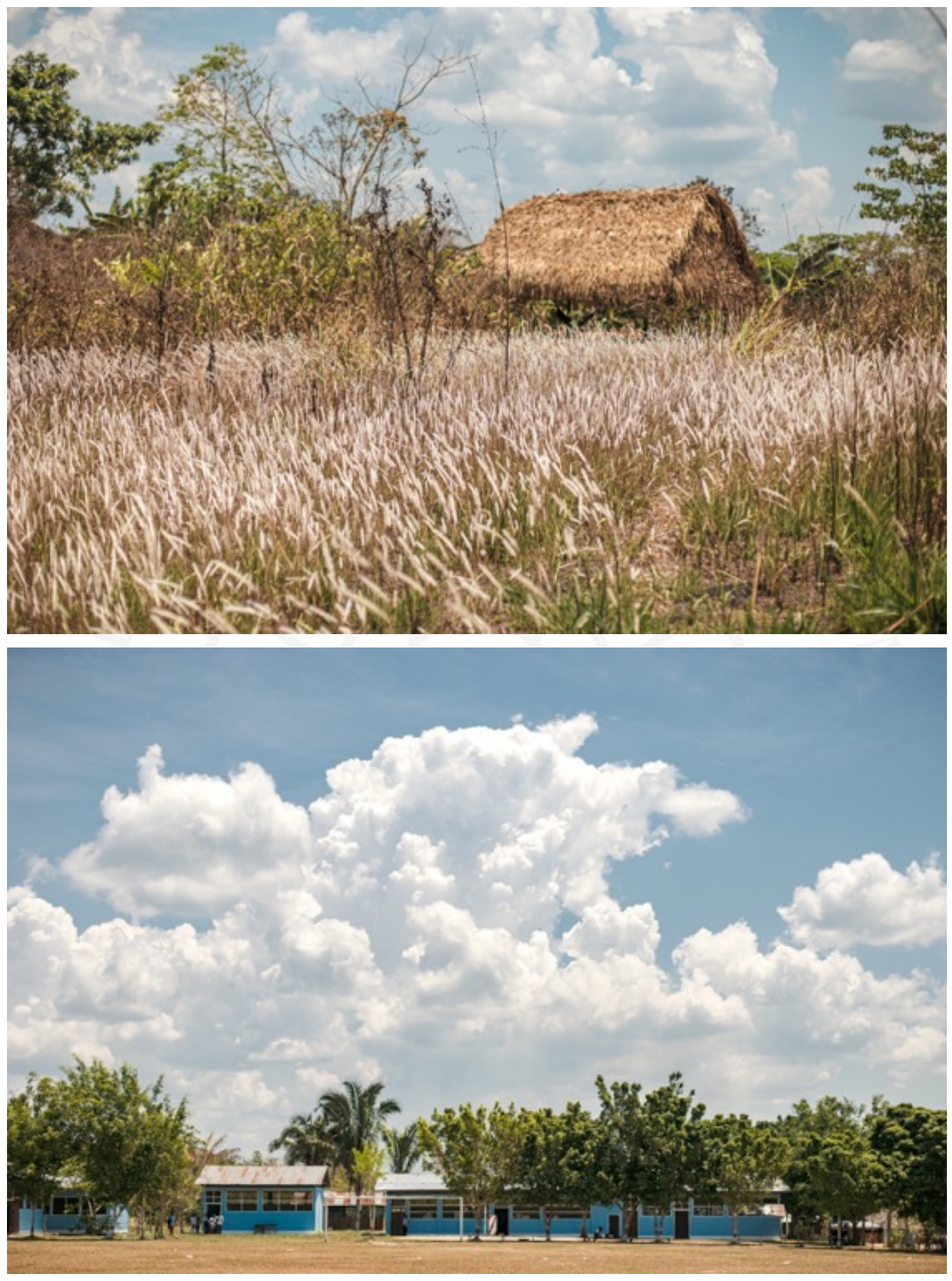

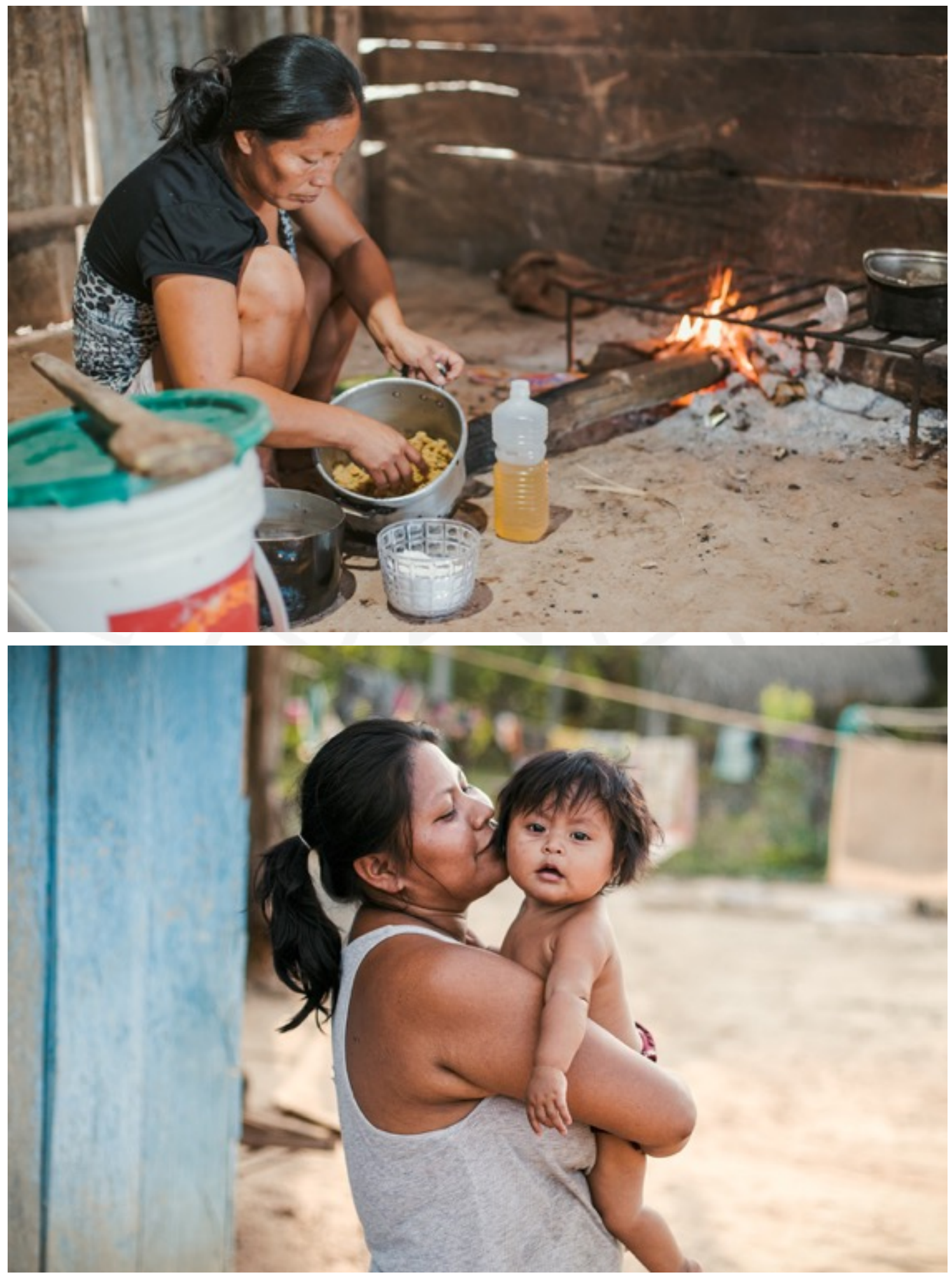

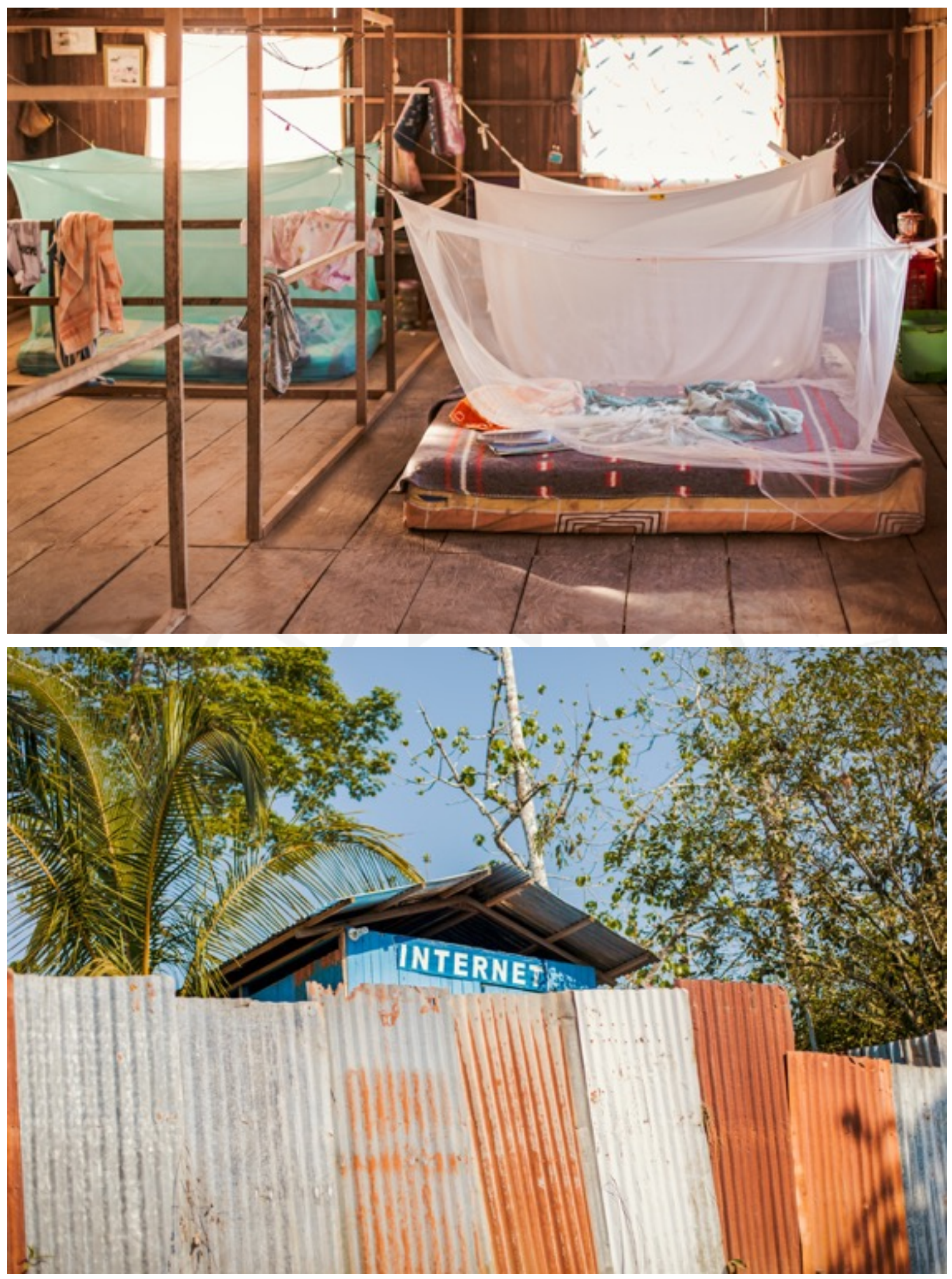

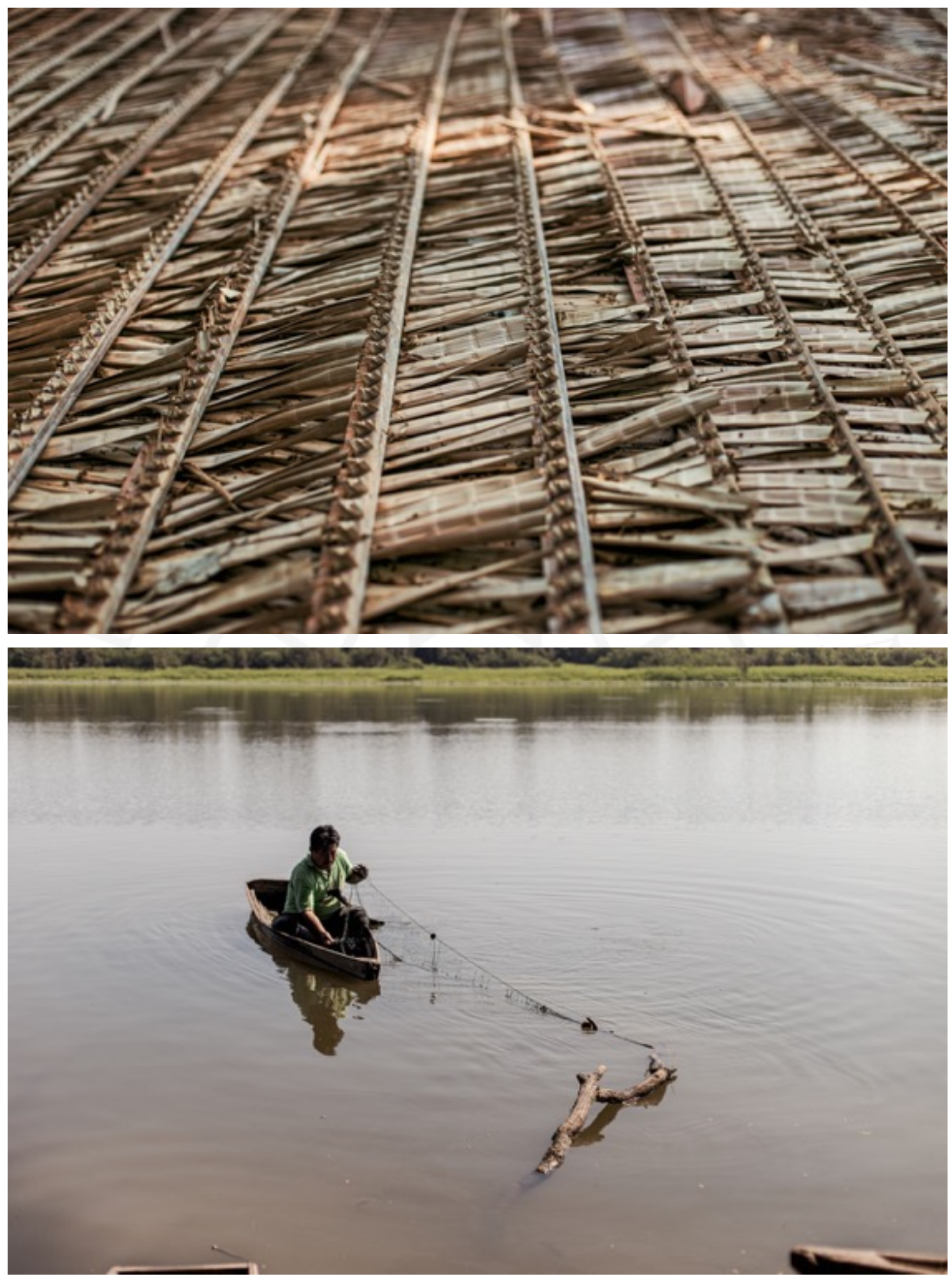


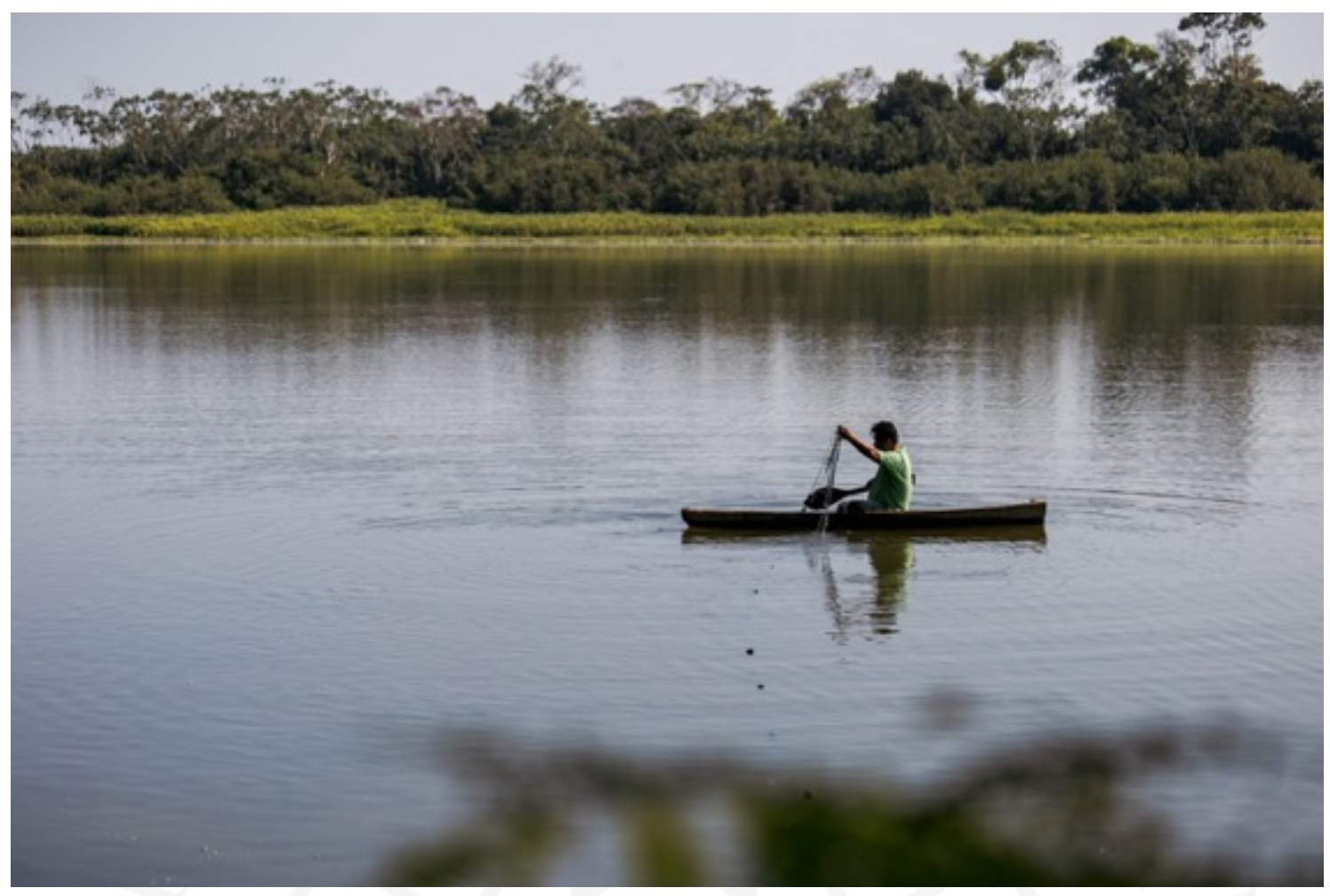




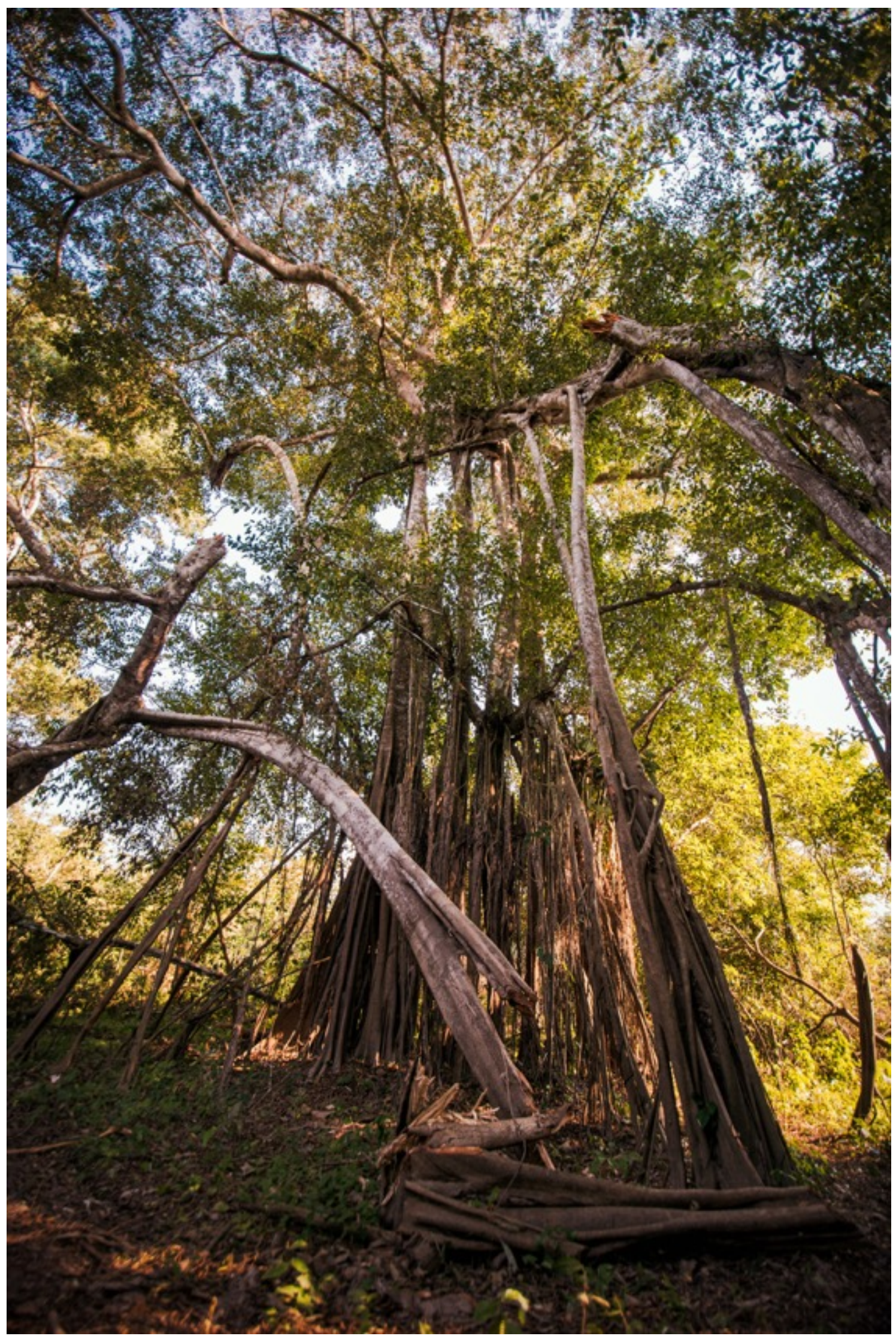



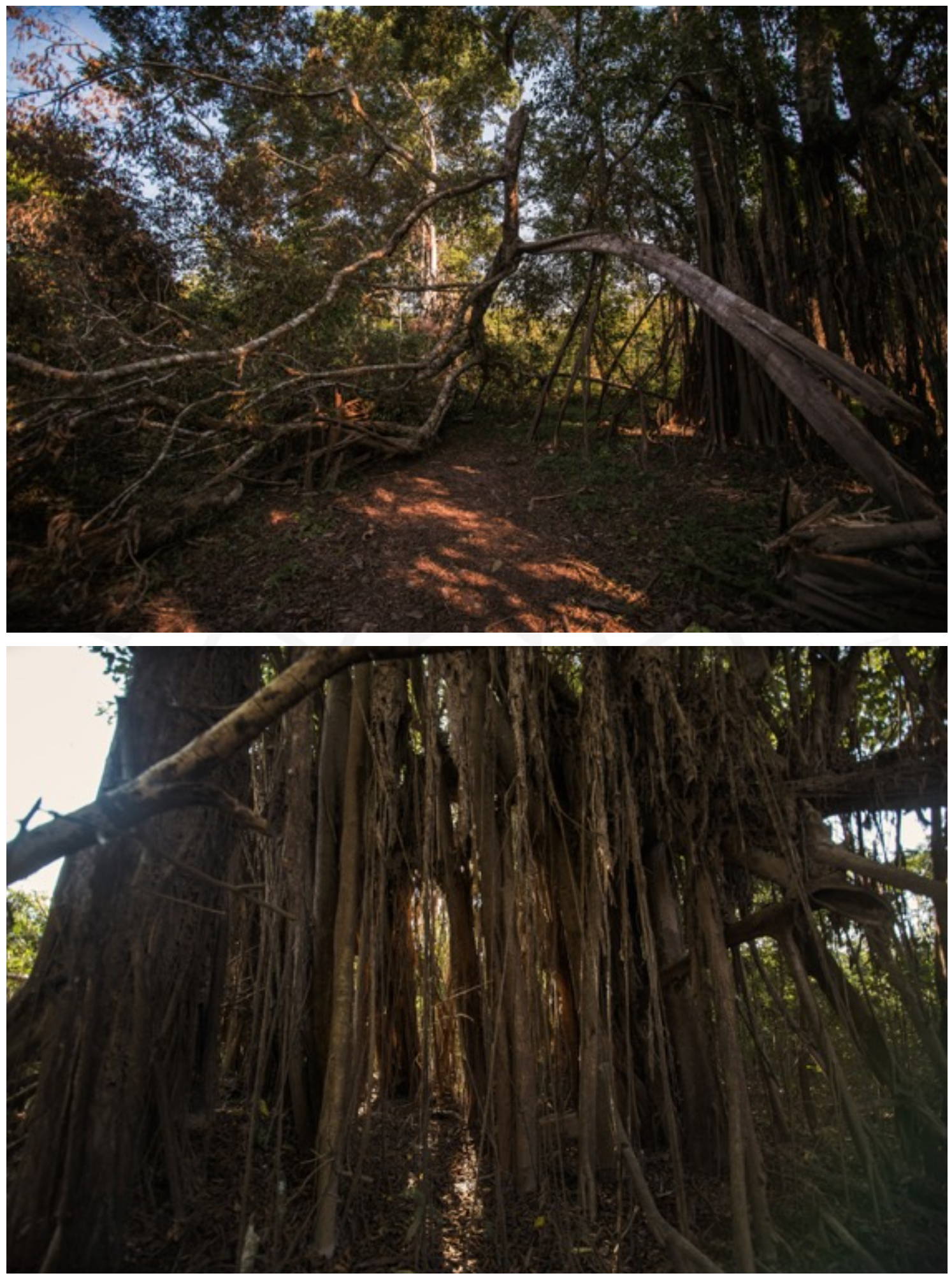


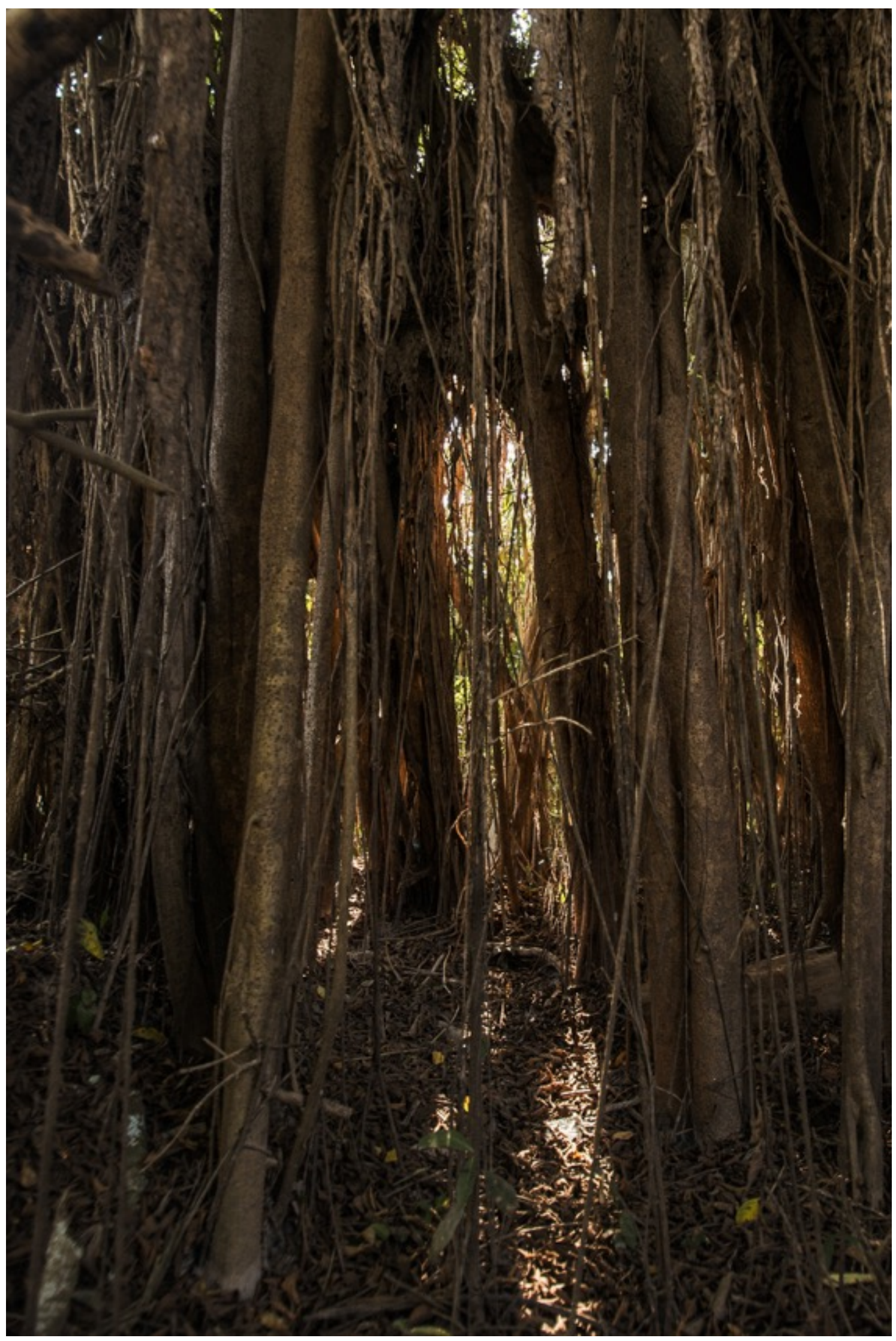



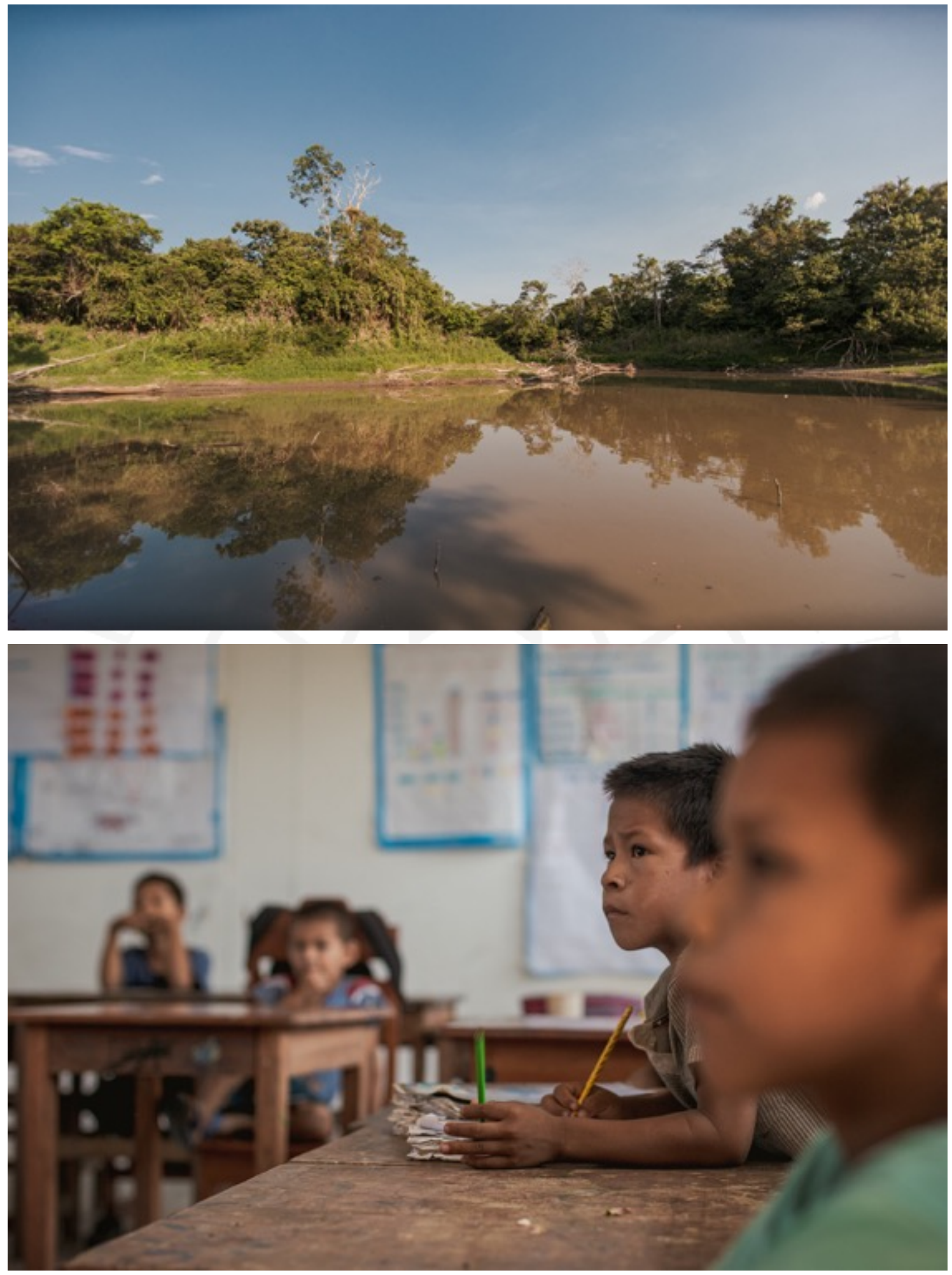

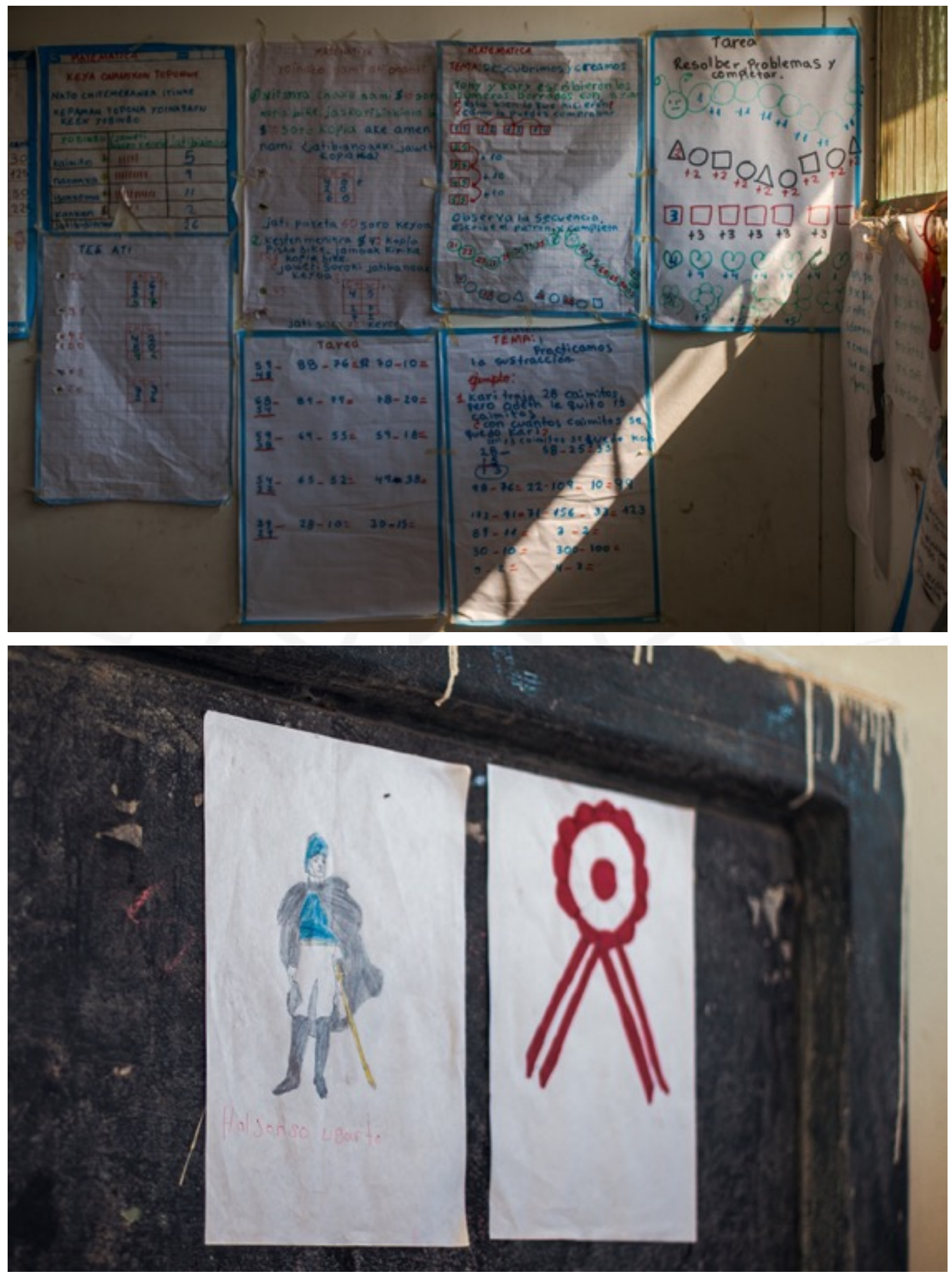

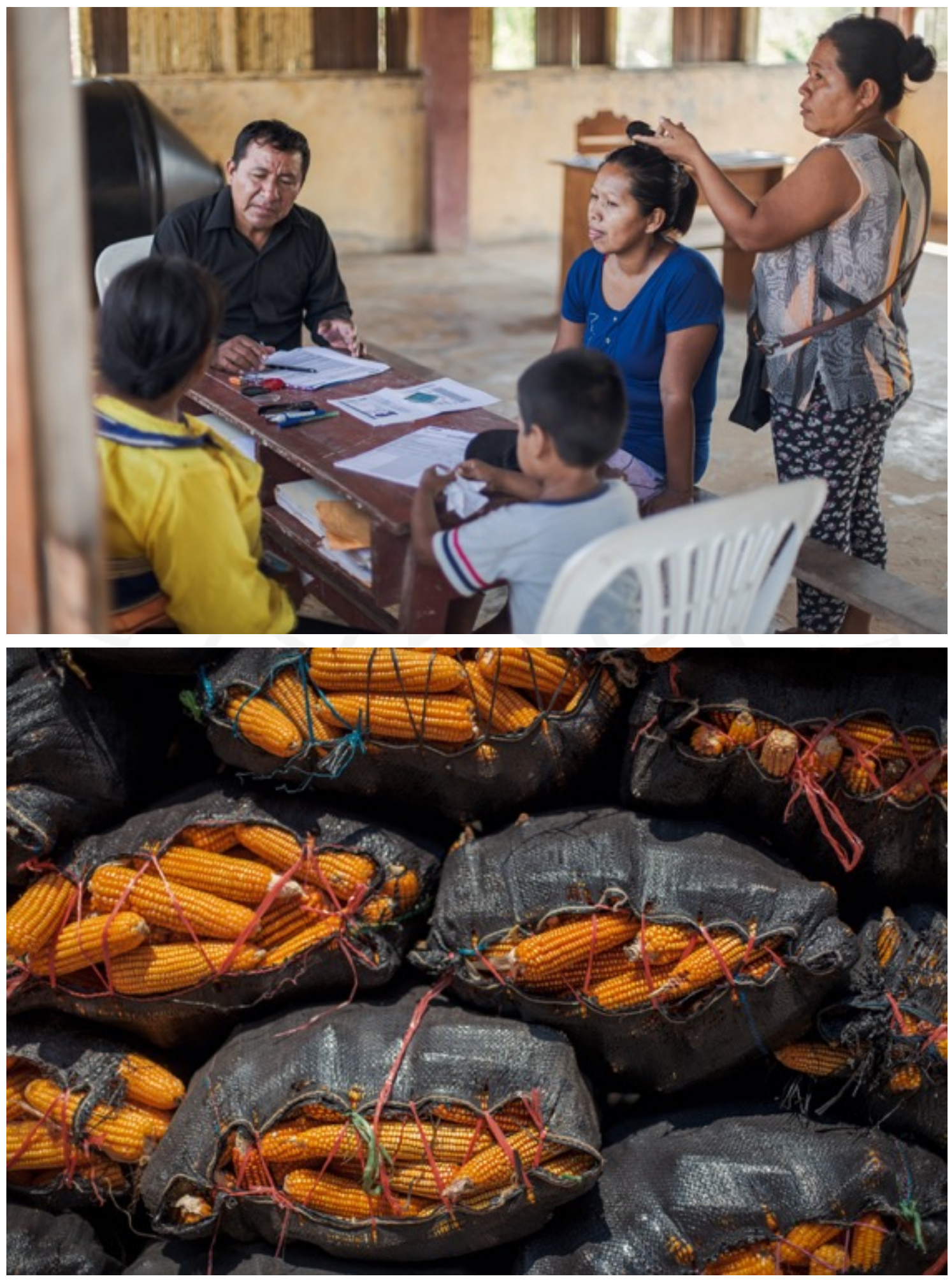
5. Plano de la Galería Miró Quesada, donde se realizaría la exposición

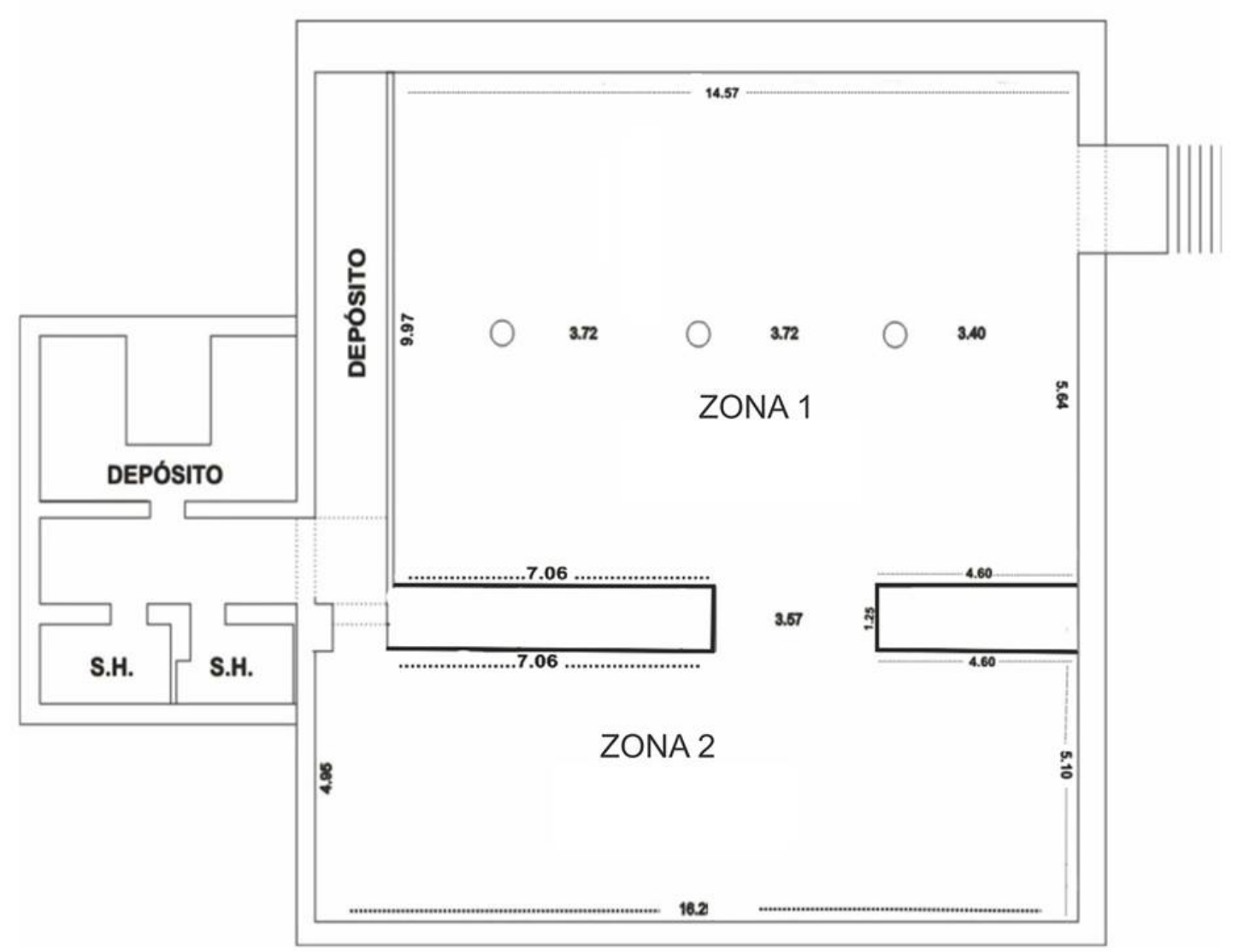


6. Bosquejo del recorrido en la muestra

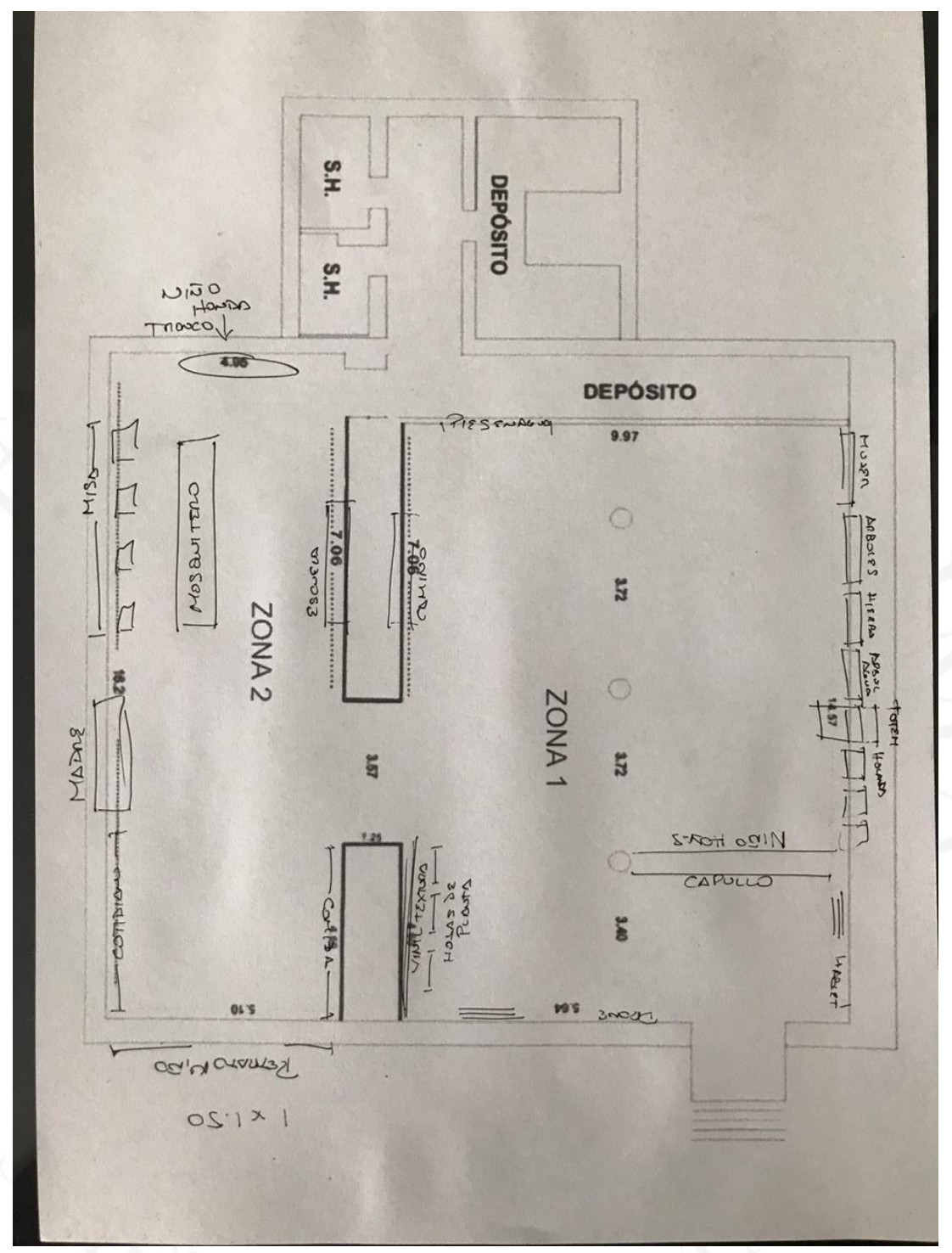


7. Avance de fotos editadas 3er viaje
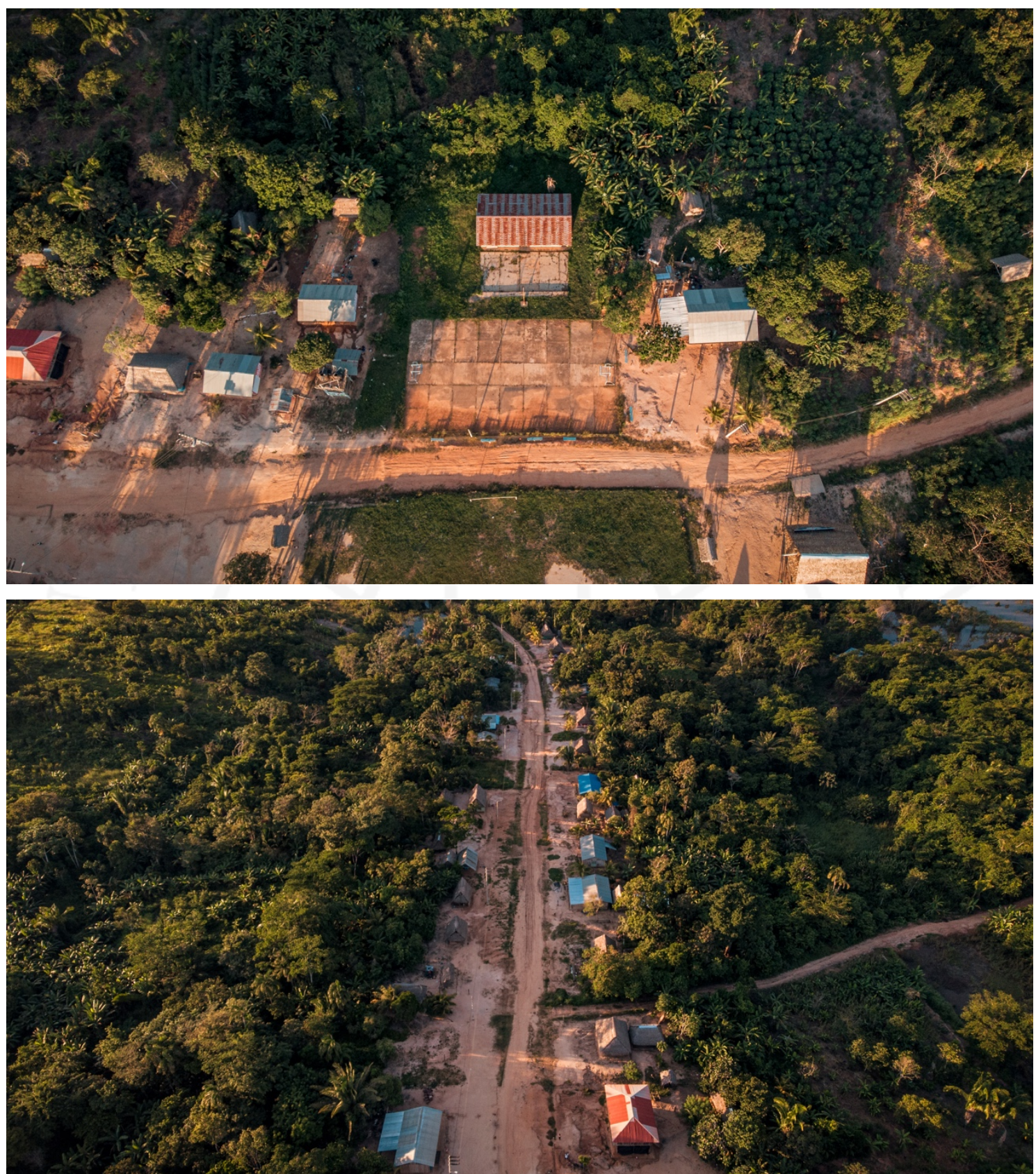

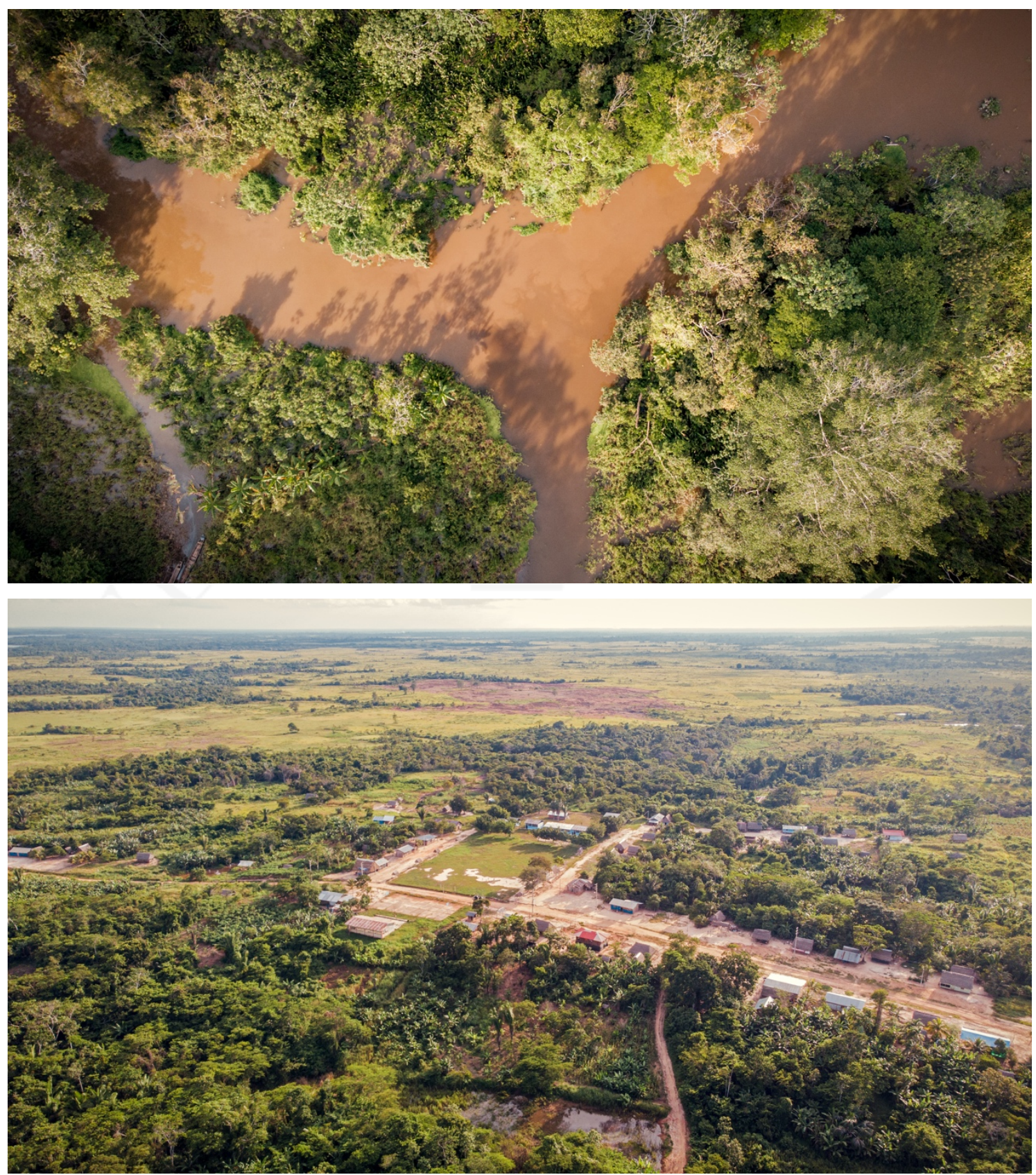


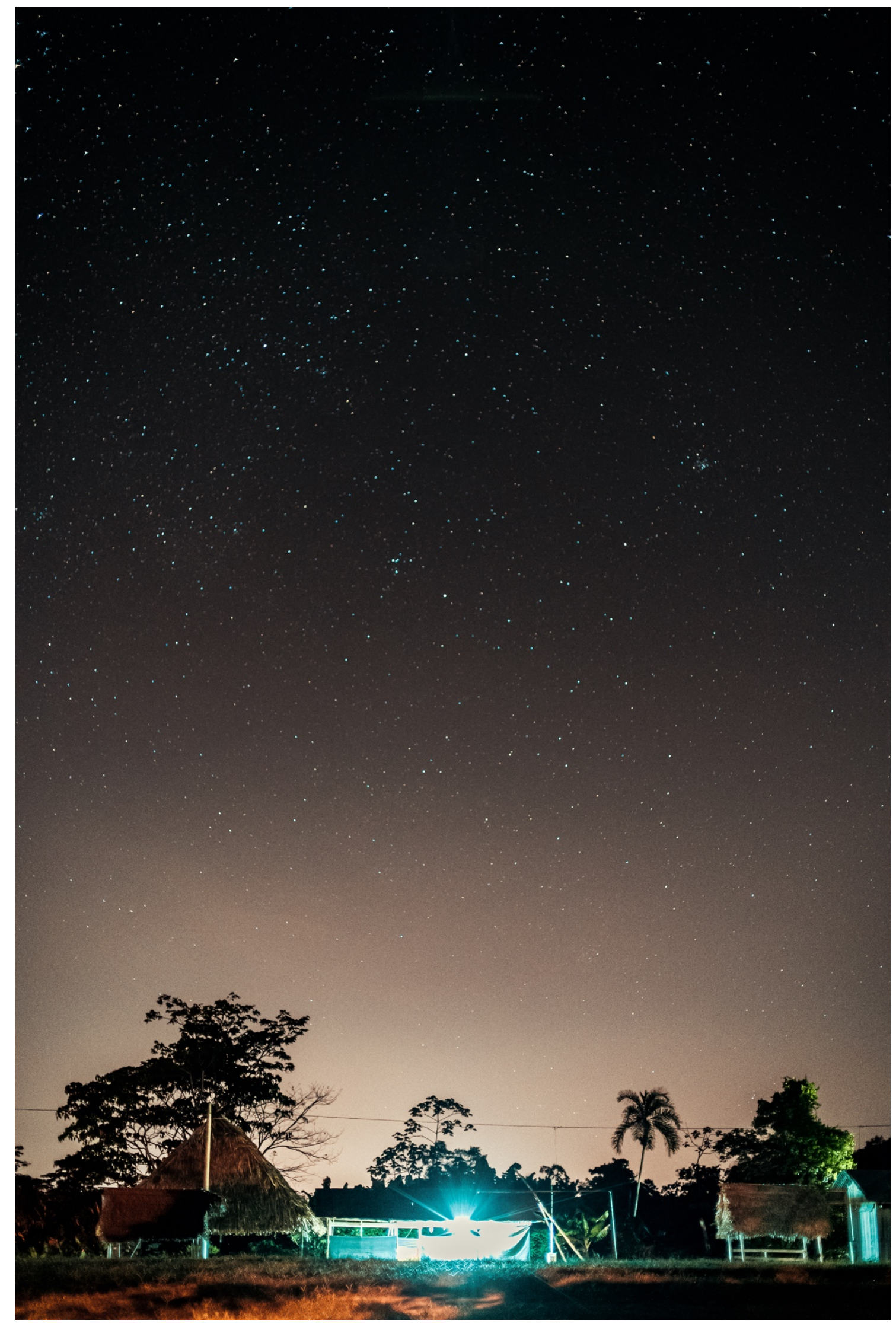




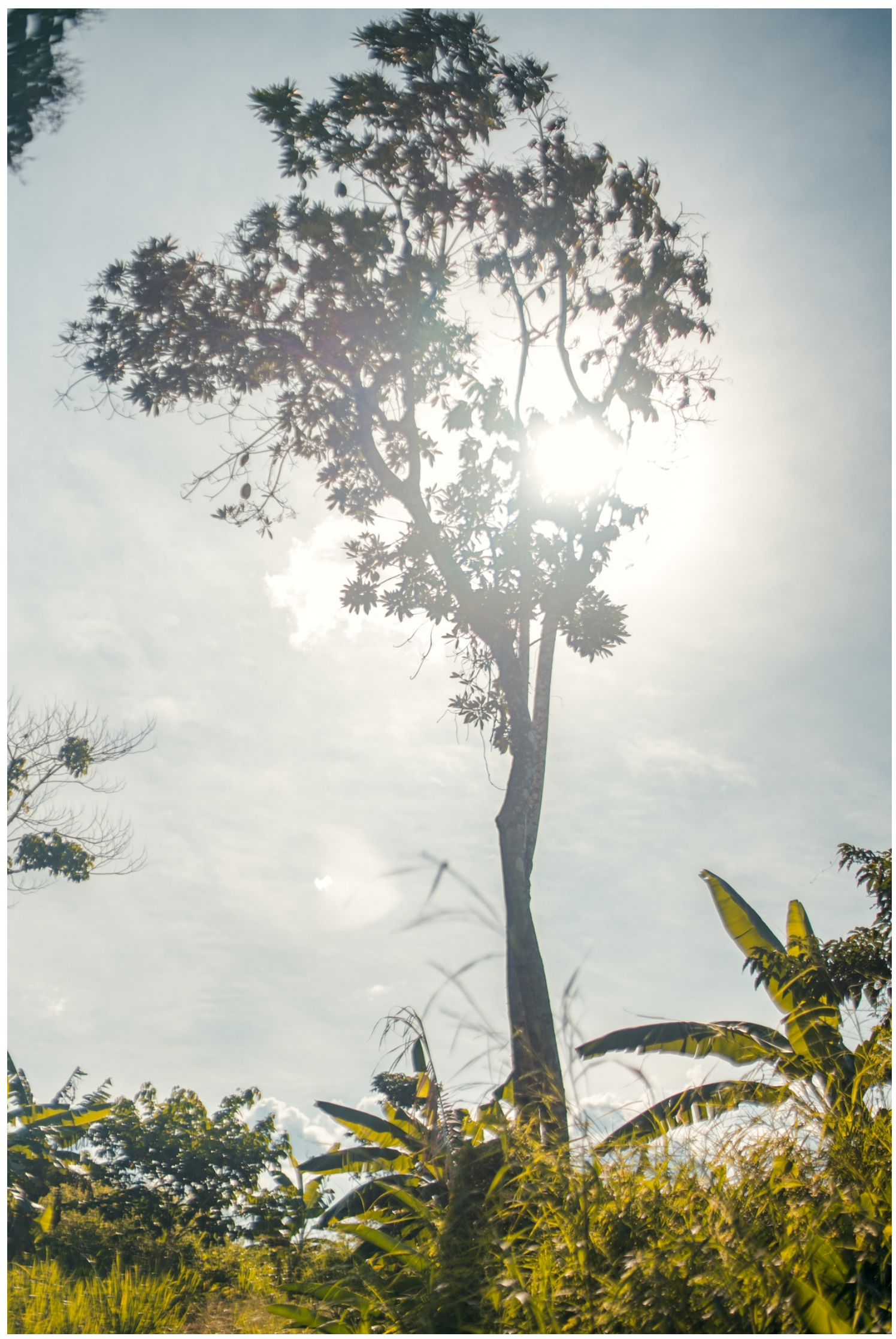



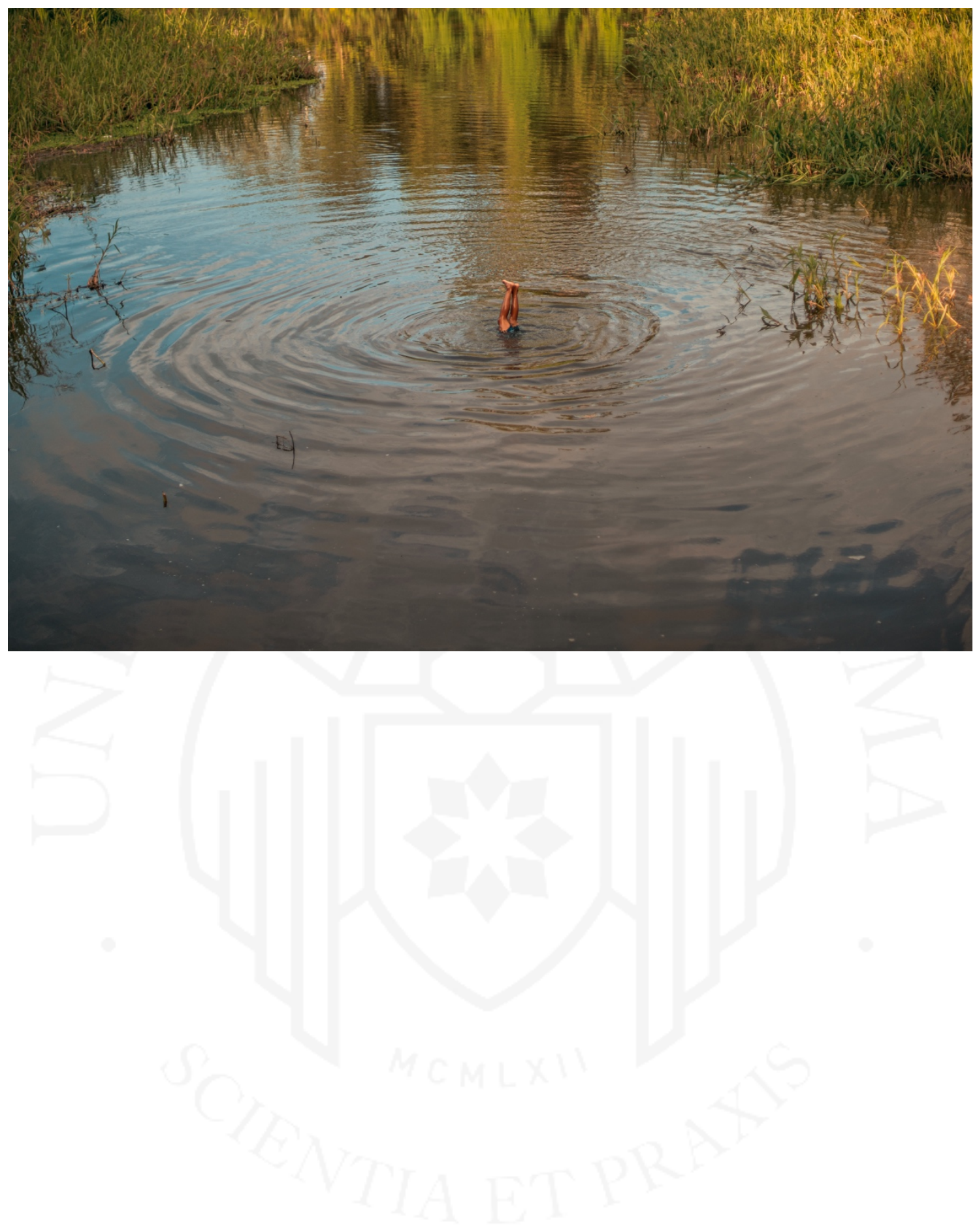


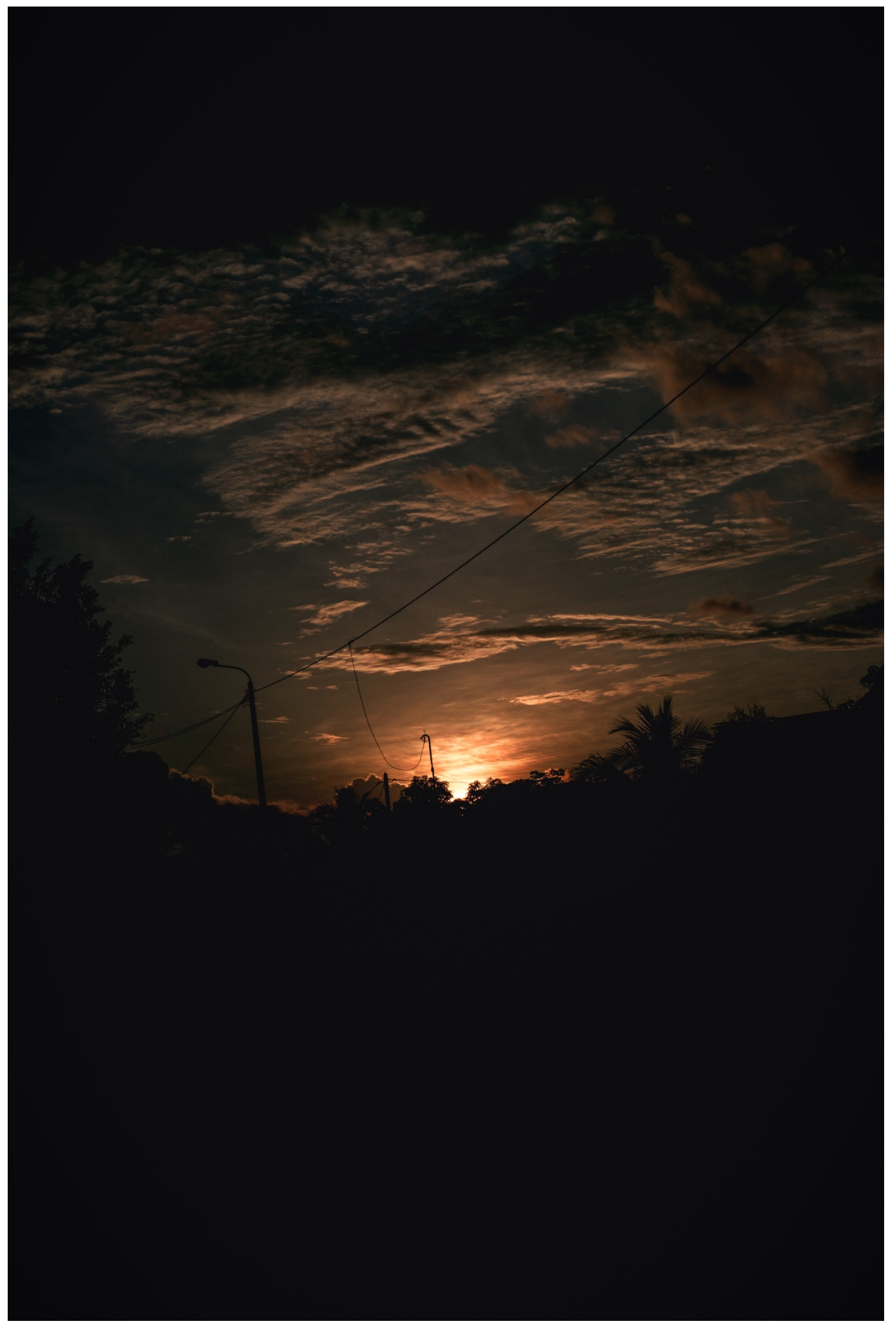




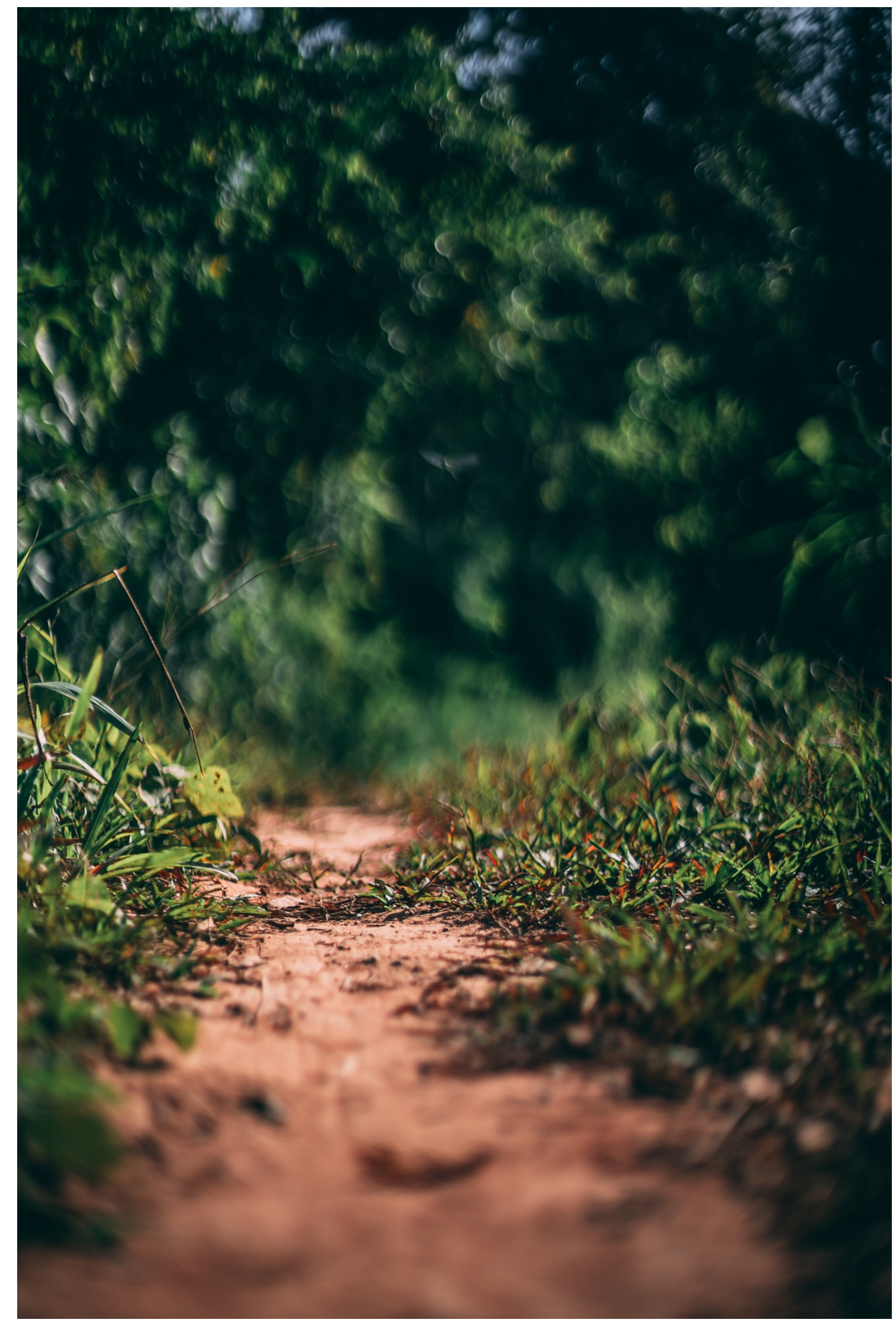



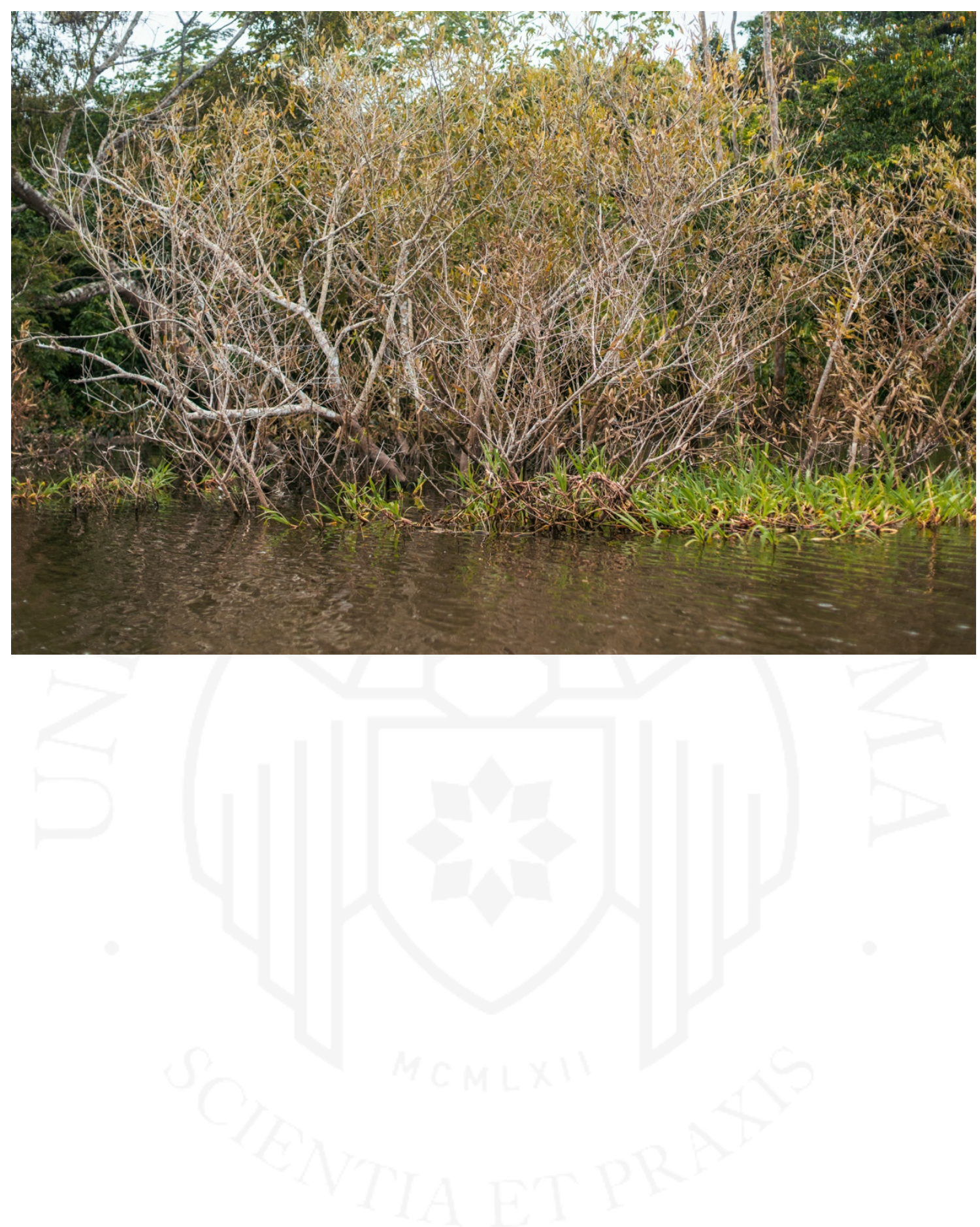